Portland State University

PDXScholar

\title{
Development of Middle School Teachers' Knowledge and Pedagogy of Justification: Three Studies Linking Teacher Conceptions, Teacher Practice, and Student Learning
}

Carolyn McCaffrey James

Portland State University

Follow this and additional works at: https://pdxscholar.library.pdx.edu/open_access_etds

Part of the Elementary Education and Teaching Commons, and the Science and Mathematics Education Commons

Let us know how access to this document benefits you.

\section{Recommended Citation}

James, Carolyn McCaffrey, "Development of Middle School Teachers' Knowledge and Pedagogy of Justification: Three Studies Linking Teacher Conceptions, Teacher Practice, and Student Learning" (2016). Dissertations and Theses. Paper 2955.

https://doi.org/10.15760/etd.2951

This Dissertation is brought to you for free and open access. It has been accepted for inclusion in Dissertations and Theses by an authorized administrator of PDXScholar. Please contact us if we can make this document more accessible: pdxscholar@pdx.edu. 
Development of Middle School Teachers' Knowledge and Pedagogy of Justification:

Three Studies Linking Teacher Conceptions, Teacher Practice, and Student Learning

by

Carolyn McCaffrey James

A dissertation in partial fulfillment of the requirements for the degree of

\author{
Doctor of Philosophy \\ in \\ Mathematics Education
}
Dissertation Committee:
Sean Larsen, Chair
Megan Staples
Paul Latiolais
Anita Bright

Portland State University

2016 
C 2016 Carolyn McCaffrey James 


\begin{abstract}
Justification and argumentation have been identified as important mathematical practices; however, little work has been done to understand the knowledge and pedagogy teachers need to support students in these ambitious practices. Data for this research was drawn from the Justification and Argumentation: Growing Understanding in Algebraic Reasoning (JAGUAR) project. JAGUAR was a multi-year research and professional development project in which 12 middle school math teachers and a group of researchers explored the knowledge and pedagogy needed to support student justifications. This dissertation consists of three case study analyses. The first paper describes the development of teacher conceptions of justification, including their proficiency with justification and purpose of justification in the middle school classroom. The second paper examines the relationship between teacher understanding of empirical reasoning and their use of examples in their classrooms. The final paper describes the relationship between task scaffolding and student forms of reasoning in the context of a justification task. Collectively, this body of work identifies important relationships between teacher knowledge, practice, and student justification activity.
\end{abstract}




\section{Acknowledgements}

First and foremost, I would like to thank all of the JAGUAR participating teachers who opened up their minds and their classrooms. They challenged themselves with ambitious teaching practices and allowed me to join them on their journey. I would also like to thank my adviser, Sean Larsen, for his guidance, support, and critical feedback. Thanks for believing that I had something significant to say. I also thank Megan Staples for her continued support and outstanding leadership on this project. Thank you to my other committee members, Paul Latiolais and Anita Bright for their critical reading of my work and thoughtful feedback. Many thanks to all of those who have helped with the analysis of this large data set, including Dana Kirin, Krista Strand, Kate Melhuish, Ann Sitomer, Joanna Bartlo, and Eva Thanheiser. Thank you Helen Gordon, Helen Mead, and Jordan Drebin, who allowed me the time to focus my mind worry-free. Thank you to my cohort, who offered encouragement, resources and humor all the way through. Finally, thanks to my husband OJ who has stood by me the whole way, and my little ladies Lily and Jaya, who give me purpose and inspiration. 


\section{Table of Contents}

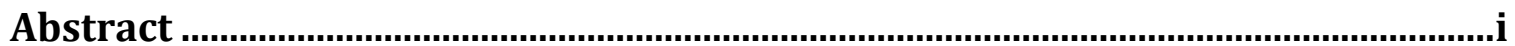

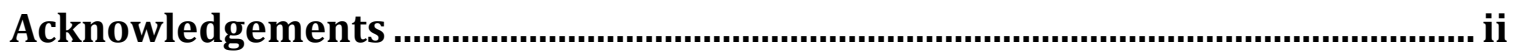

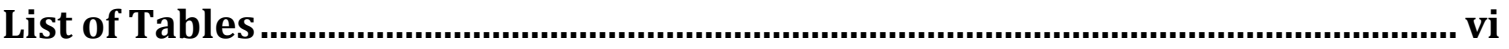

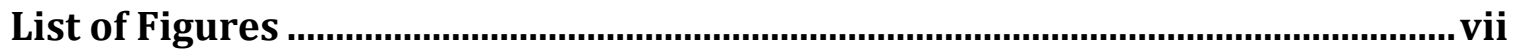

Chapter 1: Introduction ........................................................................................ 1

Project Overview

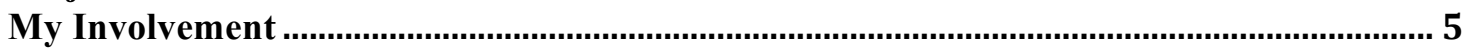

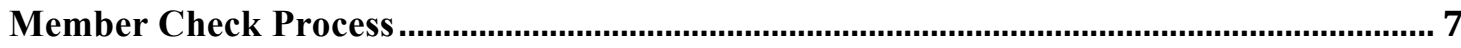

Chapter 2: JAGUAR Project Overview .....................................................................10

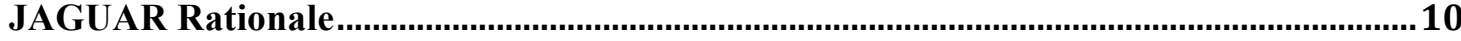

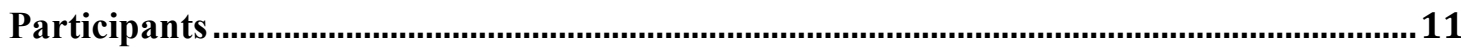

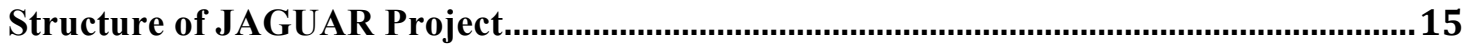

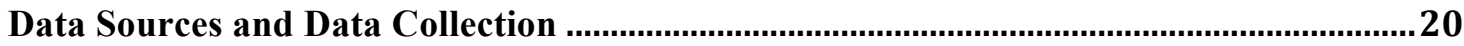

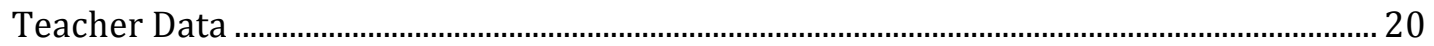

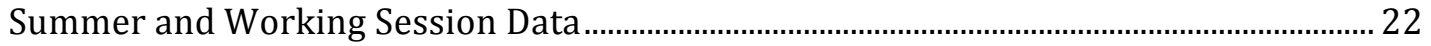

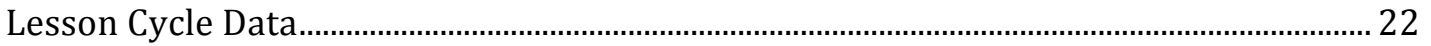

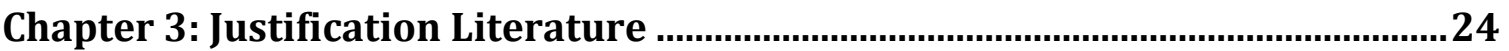

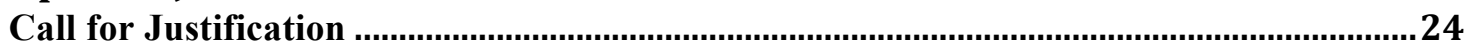

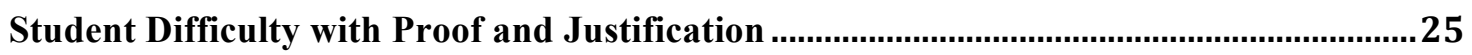

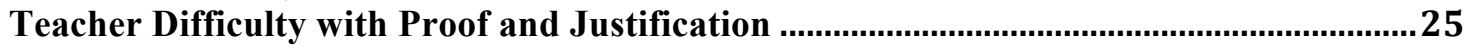

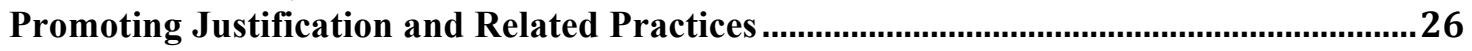

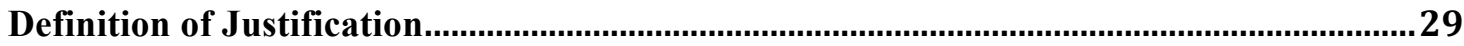

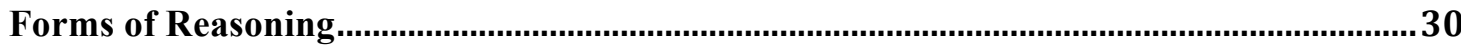

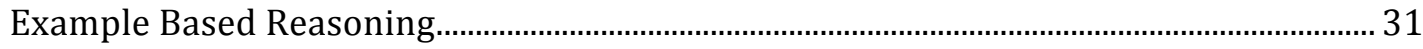

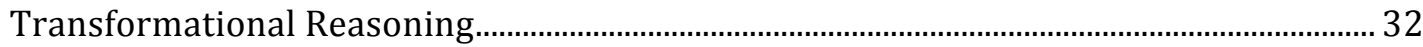

Appealing to Known Information and Model Based Reasoning .............................................. 33

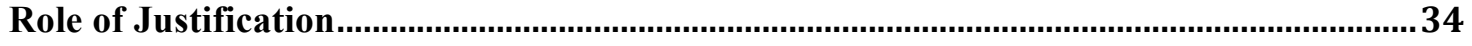

Chapter 4: Theoretical Perspective and Methodology …........................................36

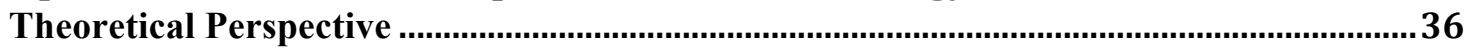

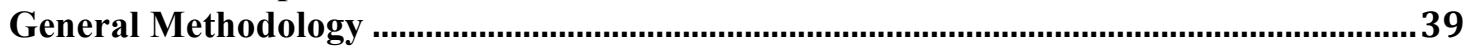

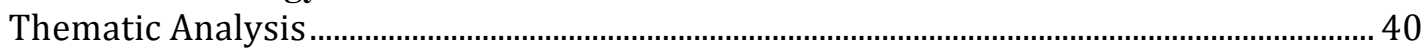

Chapter 5: Teacher Conceptions of Justification ..................................................43

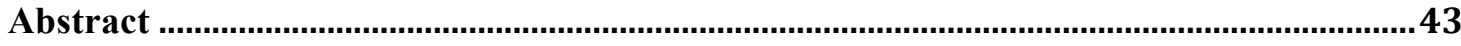

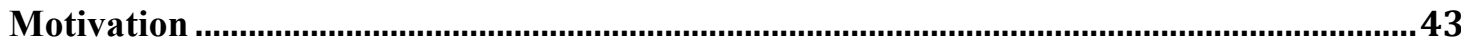

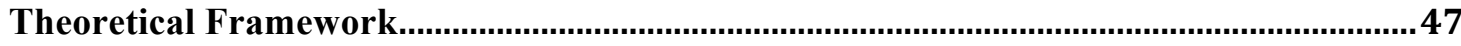

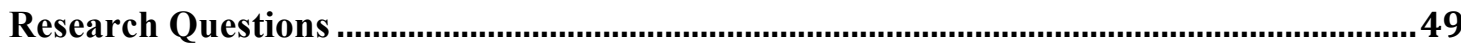

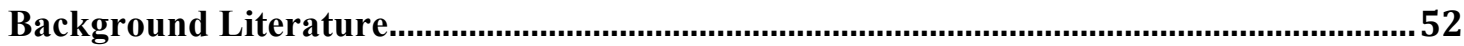

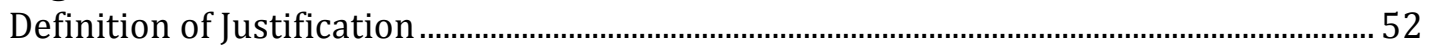

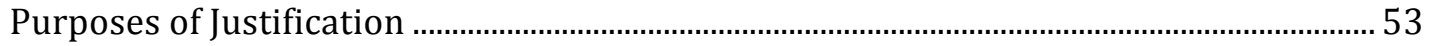

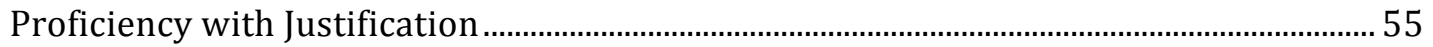

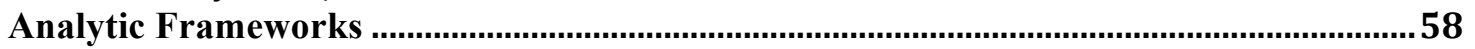

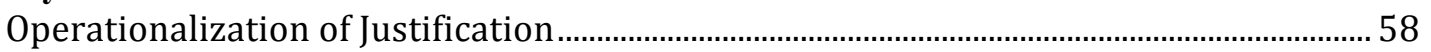




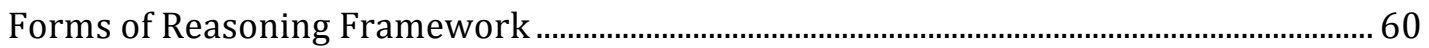

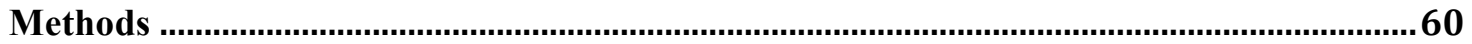

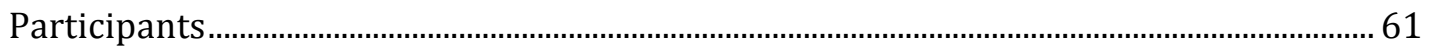

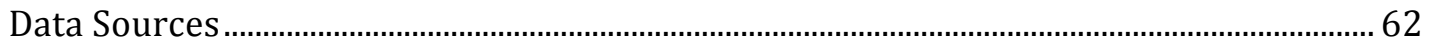

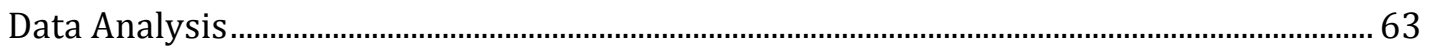

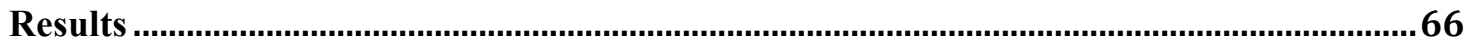

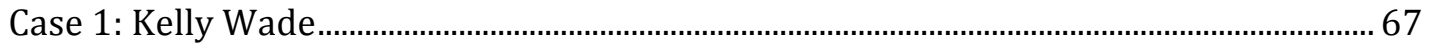

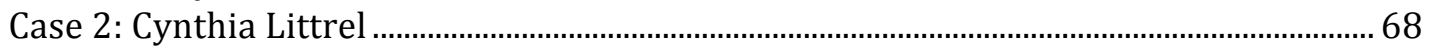

Case 3: Irene Primm ...................................................................................................................... 71

Case 4: Paige Davilla ..................................................................................................................... 73

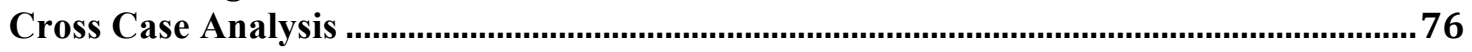

Question 1: What do JAGUAR teachers think justification is? ................................................. 76

Question 2: What do they see as its purpose in their classroom? ......................................... 81

Question 3: What are teacher proficiencies with justification? .............................................. 86

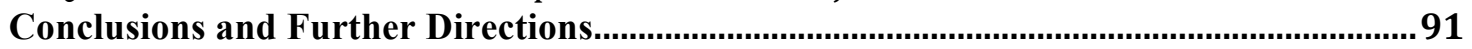

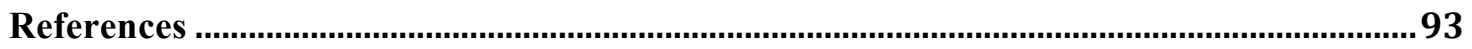

\section{Chapter 6: Middle School Teacher Treatment of Examples in the Context of} Justification Activity ................................................................................................. 103

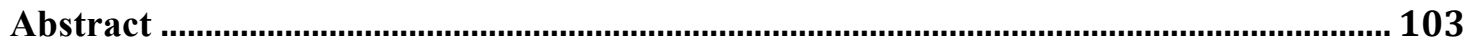

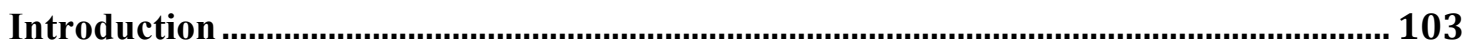

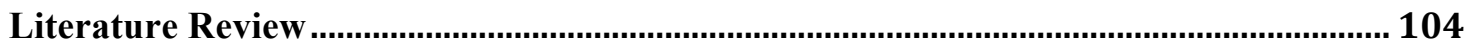

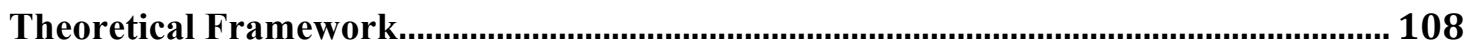

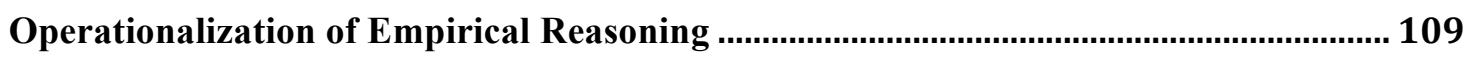

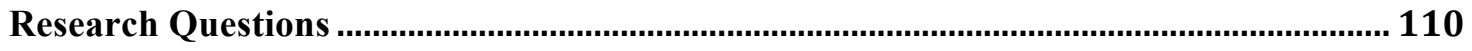

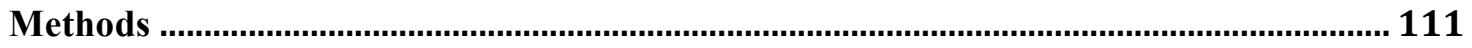

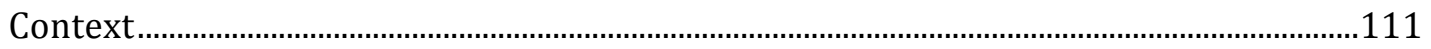

Methods for RQ1: Teacher Understanding of Empirical Reasoning ................................113

Methods for RQ 2: Teacher Treatment of Empirical Reasoning in the Classroom ........114

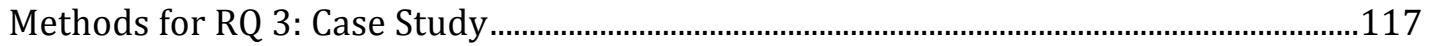

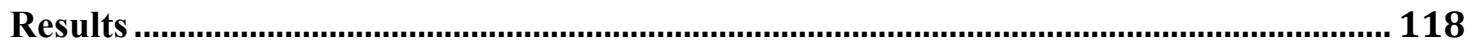

Framework: Teacher Use of Examples in the Classroom ...................................................119

Case Descriptions of Teacher Treatment of Examples …………...........................................126

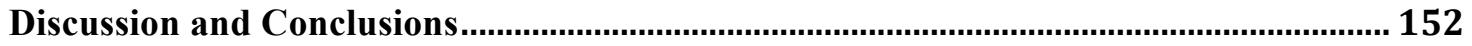

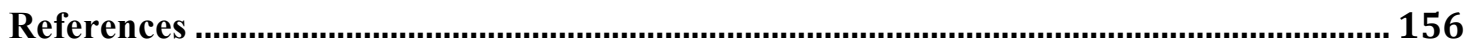

Chapter 7: Scaffolding Mathematical Tasks to Support Student Justification 162

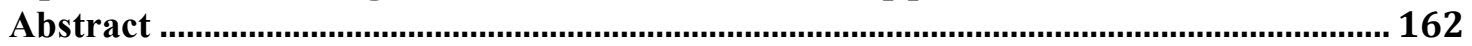

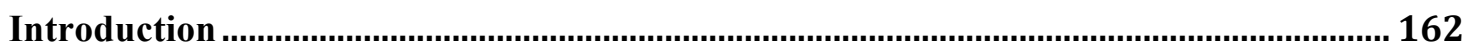

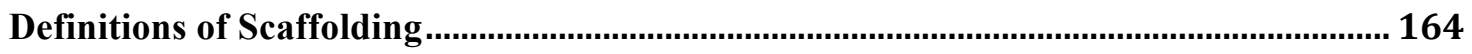

Research on the Impact of Task Structuring ................................................................... 166

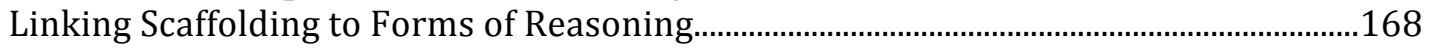

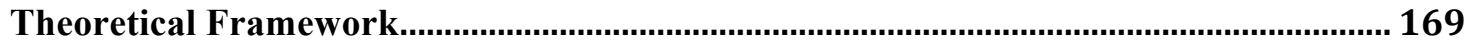

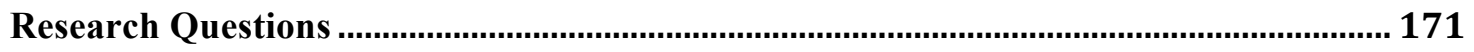

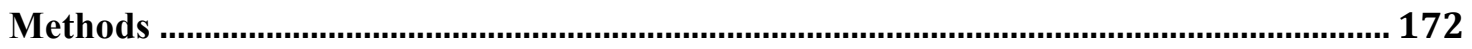

Written-Task Analysis Methods and Data Sources ..............................................................174

Task Set Up and Implementation Methods ...........................................................................176

Tasks as Enacted by Students and Student Learning Outcomes Analytic Methods ......177

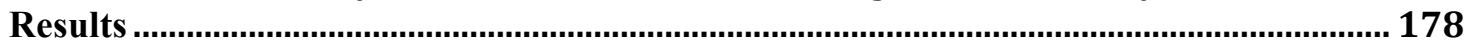


Results Year 1

Results: Year 2

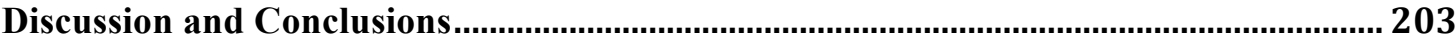

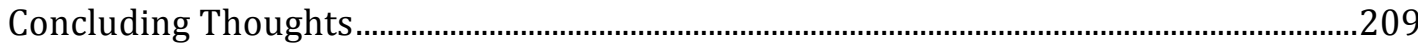

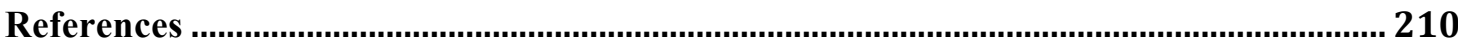

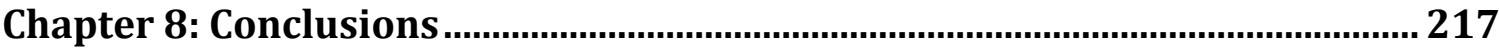

Terminal References................................................................................................. 219

Appendix A: Teacher Justification Survey Sample ............................................. 230

Appendix B: Student Justification Survey Sample.......................................... 232

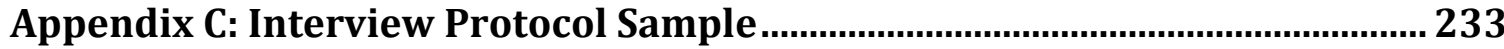

Appendix D: Reflective Journal Questions ........................................................... 236

Appendix E: Classroom Data Collection Forms ................................................. 238

Appendix F: Teacher Working Session Task ............................................................ 240 


\section{List of Tables}

Table 1: Demographic data for participating JAGUAR teachers ........................................... 12

Table 2: Stylianides' (2007) definition of proof..........................................................................59

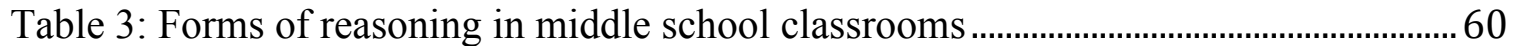

Table 4: Questions guiding transcript analysis of teacher conceptions of justification..... 63

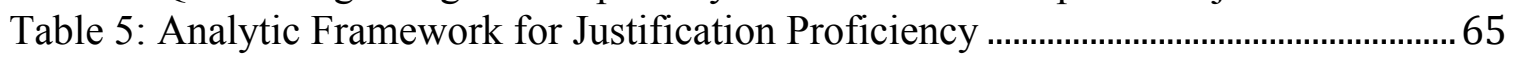

Table 6: Summary of Case Study Teacher Conceptions of Justification ...............................75

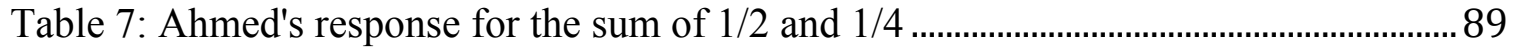

Table 8: Empirical Reasoning Task ....................................................................................... 112

Table 9: Mr. Hummel's treatment of examples by task and year........................................ 129

Table 10: Ms. Primm's treatment of examples by task and year........................................ 138

Table 11: Ms. Davilla's treatment of examples by task and year......................................... 146

Table 12: Number Trick example with starting value of 9 ................................................. 151 


\section{List of Figures}

Figure 1: Model of case connections between teacher knowledge, teacher practice, and

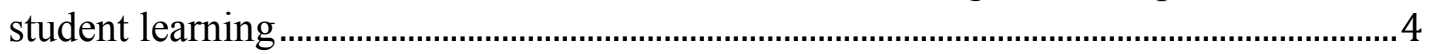

Figure 2: JAGUAR Project Overview …………………………………………………..16

Figure 3: General statement of the Hexagon Task................................................................ 19

Figure 4: General statement of the Number Trick Task ........................................................19

Figure 5: Theoretical framework linking teacher orientations, goals and resources with

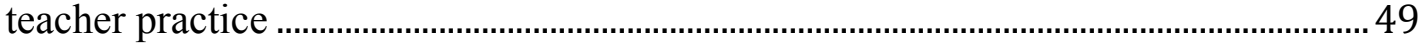

Figure 6: Fiona's pictorial argument that the sum of two even numbers is even.................70

Figure 7: Sarah's generic example argument that the sum of two consecutive numbers is always odd ............................................................................................ 71

Figure 8: Ms. Primm's generalized pictorial diagram representing that the sum of three

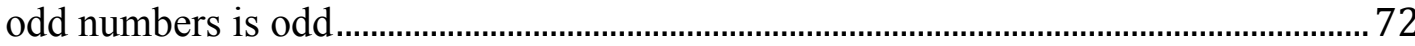

Figure 9: Fiona's pictorial justification that the sum of two even numbers is even.............74

Figure 10: Consecutive number task with hypothetical student work ............................... 127

Figure 11: The stages on implementation for the mathematical task framework (Stein,

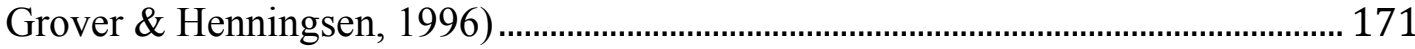

Figure 12: Framework for analyzing task features of the written task ............................ 175

Figure 13: Task as written in year 1 ................................................................................. 181

Figure 14: Illustration of common student misconception. …………………………….... 184

Figure 15: Student work for scaling of shapes. The yellow highlighted regions are the original areas, and the red highlighted columns are the areas for the scaled figure.

Figure 16: Student work of the scaling of shapes. The green column indicates the scale factor. The blue column is the scale factor squared. The brown cells and arrows display the steps in the computation of the area of a scaled up trapezoid................. 189

Figure 17: Student partial explanation for relationship between area and scale factor .. 191

Figure 18: Student statement of the relationship between area and scale factor .............. 192

Figure 19: Written task for the Scaling Task in Year 2 (questions 5-7 were written on the back of the sheet)....................................................................................................... 195

Figure 20: Nate's generic-example argument for the area of a scaled-up square .............. 198

Figure 21: Kay's picture of a scaled up square and parallelogram ....................................... 199

Figure 22: Student appeals to known information as the form of reasoning in this

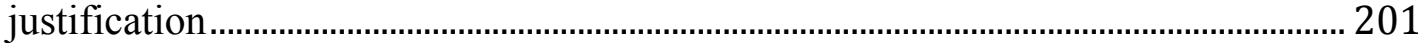

Figure 23: Student diagram indicates the scale factor of 2 results in a rectangle with 4

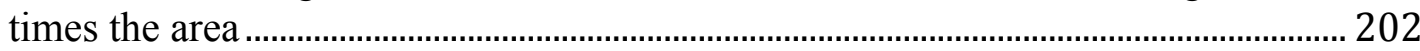

Figure 24: Pattern-result reasoning is indicated by the table of values: the student assumes the pattern will hold by does not justify why 203 


\section{Chapter 1: Introduction}

This dissertation's primary contribution consists of three empirical case studies that each address important questions regarding teaching with justification. Before I present my papers, I begin with an introduction that situates the papers with respect to the project background. This introduction also describes ethical considerations, including a positioning of myself as a researcher relative to the data and ethical considerations for teacher participants.

\section{Project Overview}

The Justification and Argumentation: Growing Understanding in Algebraic Reasoning (JAGUAR) was a multiyear, bicoastal research and professional development project that investigated teaching with justification in middle school math classrooms. The JAGUAR project focused on how teacher's understanding of justification develops, how teacher understanding of justification impacts practice, and how advanced teacher pedagogy impacts students' ability to construct justifications. Twelve teachers participated in the project, which included two years of collaborative professional development alongside justification lesson implementation in the classroom.

This dissertation is a retrospective analysis of portions of the JAGUAR data set. As a research assistant working on the JAGUAR project, I helped to collect and analyze JAGUAR data, and I became curious about specific aspects that warranted further analysis. My dissertation consists of three case studies that investigate teachers' understanding of justification and teachers' practice supporting student justifications in the classroom at an in-depth level. 
The first paper is a case study analysis of teacher conceptions of justification. Using Schoenfeld's (2011) framework for teacher decision-making, I explored teacher conceptions of justification guided by three questions: What is justification? What is the purpose of justification? What are teacher proficiencies with justification? This investigation resulted in a case study analysis of four teachers' conceptions of justification and their development over time. One primary result of the study was the relationship between justification as a mathematical practice that demonstrated why something was true and justification as a pedagogical practice that focused on voicing student thinking.

The second paper in this dissertation is a case study that examines teacher treatment of example-based reasoning. I investigated of teachers' understanding of example-based reasoning, including their reaction to students' example-based justifications and the teachers' use of examples within their justification work. Additionally, this paper connects teacher understanding of example-based arguments with their treatment of examples in the classroom. The research questions for this case were:

1) How do JAGUAR teachers understand empirical reasoning? How do teachers evaluate empirical reasoning? What kinds of empirical arguments do teacher produce?

2) How to JAGUAR teachers treat examples in the context of classroom justification tasks? 
3) What is the relationship between teachers' understanding of empirical reasoning and treatment of empirical reasoning in their classrooms? How does this shift over time?

This paper "zooms in" on one important aspect of justification—example based reasoning-- and provides a more detailed accounting of this single component. The results of the study include a framework of different ways teachers treat examples in the classroom, as well as a set of three case studies that explore the connections between teacher conceptions and their practice. This study found that teacher beliefs about justification and their value for sharing student reasoning mediated the impact of content knowledge about examples within their classroom practice.

The final case study investigated how the scaffolding of a justification task can impact students' justification activity. The research question for this case was: How does teacher scaffolding of open-ended, justification tasks relate to student forms of reasoning as they engage with the task? The paper consists of a detailed case study of a single teacher's implementation of a single task over two different years. I used Stein, Grover and Henningsen's (1996) Math Task Framework as the theoretical framework to guide the analysis of the task as it was written, as it was set-up in the classroom, as it was implemented by students, and the resulting student justifications. I identified three attributes of task scaffolding that promoted more complete student justifications, including a focus on concept building, strong use of models and examples, and a sustained press for justification. 


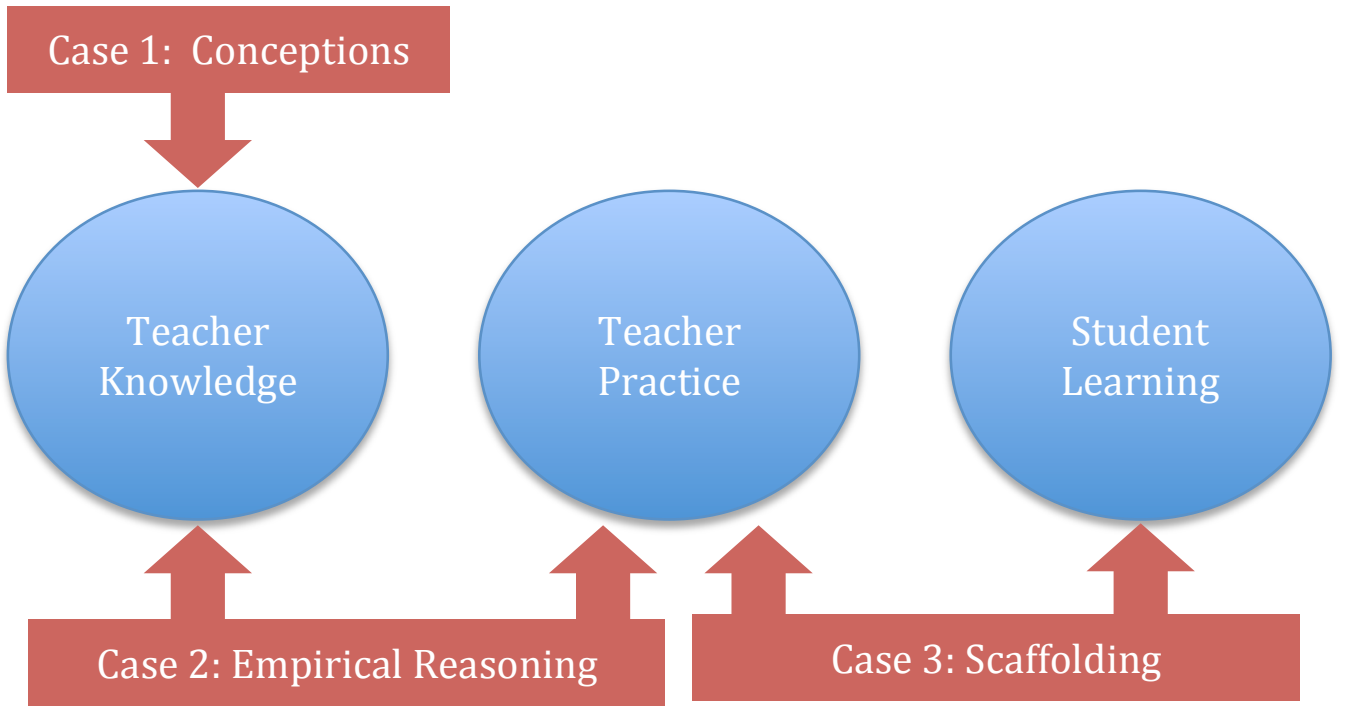

\section{Figure 1: Model of case connections between teacher knowledge, teacher practice, and student learning}

This set of studies contributes to the field of mathematics research education in a number of ways. At a local level, each of my case studies will contribute to the larger research agenda of the JAGUAR project. My research questions are designed to elaborate on specific topics within the broader JAGUAR project questions of how teacher understanding of justification impacts practice, and how advanced teacher pedagogy impacts students' ability to construct justifications. Specifically, the case of teacher conceptions of justification will provide detailed description of the beliefs, goals, and practices teachers had about justification. The second case unpacks teacher pedagogy of empirical reasoning, an important sub-element of the pedagogy of justification. Finally, the third case looks squarely at how advanced teacher pedagogy impacts students' ability to justify, but confines itself to how teacher scaffolds impact student forms of reasoning.

In this dissertation, I begin with a brief self-reflection, locating myself within the context of the investigation and addressing ethical concerns and member-checking. Next, I give a description of the JAGUAR project and its related data sources, an overview of 
literature relevant to teaching with justification, and the theoretical perspective for the study. The main body of the dissertation consists of three research papers. Each paper is intended to be a stand-alone document that ready for submission to a journal pulication. I conclude the dissertation with a brief summary, including directions for future work.

\section{My Involvement}

I have been involved in the data collection and analysis of the JAGUAR project for the past five years. In the first year of the project I assisted with data collection and ongoing analysis. In the second year I was the primary data collector and lead contact for the teachers. I visited classrooms and collected data, co-created and conducted interviews, and participated in the ongoing collaborative working sessions. These teachers allowed me into their classrooms, shared their thoughts, and exposed their perceived weaknesses for group reflection. My teaching has been challenged and changed because of what I've witnessed in their classrooms, and for that I'm grateful.

While filming, transcribing, and reviewing the data for this project, I became curious about aspects of the data. The research questions for this study have emerged from my informal reflections on the teachers and data. Before embarking on formal analysis of the data, I constructed a set of conjectures based on my perceptions of the data set. By explicating these conjectures, I was more aware of my preexisting ideas and actively seek out both confirming and disconfirming evidence to refute or revise them.

As a qualitative researcher, it is important not only to locate one's self within the context of the research, but to examine that self. In a manner recommended by Peshkin (1988), I will perform a "subjectivity audit" and identify "when I felt moved to act in 
roles beyond those necessary to fulfill my research needs" (1988, p. 18). I arrived at a set of three roles.

The Relational I: My relationship with the teachers extended beyond that of observer. I was at times a friend sharing a meal, at times a task-manager asking for documents and paperwork, at times the student learning from their classroom practice, and at times an "expert" giving solicited advice on math content or curricular choices. As could be expected, I had different relationships with different teachers, and those relationships impacted how I viewed their thinking and teaching.

The Mathematical I: I am trained as a mathematician. I have personal opinions about the value, purpose, and applicability of mathematics. Conventionally valid mathematics is extremely appealing to me, and deviations from valid mathematics can be painful. My feelings toward the validity of the mathematics needed to be considered separately from the role that mathematics plays within this research.

The Math Education Researcher I: I am also trained as a math education researcher. Current research leads me to believe that a reform-oriented approach to teaching, one that empowers students to question, explore and verify, leads to deeper understanding and is thus a preferred method of instruction. This bias influences the way that I think about learning and how I see the classroom environment. This perspective has the potential to bias my analysis or limit my appreciation for other approaches or perspectives. 
Rather than allowing my I's to unintentionally distort, transform, or misconstrue the analysis, I can see them as valuable I's: recognizing my own subjectivity is not a way to distance myself from it, but to operationalize it into a productive team of analysts, each with specialties and weaknesses.

\section{Member Check Process}

Part of recognizing my I's included a recognition of all of the other I's who participated in the creation of this work. I included a member check out of ethical regard for the teacher participants and to promoting further learning for teachers and researchers. I did not use member checks as a tool for establishing external validity: this research was intended to "explain the teacher's perspective from the researcher's perspective" (p. 254, Simon \& Tzur, 1999). Some researchers view member checks as an essential element in ensuring credibility of the findings and interpretations (Lincoln, 1985; Stake, 1995); however, a participant's ability to interpret research may have limitations. The participant may have changed as a result of the intervention experience, or may revise their statements to more closely align with what they believe the researcher expects or how they wish to appear. Moreover, the premise that member checks can improve validity relies on the notion that there is universal, fixed reality to which the results of a study can be compared (Angen, 2000). In this study, the primary tools to establish validity were triangulation and rich description (Cresswell, 2007).

More important for this research, member checks were conducted out of ethical regard for the teacher participants. This set of case studies was made possible because of the teacher participants who agreed to take part in the JAGUAR project. It is an act of trust to allow a stranger into one's classroom, and outright bravery to agree to be 
videotaped and analyzed. These teachers were willing to share their ideas, try new things, and open themselves up for critique. In light of the pivotal role that the teachers have played in this research, it is fitting that they were given the opportunity to contribute to the analysis of the data through member checks.

Most importantly, member checks allowed for growth opportunities for both teachers and researchers. The JAGUAR project was conceptualized as a collaborative exploration of justification practices among the teacher participants and researchers. The teachers have been co-contributors in the development of our ideas of justification and how best to support justification in the classroom. Contribution to the process of analysis is a natural extension of that participation. By allowing teachers the opportunity to reflect on their own data and researcher interpretations of that data, they may see elements in their practice in a new way. Additionally, they may have new ideas to contribute that will help improve the overall depth and scope of the analysis.

It is important that teacher participants were given an opportunity to participate in a way that both allowed for meaningful contribution and was easy to be followed through by the teachers. Traditional member checks frequently include a review of paper drafts before submission. Although that allows members the opportunity to review the entire data corpus, such documents are lengthy and can sometimes be overwhelming. My member check plan included multiple types of possible feedback to maximize the potential for participation.

Step 0: Notification. Data collection for the JAGUAR project concluded three years prior to this study, and the teachers had very few updates about results of the project in that time. Once I proposed my dissertation, I contacted the teachers to let them know 
about my research interests for this particular set of analyses. This step did not include a request for member checks, but it simply let them know what I was planning and provided the opportunity for them to learn more if they were interested.

Step 1: Member Check Request: Once the analysis had taken shape, I sent each case teacher a synopsis of their case and asked for feedback. Teachers had the opportunity to make contributions and add revisions to the shape of the analysis; however ultimately I was responsible for the final interpretation of the data. By putting on the analytic lens, teachers would hopefully have the additional benefit of learning something new about their practice in the process. None of the participates opted to participate in the data analysis of this project. However, the renewed contact did result in the finalization of a collaboration that resulted in an accepted joint publication in Mathematics Teaching in the Middle School.

Step 2: Member Review of Draft. Once a formal draft was complete, I shared the entire draft with the case teachers, highlighting the portions that included their case. This had the benefit of allowing the teachers to learn from one another, but the drawback was that a long dissertation document was unlikely to be read with a lot of rigor. Although most of the teachers responded with limited feedback, all of the feedback I received was positive. In particular, Ms. Davilla commented that she was impressed by the amount she changed over the two year project. Several other teachers and I hope to continue the work of the third paper with a second submission to Mathematics Teaching in the Middle School. 


\section{Chapter 2: JAGUAR Project Overview}

In the following section, I describe in detail the JAGUAR project, which was the large-scale research and professional development project from which the data for my dissertation was drawn. This section includes an overview of the rationale for the JAGUAR project, the JAGUAR project research questions, an overview of the participants, and a description of the structure of the project, which includes the data collection elements. This detailed description of the parent project helps to set the stage for my contribution, which are the three research papers in the following three sections.

\section{JAGUAR Rationale}

Much of mathematics education professional development in the past several decades has shifted away from lecture-oriented teaching and toward a more student centered, "reform-oriented" approach. Generally speaking, the reform orientation places greater emphasis on attentiveness and responsiveness to student thinking and allows students opportunities to engage in authentic mathematical activities such as sensemaking, problem solving, modeling, and argumentation. These ideals are reflected in current policy documents, such as the NCTM process standards and the Common Core Standards for Mathematical Practice (NCTM, 2000; CCSSO, 2010). Previous research has investigated teacher transitions to reform-oriented teaching (e.g. Cohen, 1990; McClain \& Cobb, 2001; Nathan \& Knuth, 2009; Speer \& Wagner, 2009), however there has been relatively little research into the links between teacher knowledge of and pedagogy surrounding justification specifically.

The JAGUAR project was the parent project from which the data for this dissertation was drawn. JAGUAR focuses more narrowly on teacher development of 
justification understanding and pedagogy within the context of middle school algebra. The math content domain of algebra was chosen because of its importance in future mathematics and its role as a "gatekeeper" for further mathematics and science training (Ladson-Billings, 1998; Moses \& Cobb, 2001). Justification was chosen as a content topic because of the importance proving plays in the discipline of mathematics (Toulmin, 1969), as well as the opportunities justification provides for promoting equitable access among students (Boaler \& Staples, 2008).

The three research questions that guided the JAGUAR project are:

1) How do teachers' develop in their understanding of algebraic justification and argumentation as new content knowledge?

2) How do teachers' transform new content knowledge (justification and argumentation) to their classroom practice and develop advanced practice?

3) How does teachers' advancement in practice affect their students' capabilities for justification and argumentation?

These research questions guided the data collection and intervention for the JAGUAR project as a whole. My dissertation work focused in on answering tractable sub-questions within the larger questions of the project.

\section{Participants}

In order to study student justifications, we intentionally selected teacher participants who attended to student thinking and supported student discourse as part of their preexisting pedagogy. We believed that classroom environments of this type are more conducive for student justification, and thus had a foundation more easily built upon to reach the goals of our research, which included an analysis of student 
justification. Thus the sampling for this project was purposive sampling (Creswell, 2007), and is certainly not representative of typical middle school math teachers. Twelve middle school teachers in two states volunteered to participate. The teachers were recruited based upon participation in past professional development projects that focused on student discourse and researcher familiarity with teacher practice.

Table 1 gives an overview of each of the case study teacher participants and associated school demographic information:

Table 1: Demographic data for participating JAGUAR teachers

\begin{tabular}{|c|c|c|c|c|c|}
\hline Pseudonym & $\begin{array}{c}\text { Bruce } \\
\text { Hummel }\end{array}$ & $\begin{array}{c}\text { Paige } \\
\text { Davilla }\end{array}$ & $\begin{array}{l}\text { Irene } \\
\text { Primm }\end{array}$ & $\begin{array}{l}\text { Cynthia } \\
\text { Littrell }\end{array}$ & $\begin{array}{l}\text { Kelly } \\
\text { Wade }\end{array}$ \\
\hline $\begin{array}{l}\text { LMT Score } \\
\text { (pre/post) }\end{array}$ & $79 \% * * / 94 \%$ & $85 \% / 87 \%$ & $79 \% / 81 \%$ & $64 \% / 58 \%$ & $57 \% / 66 \%$ \\
\hline Grade (y1/y2) & $8^{\text {th }} / 8^{\text {th }}$ & $7^{\text {th }} / 7^{\text {th }}$ & $7^{\text {th }} / 8^{\text {th }}$ & $7 / 7$ & $8 / 8$ \\
\hline Location & Town in west & Urban east & $\begin{array}{l}\text { Town in rural } \\
\text { west }\end{array}$ & $\begin{array}{l}\text { Town in rural } \\
\text { west }\end{array}$ & Suburban east \\
\hline Demographics & $75 \%$ minority & $70 \%$ minority & $\begin{array}{l}<10 \% \\
\text { minority }\end{array}$ & $\begin{array}{l}<10 \% \\
\text { minority }\end{array}$ & $\begin{array}{l}<10 \% \\
\text { minority }\end{array}$ \\
\hline$\%$ FRL & $80 \%$ FRL & $30 \% \mathrm{FRL}$ & $20 \% \mathrm{FRL}$ & $20 \% \mathrm{FRL}$ & $<10 \%$ FRL \\
\hline$\%$ ELL & $50 \%$ ELL & $<5 \%$ ELL & $<5 \%$ ELL & $<5 \%$ ELL & \\
\hline $\begin{array}{l}\text { Primary } \\
\text { Curriculum }\end{array}$ & $\begin{array}{l}\text { Connected } \\
\text { Math Project }\end{array}$ & $\begin{array}{l}\text { Littell's Pre- } \\
\text { Algebra } \\
\text { curriculum } \\
\text { with } \\
\text { supplements }\end{array}$ & $\begin{array}{l}\text { Connected } \\
\text { Math Project }\end{array}$ & $\begin{array}{l}\text { Connected } \\
\text { Math Project }\end{array}$ & $\begin{array}{l}\text { Connected } \\
\text { Math Project }\end{array}$ \\
\hline $\begin{array}{l}\text { Years of } \\
\text { teaching } \\
\text { experience at } \\
\text { the start of the } \\
\text { project }\end{array}$ & $\begin{array}{l}10 \text { total (all } \\
\text { math and } \\
\text { science at } \\
\text { middle school } \\
\text { level) }\end{array}$ & $\begin{array}{l}1 \text { year } \\
(\text { middle) }\end{array}$ & $\begin{array}{l}7 \text { total (2 at } \\
\text { middle school } \\
\text { level. } \\
\text { Previously } \\
1 \text { st grade } \\
\text { teacher and } \\
\text { elementary } \\
\text { math coach) }\end{array}$ & $\begin{array}{l}14 \text { (all middle } \\
\text { school) }\end{array}$ & $\begin{array}{l}29 \text { total }(28 \\
\text { middle } \\
\text { school })\end{array}$ \\
\hline $\begin{array}{l}\text { Class } \\
\text { Composition }\end{array}$ & $\begin{array}{l}\text { Non-ability } \\
\text { grouped }\end{array}$ & Top 1/3 & & $\begin{array}{l}\text { Homogeneou } \\
\text { S }\end{array}$ & $\begin{array}{l}\text { Mainstream } \\
8^{\text {th }} \text { grade }\end{array}$ \\
\hline
\end{tabular}




\begin{tabular}{|l|l|l|l|l|l|}
\hline $\mathbf{y 1} 1 / \mathbf{y} 2)$ & & & & $\begin{array}{l}\text { math (does } \\
\text { not include } \\
\text { top third who } \\
\text { take algebra) }\end{array}$ \\
\hline $\begin{array}{l}\text { Other } \\
\text { professional } \\
\text { development }\end{array}$ & OMLI & & $\begin{array}{l}\text { Studio, } \\
\text { OMLI }\end{array}$ & $\begin{array}{l}\text { Studio, } \\
\text { OMLI }\end{array}$ & \\
\hline
\end{tabular}

Cynthia Littrell: Ms. Littrell taught $7^{\text {th }}$ grade math both years at a 6-8 middle school in a town in the rural west. The student body was primarily white and middle class, with less than 10\% minority, 20\% Free/reduced lunch, and less than 5\% classified as English Language Learners. Her $7^{\text {th }}$ grade classes were not ability grouped and used the Connected Math Project curriculum. At the start of the project, Ms. Littrell had 14 years of teaching experience, all of which were at the middle school level. In addition to the JAGUAR project, Ms. Littrell had participated in a number of other intensive professional development programs, such as $\mathrm{OMLI}^{1}$ and Studio. ${ }^{2}$

Irene Primm: Ms. Primm taught $8^{\text {th }}$ grade math both years at a 6-8 middle school in a town in the rural west. The student body was primarily white and middle class, with less than $10 \%$ minority, $20 \%$ Free/reduced lunch, and less than 5\% classified as English Language Learners. Her $8^{\text {th }}$ grade classes were not ability grouped. At the start of the project, Ms. Primm had 7 years of teaching experience, 3 of which were at the middle school level. Before becoming a middle school math teacher, Ms. Primm was a $1^{\text {st }}$ grade teacher and an elementary school math coach. In addition to the JAGUAR project, Ms. Primm had participated in a number of other intensive professional development programs, such as $\mathrm{OMLI}^{1}$ and Studio. ${ }^{2}$ 
Bruce Hummel: Mr. Hummel taught in a midsized town in a populated area of the west coast. The students at his school were primarily Hispanic, with $75 \%$ minority, $80 \%$ Free or Reduced Lunch, and 50\% classified as English Language Learners. Mr. Hummel taught $8^{\text {th }}$ grade math both years, using Connected Math Project as the curriculum. His classes were heterogeneously grouped. At the start of the project, Mr. Hummel had been teaching for 10 years at the middle school level, although he taught science for the first two years. Mr. Hummel participated in OMLI ${ }^{1}$ prior to his involvement with JAGUAR. Kelly Wade: Ms. Wade taught at a small suburban school on the east coast. Less than $15 \%$ of the student body identified as a minority and less than $25 \%$ qualified for free or reduced lunch program. Ms. Wade had been teaching for 29 years before the start of the program, 28 of which were at the middle school level. Ms. Wade taught $8^{\text {th }}$ grade using the Connected Math Project curriculum for both years of her focal classes. In the second year, the many of her students had been exposed to the justification tasks in Mr. Ferris's class the previous year.

Paige Davilla: Ms. Davilla taught at an urban school on the east coast. The student body was $70 \%$ minority, $30 \%$ qualified for free or reduced lunches, and fewer than $5 \%$ were English Language Learners. Ms. Davilla was relatively new to teaching, with only one year of teaching experience prior to the start of the JAGUAR project. She taught $7^{\text {th }}$ grade for both years of the project, using Littell's Pre-Algebra as the primary curriculum, but with supplementation from other sources, including Connected Math Project and other outside materials. The math classes at her school were ability grouped, and her focal class was drawn from the top third of the students. 


\section{Structure of JAGUAR Project}

The JAGUAR project consisted primarily of summer sessions, working sessions, and focal task implementations (see Error! Reference source not found.). Each year of the two-year project began with a weeklong summer session, in which teachers worked with mathematicians, math education researchers, and one another on justification and pedagogy activities. Although teacher learning and instructional development were goals of the JAGUAR project, the project was not a professional development program in the traditional sense. We view the project as a co-investigation of justification, in which ideas were generated collaboratively, tested out in the classroom, and reflected upon as a community of teachers and researchers.

These sessions provided an opportunity for teachers to both reveal their conceptions of justification and to refine that conception through discussion with other teachers and the researchers. In addition, the sessions provided opportunities for teachers to reflect on their pedagogy and the pedagogy of other teachers. In these sessions the researchers served two roles: that of co-participants collaboratively exploring ideas and that of experienced teacher-educators facilitating conversations, posing questions and offering insights. My involvement shifted over the course of the project. For the first working session I was strictly an observer and data collector. Over time I joined conversations and gave input into planning the sessions. In the final working session I was responsible for planning the session, and I served as lead facilitator for the Oregon site. 


\section{Summer Session Year 1}

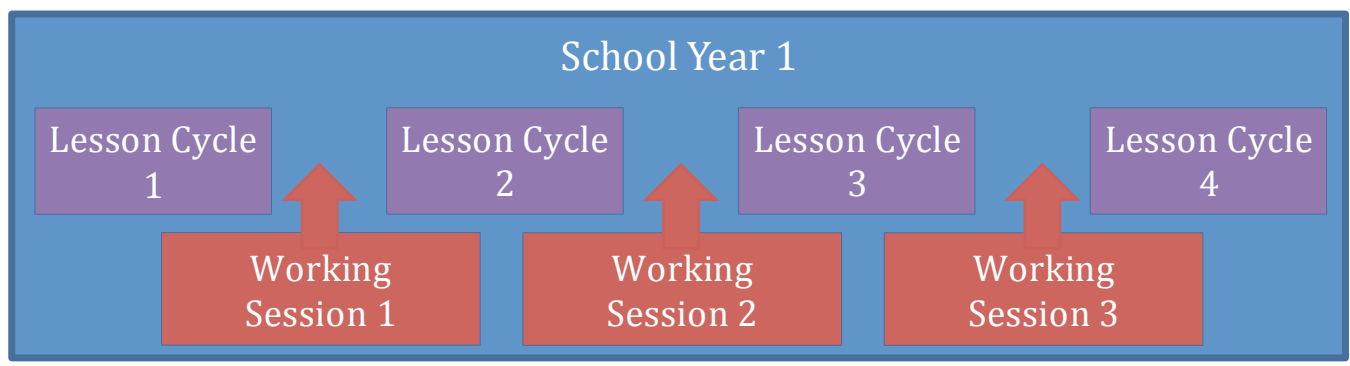

\section{Summer Session Year 2}

\section{School Year 2}

Lesson Cycle

1
Lesson Cycle

2
Lesson Cycle

3
Lesson Cycle

4

Working

Session 1

Working

Session 2

Working

Session 3

\section{Figure 2: JAGUAR Project Overview}

Each week-long summer session included activities such as:

- Discussing the definition of justification, roles of justification, and related content such as representations and forms of reasoning

- Working individually and collaboratively on justification tasks designed by the researchers

- Reflecting on and analyzing student work

- Goal setting and lesson planning for justification tasks

- Discussing pedagogy surrounding classroom justification activity

- Reflecting on past justification task implementations

- Written assessments of teacher knowledge and justification proficiency 
- One-on-one interviews with researchers

In addition to the summer sessions, teachers and researchers met three times throughout the school year for working sessions. The working session activities were similar to the summer session activities, but due to their proximity within the school year, the working sessions placed greater emphasis on practice: more time was spent reflecting on past task implementations, discussing and analyzing the difficulties of implementing justification tasks, and planning of focal tasks.

The summer sessions and working sessions helped to further our understanding of teacher development of understanding of justification (Project research question 1) and helped teachers to reflect on and improve on their instructional practices that support justification in the classroom (Project research question 2).

Between each of the working sessions the teachers would implement a justification task, which I will refer to as a focal task. Three of the focal tasks were common among all of the teachers, and the fourth task was open for the teachers to design themselves. Teachers implemented the tasks once in Year 1 and again in Year 2. Having a common task across teachers and years allowed for stronger comparisons and evidence of change. At the same time, allowing teachers to design their own task allowed the task to fit more snugly with the existent curriculum and align more closely with the natural classroom environment.

In preparation for the focal lessons, teachers worked on the tasks in the summer and working sessions. Teachers explored the tasks by solving the tasks themselves and in groups, analyzing potential student thinking, aligning the tasks within their curricular goals and standards, and developing detailed lesson plans. Teachers structured the tasks 
according to their own classroom's mathematical goals, and in the second year they revised their tasks based on the first year's implementation and reflection.

Teachers selected one of their classes (either a $7^{\text {th }}$ or $8^{\text {th }}$ grade class) to be the focal class for the year. For logistical reasons data collection took place only for the focal class, although the majority of the teachers implemented the justification lesson in other classes as well. The selection of the focal class took place before the start of the school year and was primarily motivated by convenience: teachers in the same school staggered their focal classes for filming purposes. The focal lesson lasted between 1 and 5 class periods, depending in part on the length of the class session.

\section{The Tasks}

Each of the common focal tasks were open-ended, lent themselves to multiple representations, drew upon multiple big ideas from middle school mathematics curriculum (such as proportional reasoning, equivalent representations, and patterning), and posed justification questions appropriate for middle school math students.

The Hexagon Task asked students to identify a pattern in a geometric figure and justify a generalization of that pattern for any length figure (See Figure 3). The task gave students opportunities to describe a mathematical relationship and form connections between multiple representations. This task could be crafted to focus on a number of different mathematical goals, from understanding linear functions to comparing equivalent mathematical expressions. 


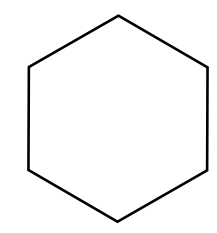

Figure 1

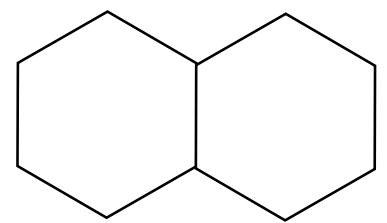

Figure 2

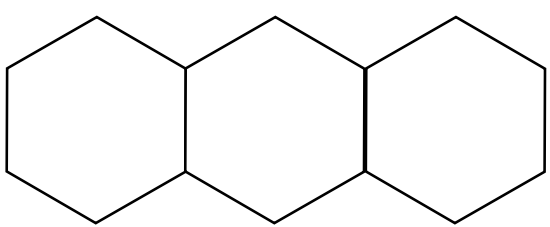

Figure 3

What is the perimeter of Figure 3? What is the perimeter of Figure 5? How might you find the perimeter of any figure?

\section{Figure 3: General statement of the Hexagon Task}

The Number Trick task provided an opportunity for students to explore a specific case of the distributive property. In the Number Trick students applied two different sets of operations to the same number and justified why the results would always be the same (see Error! Reference source not found.). Although students started by applying the procedure to a specific number, they were asked to justify why the trick holds for all numbers. This task provided an explicit opportunity to discuss why individual examples cannot prove the general case.

Jessie discovers a cool number trick. She thinks of a number between 1 and 10, she adds 4 to the number, doubles the result, then she writes this answer down. She goes back to the number she first thought of, she doubles it, she adds 8 to the result, and then she writes this answer down.

Will Jessie's two answers always be equal to each other for any number between 1 and 10? Explain your reasoning.

Will Jessie's two answers always be equal to each other for any number (not just between 1 and 10)? Explain your reasoning.

Figure 4: General statement of the Number Trick Task 
The third common focal task was the Scaling Task. The Scaling Task asked: "How does scaling various 2-dimensional [and 3-dimensional] figures impact the perimeter, area, and volume? Why?" Teachers were able to operationalize this task in a number of ways depending on the types or dimensions of the figures, context, and expectations for representation. This task provided opportunities to connect proportional reasoning with geometric understanding and algebraic representations.

\section{Data Sources and Data Collection}

\section{Teacher Data}

We collected data about the teacher participants in a number of different forms. To contextualize the teachers, teachers completed questionnaires detailing personal information such as teaching background, education, and previous or concurrent professional development. We also administered the Learning Mathematics for Teaching: Survey of Middle School Teachers of Mathematics (LMT) at the start of the first summer session and at the end of the last working session. The LMT measures mathematical knowledge for teaching specialized at the middle school level, developed by University of Michigan (LMT, 2006). In addition the teachers took a justification survey at the start and end of the project. The justification survey was developed by the JAGUAR team, which included some original questions and some questions adapted from Healy and Hoyles (2000). The justification survey provided a closer look at teacher justification proficiency, including how they represented their arguments (e.g. pictures, algebra) and the type of reasoning they used in their argument (e.g. using examples, relying in known information). 
In addition to written assessments, teachers participated in seven one-on-one of interviews over the course of the project; five standard interviews and two video interviews. The standard interviews were semi-structured (Creswell, 2007), lasting 45 to 90 minutes (see Appendix C for representative interview protocol). Several interview questions were repeated in multiple interviews to help demonstrate whether teacher thinking had changed over time. Other questions were unique to one specific interview. However, most of the interview questions related to the following themes (a) teacher conceptions of justification, (b) teacher understanding of the roles of justification, (c) analysis of teacher understanding of justification and forms of reasoning, (d) teacher analysis of student justifications, (e) reflection on the pedagogy of justification, including specific classroom practices, and (f) reflection on the previous working sessions or summer sessions.

The video interviews provided an in-depth analysis of teacher noticing of student thinking. In these interviews, teachers were presented with videos of student justification activity: one of the clips was common to all teachers and across interviews, and two of the other clips were specific to that teacher and taken from the teacher's classroom or another JAGUAR teacher's classroom. Teachers were asked to diagnose student thinking in the context of justification tasks.

The interviews were audio recorded, and written work by the teacher during the interview was collected. In the first pass of data processing, a team of researchers transcribed all of the interviews. The interviews were transcribed to balance integrity of teacher meaning (all words transcribed) with readability (e.g. "umms" omitted and 
punctuation added). Teacher work was scanned and copied into the transcription document.

\section{Summer and Working Session Data}

All of the summer sessions and working sessions were video taped using two cameras. During whole class discussions one camera captured board work (when appropriate), while the other remained focused on the participants. During group work, each camera focused on one group with a dedicated table-microphone to capture conversations. If participants broke into more than two groups (which occurred infrequently), the third group's conversation would be audio recorded only. In addition to the video recordings, all written work by teachers was scanned and all instructional materials were saved. A content log of events was created, and notes or reflections made by the researchers in the moment were saved on a volunteer basis.

\section{Lesson Cycle Data}

All focal lessons were videotaped with two cameras. The main camera focused primarily on the teacher and captured board-work when appropriate. That camera had two microphone systems; the boom microphone captured whole class discussions and a dedicated lapel microphone captured the teacher's speech. Whenever possible, an additional camera followed over the teacher's shoulder during group-work to better capture student-teacher interactions and student work. In addition, we filmed the lesson directly preceding the focal lesson in order to form a comparison between a "typical" lesson and focal lesson and to see how the focal lessons were embedded within the curriculum. 
A log was created for each focal lesson that outlined the organization of the class and types of interaction during the class along with timestamps (see Appendix E for focal lesson log sheet). Copies of the task as written were collected, and all written student work related to the focal lesson was scanned and blinded.

Teachers were responsible for creating reflective journals for each focal task implementation. Before the lesson the teachers described their goals and the types of justifications teachers expected from their students for the lesson. After the lesson the teachers watched the video and discussed specific details of the lesson. For example, teachers identified and described instances of student justification that went particularly well or poorly, reflected on what they learned about teaching with justification, and planned ahead about what future goals they have regarding student justification (see Appendix D for reflective journal prompts).

To summarize, the JAGUAR project investigated knowledge and pedagogy necessary for teaching justification in middle school math classrooms. It was a collaborative investigation between 12 middle school math teachers and a team of researchers, with two years of data collection that consisted of summer and working sessions and classroom observations. This dissertation is a retrospective analysis of the data collected from the JAGUAR project: the research questions of this dissertation are in alignment with the goals of the larger project, but probe more deeply into specific aspects of teacher work with justification. 


\section{Chapter 3: Justification Literature}

This section provides an overview of literature relating to justification. This background is helpful in understanding the context of my contribution. In addition to the following section, each of my three research papers will also include a more targeted review of the literature that is relevant to that specific paper.

\section{Call for Justification}

Recent initiatives in mathematics education reform have identified proof and reasoning practices as critical for all grades of mathematics (NCTM, 2000; CCSSO, 2010). The Principles and Standards guideline created by the National Council of Teachers of Mathematics states that all students from Kindergarten through $12^{\text {th }}$ grade should:

... recognize reasoning and proof as fundamental aspects of mathematics, make and investigate mathematical conjectures; develop and evaluate mathematical arguments and proofs; select and use various types of reasoning and methods of proof (p. 56).

Similarly, in the Common Core State Standards one of the eight Standards for Mathematical Practices includes "constructing viable arguments and critiquing the reasoning of others" (CCSSO, 2010).

These standards are ambitious. As the following review of the literature indicates, students struggle with argumentations and proving (e.g. Knuth, Choppin, Slaughter \& Sutherland, 2002; Healy \& Hoyles, 2000), and teachers similarly struggle to support students in these activities (e.g. Bieda, 2010; Chazan, 1993). 


\section{Student Difficulty with Proof and Justification}

Although policy makers encourage the incorporation of proof and reasoning within the classroom, it has been well documented that students struggle to construct deductive arguments (e.g. Chazan, 1993; Knuth, Choppin, Slaughter \& Sutherland, 2002; Hoyles, 1997; Weber, 2001). In a study of 99 high school geometry classes in five states, Usiskin (1987) found that less than a third of the students (31\%) were able to construct a valid deductive proof by the end of the course. Healy and Hoyles (2000) administered a justification survey to 2,459 high achieving 14- and 15- year old students in 94 classes in 90 schools. They found that $90 \%$ of students could not present even a partial proof when presented with an unfamiliar conjecture. In a study of 128 undergraduate students Harrel and Sowder (1998) found that the majority of students have proof schemes that are mathematically invalid, such as using a single example to prove a general result. Others have also documented a student preference for inappropriate use of empirical arguments (Balacheff, 1998; Selden \& Selden, 2008).

\section{Teacher Difficulty with Proof and Justification}

Students are not alone in their struggles with proof. Pre-service teachers frequently use empirical reasoning in a manner similar to students when engaging in justification activity; teachers rely on boundary-cases or sets of examples to provide evidence that a proof is valid (Stylianides \& Stylianides, 2009; Simon \& Blume, 1996; Martin \& Harel, 1989). Buchbinder and Zaslavsky (2011) also found similarities between secondary school teachers' and secondary students' proving; both groups exhibited doubt that a counterexample provided sufficient evidence of the falsehood of a claim. In a study of 16 high school mathematics teachers, Knuth (2002) found that teachers tended to be 
too lenient in their evaluation of the validity of proofs: the teachers rated over a third of the non-proofs as proofs in the study. In their evaluations of proofs, teachers frequently attended to the validity of the methods in the arguments rather than the applicability of arguments themselves.

Not only do teachers struggle with proving themselves, they also struggle to promote proof and justification within their classrooms. Bieda (2010) looked at student opportunities to justify within the middle school setting and found that $71 \%$ of the proof related problems were implemented in a manner that encouraged proof. Of those opportunities to prove, $54 \%$ were supported with a student justification, although the majority (53\%) of those "justifications" consisted of invalid arguments.

\section{Promoting Justification and Related Practices}

Many researchers have investigated teacher practices that develop skills related to justification, such as mathematical discourse, conceptual understanding, argumentation, explanation, and generalization (e.g. Ball et al., 2003; Nathan \& Knuth, 2003; McClain \& Cobb, 2001; Rasmussen \& Marrongelle, 2006). Research in this area tends to focus on one of two factors, or both: teacher moves and classroom culture.

Franke and colleagues (2009) focused on the role of teacher questioning in encouraging student explanation. Franke and her team found that leading questions and asking students to explain their thinking did not consistently lead to explanations; instead a sequence of probing questions was more effective for eliciting student explanations. Similarly, Chazan and Ball (1999) described other types of teacher talk that helped to promote productive argumentation. They showed that creating constructive disagreement or establishing context during the launch of a task can lead to productive student 
argumentation. Staples (2007) further specified a model of teacher activity during discussions. This model included supporting students in making contributions, including eliciting and scaffolding student ideas and creating contributions through linking and demonstrating logic; establishing and monitoring a common ground, which required a common understanding of the mathematical task and positioning students to collaborate with one another; and guiding the mathematics, which utilized student thinking to build on the mathematical goals of the task.

Martino and Maher (1999) focused specifically on how teacher questioning could promote justification and generalization. They found that students did not naturally generate justifications when comparing solutions with one another; however, by inserting him or herself into the conversation after students have worked on a problem, the teacher could elicit justification, solution reorganization, and possibly generalization through effective questioning. Teachers used questioning to monitor student thinking, focus student attention to incomplete arguments, offer opportunities for students to form and test hypotheses, push students to generalize, and facilitate communal awareness. Based on effective teacher questioning, students were able to shift from their original method of exploration (through trial and error) to a more organized and complete justification.

In contrast Mueller, Yankelewitz and Maher (2011) focused on student-student interactions rather than teacher-student interactions. They found that peer interaction led to three different types of argument construction: 1) co-construction, where arguments were build collaboratively from the ground up through back and forth exchanges, 2) Integration of arguments, in which one student's argument was strengthened using elements from another peer's argument, and 3) modification, when one peer attempted to 
correct or make sense of an argument, and the argument was modified as a result. Their work's findings were counter to the findings of Martino and Maher (1999), who found that students did not typically seek further elaboration or justification from one another when sharing solutions.

Other research has focused on how teachers can influence classroom culture. Martin, McCrone, Wallace and Dindyal (2005) found that use of open-ended tasks coupled with classroom discourse that held students accountable for analyzing arguments and providing reasoning helped to promote student conjecturing, justification, and reasoning activity. In particular, the researchers highlighted the importance of teacher “coaching:" attending to student ideas by acknowledging ideas, pursuing suggestions, encouraging continued participation, or offering praise.

Engle and Conant (2003) had finding similar to Martin, McCrone, Wallace and Dindyal (2005): productive disciplinary engagement could be supported by establishing a classroom learning environment that (a) problematized subject matter, (b) gave students authority to address problems, (c) held students accountable to others and disciplinary norms, and (d) provided students with proper resources. This type of engagement relied on both classroom design as well as specific in-the-moment activities. In particular, teachers could play role in supporting productive disciplinary engagement in-the-moment by (i) giving students agency (emphasizing that they must decide among themselves), (ii) holding students accountable for providing information to support their arguments, and (iii) proposing counterarguments to keep the issue problematic.

Similarly, McClain and Cobb (2001) found that by carefully managing social expectations, such as what constitutes a mathematical explanation, one first grade teacher 
helped to establish a social environment in which students spontaneously provided explanations and reasoning. Kazemi and Stipek (2001) had similar findings; they identified four sociomathematical norms that supported conceptual thinking: explanation is a mathematical argument rather than procedure, mathematical thinking includes understanding relationships between multiple solution strategies, errors are valuable opportunities for exploration, and collaboration requires individual accountability and argumentation for consensus.

The preceding summary of the literature indicates that teacher moves and classroom culture can contribute to productive student activity related to justification, such as explaining, conjecturing and comparing ideas. In the next section, I describe definitions of justification found in the literature, as well as the one used to guide this study.

\section{Definition of Justification}

The specific meaning of the terms "proof" and "justification" are not universally agreed upon within the mathematics education research community (Balacheff, 2002). For example, Harel and Sowder (1998) focused on the verification process of an individual person: "By 'proving' we mean the process employed by an individual to remove or create doubts about the truth of an observation" (p. 241). Yackel's (2001) definition is similar; however, instead of focusing on one's own doubts, Yackel positioned justifications as responses to the doubts of others: "[Students and teachers] give mathematical justifications in response to challenges to apparent violations of normative mathematical activity" (p. 13).

Stylianides (2007) provided a detailed definition of proof that incorporated the 
importance of community acceptance with the idea of mathematical validity:

Proof is a mathematical argument, a connected sequence of assertions for or against a mathematical claim, with the following characteristics:

1. It uses statements accepted by the classroom community (set of accepted statements) that are true and available without further justification;

2. It employs forms of reasoning (modes of argumentation) that are valid and known to, or within the conceptual reach of, the classroom community; and

3. It is communicated with forms of expression (modes of argument representation) that are appropriate and known to, or within the conceptual reach of, the class- room community. (p. 294)

In this dissertation I use the term justification rather than the more formal construct of proof. The term justification emphasizes sense-making and focusing on why rather than the formal, stylistic elements frequently associated with the term proof. Much like Hanna's (1990) distinction between "proofs that prove" and "proofs that explain," this study focuses on the argumentation and reasoning practices that establish mathematical truth through an explanation of why something works mathematically. The definition of justification used in this paper builds on that of Stylianides (2007), with the addition that justification can be thought of as both a product (a formal argument), and a process (the logical steps used to arrive at a conclusion).

\section{Forms of Reasoning}

Stylianides' (2007) definition of proof provides a defining framework for justification in this paper. The second component of this definition is Forms of Reasoning. Larsen (unpublished manuscript) has proposed a framework of forms of reasoning relevant to middle school mathematics, which is summarized in this section. The framework was based on preexistent literature and refined through empirical 
investigation of student justifications in the JAGUAR project. The framework includes example based reasoning (including generic-example and pattern-based reasoning), transformational reasoning, and appealing to known information (including model based reasoning).

\section{Example Based Reasoning}

Example-based reasoning includes any reasoning that makes use of an example as evidence for a claim. As discussed previously, both teachers and students frequently show preference for example-based reasoning, even when that reasoning is insufficient to justify a general claim. However, examples can be leveraged in a variety of ways that extend beyond simple empiricism. Both students and mathematicians use examples in many ways within reasoning and proving activity (Ellis, 2012; Lockwood et. al, 2012; Mills, 2014), and differentiating between these uses has important implications for supporting students in justification activity.

Empirical reasoning with examples. The most basic form of empirical reasoning is naïve empiricism (Alcock \& Inglis, 2008), in which an individual uses a single example or a small set of examples to prove a general statement. This is generally not a valid approach for proving of a general claim. However, if the claim is about a finite set of objects rather than an infinite set, checking each one of the finite cases constitutes a valid proof by exhaustion. Similarly, a counter-example is a valid proof technique for refuting a general claim using a single instance: the counter-example must satisfy the propositions of a conjecture but fail to satisfy the result, which disproves the conjecture.

Generic example-based reasoning. Mason and Pimm (1984) describe generic example-based reasoning as reasoning about a specific example in a general way: "A 
generic example is an actual example, but one presented in such a way as to bring out its intended role as the carrier of the general. This is done by means of stressing and ignoring various key features, of attempting to structure one's perception of it” (p. 287) These types of arguments are also called generic proofs, (Selden \& Selden, 2008). Generic examples are an important form of reasoning as they can form a bridge between specific empirical results and proving. At a middle school level in particular, generic examples are a mechanism for students to be able to communicate general reasoning when they lack the algebraic or representational tools to represent that thinking in a fully generalized way.

Pattern-based reasoning. Pattern-based reasoning is a form of reasoning in which a pattern is observed within a set of examples. This is a specific type of example-based reasoning, but the examples are considered as a single set exhibiting a predictable pattern, frequently in the form of a table of values. The naïve form of pattern-based reasoning is result-pattern reasoning (Harel, 2001), in which a student notices a pattern and assumes it must hold. Ellis and colleagues (2012) observed a form of this reasoning in which students intentionally selected sets of numbers that formed a predictable pattern to test the validity of conjectures. A more sophisticated form of pattern-based reasoning is process-pattern reasoning in which a student notices a pattern and describes the mechanism or underlying process behind why the pattern must hold.

\section{Transformational Reasoning}

Transformational reasoning (Simon, 1996) is reasoning in which a student performs dynamic physical or mental operations on objects to transform the objects. 
Transformational reasoning is the mental or physical enactment of an operation or set of operations on an object or set of objects that allows one to envision the transformations that these objects undergo and the set of results of these operations. Central to transformational reasoning is the ability to consider, not a static state, but a dynamic process by which a new state or a continuum of states are generated. (p. 201)

These mental transformations must be mathematically appropriate; the dynamic transformation should be governed by the applicable rules of mathematics for the context. This reasoning can be thought of as "running" a mathematical system with the intention of understanding how the system works rather than generating data upon which to form a pattern-based, deductive argument. For example, one might dynamically manipulate a triangle to reason that the sum of two sides is always greater than the third side. Such manipulation can take place mentally or physically, but when physically enacted it must include "mental anticipation" of the process.

\section{Appealing to Known Information and Model Based Reasoning}

When appealing to known information, the student appeals to facts or procedures that are taken to be true. Examples include arithmetic facts, algorithms, equivalent statements, and metaphors. One particular type of known information is the use of modelbased reasoning. Model-based reasoning is reasoning that is based on an agreed upon mathematical model. Such models could be models of operations (such as the "sharing" model of division) or models of procedures (such as a "tree diagram" model for factorization).

This list of forms of reasoning is not comprehensive, but summarizes a representative set of common forms of reasoning evidenced in the JAGUAR project data set. These forms of reasoning should not be considered mutually exclusive. We see that 
many of the forms are nested: an argument can be both empirical and pattern based. Also, a student might coordinate multiple forms of reasoning within a single justification argument.

\section{Role of Justification}

Teachers and students have a tendency to view proof as a ridged, formal process whose purpose is to follow a prescribed structure rather than to communicate mathematical meaning. Many teachers tend to think of proof as a content topic that should be taught separately from regular mathematics instruction, typically as twocolumn style proofs in the context of high school geometry (Harel \& Sowder, 1998). Knuth (2002) found that teachers also believe proof is a topic that is only appropriate for the most advanced students, and the majority of secondary students are not capable of engaging in proving. He also found that teachers tended to view proof as a product rather than a process that facilitates mathematical understanding.

Math education researchers may point out teachers' impoverished view of the role of proof; however, there is disagreement about the role that proof should have in a classroom setting. Harel and Sowder (1998) argue that the purpose of proof in the classroom should closely mimic that of the mathematics community, which includes mathematical exploration and conjecturing. Usiskin agrees, stating "we seem to have failed in our teaching of proof, because we too often ignore why mathematicians do proofs" (1980, p. 419). De Villiers (1990) found six primary roles of proving among mathematicians, including verification of the mathematical truth of a statement, explanation of why something works mathematically, systemization, discovery of new mathematical ideas, and communication of mathematics. Knuth (2002) limits the list to 
five primary purposes: verification of validity, explanation of validity, communicate mathematical knowledge, to discover or create new mathematics, or to systematize statements into an axiomatic system.

Staples and Bartlo (2010) believe that the goals of the mathematics community and the classroom community differ, and thus the role of proof or justification should differ accordingly. The primary goals of the mathematical community are the invention and communication of new mathematical truths, while the goal in the classroom is for novice learners to understand previously established ideas. One important role for proof or justification is to establish the validity of a mathematical result, but justification can also be leveraged as a pedagogical practice that develops mathematical meaning and communication within the classroom (Bartlo, 2013).

This section provided an overview of research literature relating to justification. In this paper, justification is defined to be a mathematical argument that explains why a result is true. This definition is operationalized using Stylianides' (2007) threecomponent definition of proof. This section also described purposes for justification within the classroom, and teaching practices that promote student activity associated with justification. These practices include teacher activity such as questioning and framing, as well as elements of classroom culture, such as student autonomy. In the next section, I describe the theoretical framework supporting this study. 


\section{Chapter 4: Theoretical Perspective and Methodology}

So far in this document I have provided an overview of the JAGUAR project and contextualized the project with a review of the current literature regarding justification. Next, I will describe my theoretical perspective as it applies to broader issues of teaching and learning. This section also includes an overview of the general methodological approaches used for this research.

\section{Theoretical Perspective}

This study draws on both the cognitive and situated learning perspectives. I view learning as an act of individual cognition demonstrated via participation within a social context. These theoretical perspectives were chosen based on the explanatory power and relevance to the research questions. This research coordinates analysis between three different areas: teacher knowledge, teacher practice, and student activity, thus different lenses are needed to best exemplify the salient features of each area.

My interpretation of the cognitive perspective is a reformulation of Steffe and Thompson's (2000) construct students' mathematics into teachers' mathematics, which includes a teacher understanding and proficiency with justification. I conceptualize knowledge acquisition as an essentially constructivist activity in which teachers assimilate and accommodate information to construct an independent mathematical reality (Philips and Soltis, 1998). This reality is not directly accessible to anyone other than the primary thinker, thus I recognize that my conceptualization of his or her mathematical reality is an interpretation based on interaction with the thinker. In this light, I do not claim objective insight into the thinker's mind, but instead I aim to develop a model of teacher's understanding that describes the teacher's representation of her or 
his mathematical reality via verbal and nonverbal communication. Thus, teacher utterances will be interpreted at a semantic level, for those utterances are the object of interest rather than the unknowable, personal mathematical realities of the teachers.

This interpretation of the cognitive perspective accounts for the role of researcher as an observer, rather than as an interactive partner. This choice is based on the research question: the goal is not to understand the mutually constructed meaning that evolves in an interview context, but instead to develop a robust model of an individual teacher's articulated conceptions of justification. This perspective does not dismiss the role of context of the interaction; it simply views the individual contributions of the teacher as the primary mechanism for developing a model for that teachers' mathematical reality.

To further structure the development of models describing teachers' conceptions of justification, I use Schoenfeld's (2011) framework for teacher decision-making. He identified three primary factors that impact teachers' practice: teacher orientations, which include beliefs and preferences; teacher goals; and teacher resources, which include their knowledge, curriculum, and physical resources.

This research will also draw upon the situated perspective to understand teachers' evolving understanding of justification as mathematical practice. The situated view is based upon Lave and Wagner's (1991) view of learning as evolving participation within a community of practice. In this research, the teachers participate within two different, yet overlapping communities: the first is the community of teachers, math education researchers, and mathematicians within the working sessions, and the second is their middle school classroom community. The teachers' goals regarding justification development differ between the communities. In the working sessions, the primary goal 
is for teachers to develop their understanding of justification as a pedagogical and mathematical practice. In the classroom community, the teachers' primary justification goal is to promote justification proficiency within the classroom community. As such, the teachers may have different, yet related, types of participation among the different communities.

The situated perspective provides a framework for understanding the factors that influence teacher participation within and across these different contexts. Although the community is an essential aspect of situated perspective, the unit of analysis will remain individual: like Cobb and Bowers (1999) I use "individual [teachers'] reasoning as a unit of analysis while simultaneously viewing that reasoning as an act of participation in evolving communal practices" (p. 8).

The development of teacher justification practices is viewed as co-evolving across both the working session and classroom contexts. Professional development is commonly conceptualized as a causal agent that impacts how teachers teach; however this paper takes on the perspective proposed by Kazemi and Hubbard (2008), in which teacher participation in professional development can influence classroom practice, but classroom practices can also impact teacher participation within the professional development. Thus the evolving types of participation are traced along both contexts, seeking explanations that account for the changing types of participation in both communities.

Although the JAGUAR project is not conceptualized as a professional development program in the traditional sense, this model of coevolution of teacher participation is particularly apt. The JAGUAR project included sustained interventions 
over two years, including working sessions within the school year. The working sessions themselves were framed to help teachers reflect on classroom practices directly through classroom video viewing and structured discussion. Thus the ways that teachers taught in their classroom had a direct impact on the content of the working sessions.

Rather than thinking of the cognitive and situated perspectives as contradictory or competing, I view them as mutually supportive in this investigation. The cognitive perspective helps describe the knowledge needed to support justification, while the situated perspective allows for understanding of teachers' participation within the working session and the classroom. These theoretical perspectives help trace the evolution of teacher activity and ways of knowing over multiple contexts over time. The different types of analyses coordinate with one another to uncover patterns and offer explanations for relationships.

\section{General Methodology}

This section describes my general methodological approach. Each of the three case study papers includes a methods section specific to those papers. However, some of the methodological framework applies to the investigation as a whole. Taken as a whole, this research focuses on a contemporary phenomenon that cannot be subjected to controls or otherwise extracted from its context. The primary goal was to construct a rich, descriptive account of the phenomenon within that embedded context and to provide viable explanations for observed relationships between elements or events (Yin, 2009).

Data analysis proceeded in a multi-layered fashion, as consistent with the recommendations of Yin (2009). In the first stage, the data corpus was reduced to a data set that directly addresses the research question. Next, each data type within data set was 
coded and organized into themes using thematic analysis (Braun \& Clarke, 2006). Next, the themes within each data type were compared with one another seeking convergence of evidence (Yin, 2009). Triangulation occurred between the multiple data sources to create a robust description of the individual cases. Next, a chain of evidence was created that links the original data to each of the convergent themes and to the final research question. In this stage, themes across the cases within each study were considered. Ultimately, the data analysis produced a vivid description of each of the cases and a comparison of the cases across analytic themes. This analysis informed the generation of a theoretical model to explain the relationships targeted in the research questions.

\section{Thematic Analysis}

The primary analytic method used for this set of studies was thematic analysis (Braun \& Clarke, 2006). Thematic analysis is a flexible, qualitative analytic process appropriate for case study research. Much like pattern matching (Yin, 2009), patterns in the data are identified and compared to one another. However, unlike pattern matching which relates independent variables to dependent variables for explanatory studies, pattern matching can be applied to both descriptive and explanatory studies. Thematic analysis can also be similar to grounded theory in the generation of themes, but unlike grounded theory methods, thematic analysis is not bound to a particular theoretical framework and need not be inductive.

Thematic analysis can be inductive, in which themes are identified within the data itself, or theoretical, in which themes are identified in advance based on preexisting theory or researcher interest. In either case, themes are identified based on the theoretical framework guiding the study, which is chosen based on the research questions. 
Thematic analysis was conducted using 6 iterative phases. These phases are described in Braun and Clarke (2006), but modified slightly for my use within case study methodology.

Phase 1: Familiarizing yourself with the data First, the body of data was reviewed to (a) pare down the entire corpus into the set that is applicable to each study, and (b) to identify preliminary codes for phase 2 .

Phase 2: Generating Initial Codes Similar to open coding (Corbin \& Strauss, 2008) codes form the most basic unit of analysis and were used in phase 3 to form themes. The initial coding highlights or identifies particular segments of the data and attaches interpretive meaning. To help increase internal validity, the data set was systematically reviewed to ensure the codes are representative of the data.

Phase 3: Searching for themes Similar to the stage of axial coding in grounded theory (Corbin \& Strauss, 2008), the third phase consisted of organizing the set of codes into groups and subgroups to better reflect the internal relationships of the concepts.

Phase 4: Reviewing themes Once a set of themes were established, the themes need to be refined to ensure the data within the theme has meaningful coherence. Each data excerpt was reviewed to establish its fit with the given theme. This was an iterative process, and as new themes were identified they will be coded in the data set.

Phase 5: Defining and naming themes Defining and naming themes included a demarcation of the meaning and boundaries of a given theme. This stage included a description of the "story" that each theme tells, and how that individual theme's "story" fit into the larger narrative of the data in response to the research question. 
Phase 6: Writing the report In the final report, data was presented that clearly

demonstrates each theme. In addition, an interpretative account provided justification for the selection and importance of the themes, along with an analysis of how the themes address the research question of the case. 


\title{
Chapter 5: Teacher Conceptions of Justification
}

\begin{abstract}
Recent initiatives in mathematics education reform have identified proof and reasoning practices as critical for all grades of mathematics (NCTM, 2000; CCSSO, 2010). Successful enactment of these ambitious practices depends, in part, on teacher conceptions of proof and justification. This study examines middle school teacher conceptions of justification along three dimensions: What is justification? What is the purpose of justification? What are teacher proficiencies with justification? Data for this analysis is drawn from twelve middle school math teacher participants in the JAGUAR project and includes interview transcripts, justification assessments, and participation in workshops. One important result from this case study analysis is that teachers viewed justification as a mathematical practice, one that centers on why something works or is true mathematically, as well as a pedagogical practice, one that centers on communication of student reasoning.
\end{abstract}

\section{Motivation}

Using proofs to establish the validity of mathematical results is critical for the practice of mathematics. Yet many math teachers think of proof as a specific skill independent from content, with little relation to "every-day" mathematics instruction (Hanna, 2000; Knuth, 2002b; Ross, 1998; Wu, 1996). Over the past several decades math education researchers and policy makers have argued for greater integration of proof and justification into mathematics instruction. Schoenfeld (1994) argued that "proof is not a thing separable from mathematics, as it appears to be in our curricula; it is an essential 
component of doing, communicating, and recording mathematics... and it can be embedded in our curricula, at all levels" (p. 76). Similarly, reform documents have called for greater emphasis on proof and reasoning throughout all grade levels (NCTM, 2000; CCSSO, 2010).

A growing body of research indicates that justification activity contributes to student understanding. Providing students with the opportunity to engage in proving activities, such as conjecturing, generalizing, and argumentation, aids in learning of mathematics. Justification activity has been demonstrated across grade levels and led to stronger mathematical discourse, strategy creation and refinement, pattern recognition, use of structure, and improved mathematical dispositions (see, e.g., Lampert, 1990; Maher \& Martino, 1996; Reid, 2002; Stylianides, 2007; Wood, 1999; Yackel \& Cobb, 1996). Student engagement in justification activity can also lead to more equitable learning outcomes among diverse student populations (Boaler \& Staples, 2008).

In this paper I use the term justification rather than the more formal proof. This choice is intentional: the term proof tends to be associated with a rigid, formal structure that is typically focused on establishing truth rather than promoting student understanding (e.g. Hanna, 2010; Knuth, 2002a; Ross, 1998). Justification, on the other hand, meets the same purpose of proof (to establish the mathematical validity of a statement), while evoking connotations of explanation and avoiding the emphasis on formal, stylistic elements frequently associated with the term proof.

Proof and justification have been identified as important mathematical practices, but it has been well documented that students struggle with proving and justifying (e.g. Chazan, 1993; Knuth, Choppin, Slaughter \& Sutherland, 2002; Hoyles, 1997; Weber, 
2001). To support students in this ambitious practice, teachers themselves need to have a robust understanding of justification. As teachers and teacher educators, we need to have a better understanding of the conceptions of justification necessary for teachers to teach justification and how these conceptions develop.

Common sense, as well as empirical evidence, indicates that a teacher's knowledge influences his or her practice (Fennema \& Franke 1992). Stylianides and Ball (2008) elaborate:

Unless teachers have good understanding of proof, we cannot expect that they will be able to effectively promote proving among their students. The serious difficulties that students of all levels face with proof...underlie further the importance of teachers' knowledge about proof for teaching and the need for research to identify critical elements of this knowledge (p. 309).

Knowledge of proof may be important, but content knowledge alone is a weak predictor of classroom outcomes (Floden, 2001; Darling-Hammond, 2000). Thus, someone who has demonstrated expertise as a skilled justifier may not possess the knowledge necessary to lead students in justification.

In other content areas, pedagogical content knowledge has been shown to correlate strongly with classroom practices (e.g. Hill et. al, 2008; Lewis \& Blunk, 2012) and subsequent student learning (Hill, Rowan, \& Ball, 2005). Several studies have described types of pedagogical content knowledge needed for teaching proof, such as the ability to understand the components of a proof, knowledge of situations for proving (Stylianides \& Ball, 2008), essential proof understandings (e.g. a theorem has no exceptions; a proof must be general), the functions of proof (Lesseig, 2011), and the ability to evaluate the validity of students' arguments (Tabach et. al, 2011). However, none of these studies 
linked pedagogical content knowledge of proof with broader teacher beliefs or orientations, nor with specific teaching practice.

In addition to knowledge, research outside of the domain of justification has demonstrated that teacher beliefs and goals can influence teacher decision-making in their teaching practice (Ball, Thames, \& Phelps, 2008; Schoenfeld, 2011; Wilson \& Cooney, 2002). For example, Aguirre and Speer (2000) found that belief bundles inform the selection and prioritization of pedagogical goals during in-the-moment teaching practice. Beliefs themselves have been shown to impact teaching practice, although the nature of the relationship is complex (see i.e. Thompson, 1992). Thus, a constellation of factors, including beliefs, goals, and knowledge, all influence teach practice, and are included within the broadly defined construct of "conceptions of justification" within this paper.

This research is also concerned with teacher change: it describes the development of teacher conceptions of justification over the course of a two-year collaborative project. Changes in teacher knowledge, or teacher learning, has traditionally been described as a causal relationship in which a teacher's training or professional development experiences impart knowledge that is then utilized in the classroom (Cochran-Smith \& Lytle, 1999). However, I take on Kazami and Hubbard's (2008) situated perspective in which teacher knowledge develops across multiple settings: participation in and outside of the classroom contribute to teacher knowledge and reinforce ways of knowing and doing. Teacher beliefs in particular have been identified as difficult to change; beliefs may remain inconsistent with one another (Thompson, 1992). Change in beliefs usually does not occur because of argument or reason, but because of a "conversion or gestalt shift" 
(Nespor, 1987, p. 321). However, beliefs and practice mutually influence one another, so changed practice can lead to changed beliefs (Bray, 2011).

\section{Theoretical Framework}

The theoretical framework guiding this paper's exploration of teacher conceptions is based on Schoenfeld's (2011) model for teacher decision-making. Schoenfeld (2011) found that teachers rely on much more than content knowledge when engaging in the practice of teaching. He identified three factors that influence teachers' decision-making within the classroom: orientations, goals, and resources (see Figure 5). Orientations are a broad category that encompasses "beliefs, values, preferences, and tastes" (p. 460). For this paper, I consider teachers' orientations to include their beliefs about what justification is, what they value in a justification, and how they perceive justification relates to the classroom community or the mathematical community.

In this framework, goals are the results or outcomes a teacher hopes to achieve, which can take on a variety of grain sizes and may or may not be consciously realized. In this paper a teacher's goals consist of their purposes for using justification in the middle school mathematics classroom. The goals in this study are those consciously articulated by teachers, and may not represent the full spectrum of enacted goals within their practice. Just as the selection of goals can be impacted by teacher orientations (Aguirre \& Speer, 2000), goals also have the potential to impact orientations. For example, if a teacher took on the goal of improving student to student communication, using justification activity to meet that goal might shift a teacher's belief in the pedagogical value of justification. 
Resources include a teacher's knowledge (be that pedagogical knowledge, content knowledge, etc.) as well as other types of material or social resources such as access to curriculum or technology. In this paper, the resources under consideration are the teachers' proficiencies with justification, including the types of justifications they produce, their understanding of the components of justifications, and their understanding of the mathematical validity of justifications. These understandings are part of Common Content Knowledge (CCK), a type of knowledge of mathematics that is not particular to teaching, and Specialized Content Knowledge (SCK) (Ball, Thames, \& Phelps 2008). In isolation, a teacher's ability to justify is not predictive of teaching competence; however, the content knowledge associated with justification is an important resource teachers may draw upon within their classroom practice (Lesseig, 2011).

A visual representation of this theoretical framework is given in Error!

Reference source not found.. Notice that each of the elements of teacher conceptions of justification (orientations, goals and resources) are reflexively related to one another. Thus a teacher's orientation may impact a teacher's proficiency with justification, just as one's proficiency may affect one's orientations. In the center is a teacher's practice, which again is reflexively related to each component of a teacher's conceptions.

It is important to note that these dimensions are not distinct partitions; a teacher's knowledge of mathematics and beliefs about mathematics are intertwined and difficult to separate (Fennema and Franke, 1992; Thompson, 1992). Rather, this framework offers a lens through which interrelated dimensions of the conceptions of justification can be explored. 


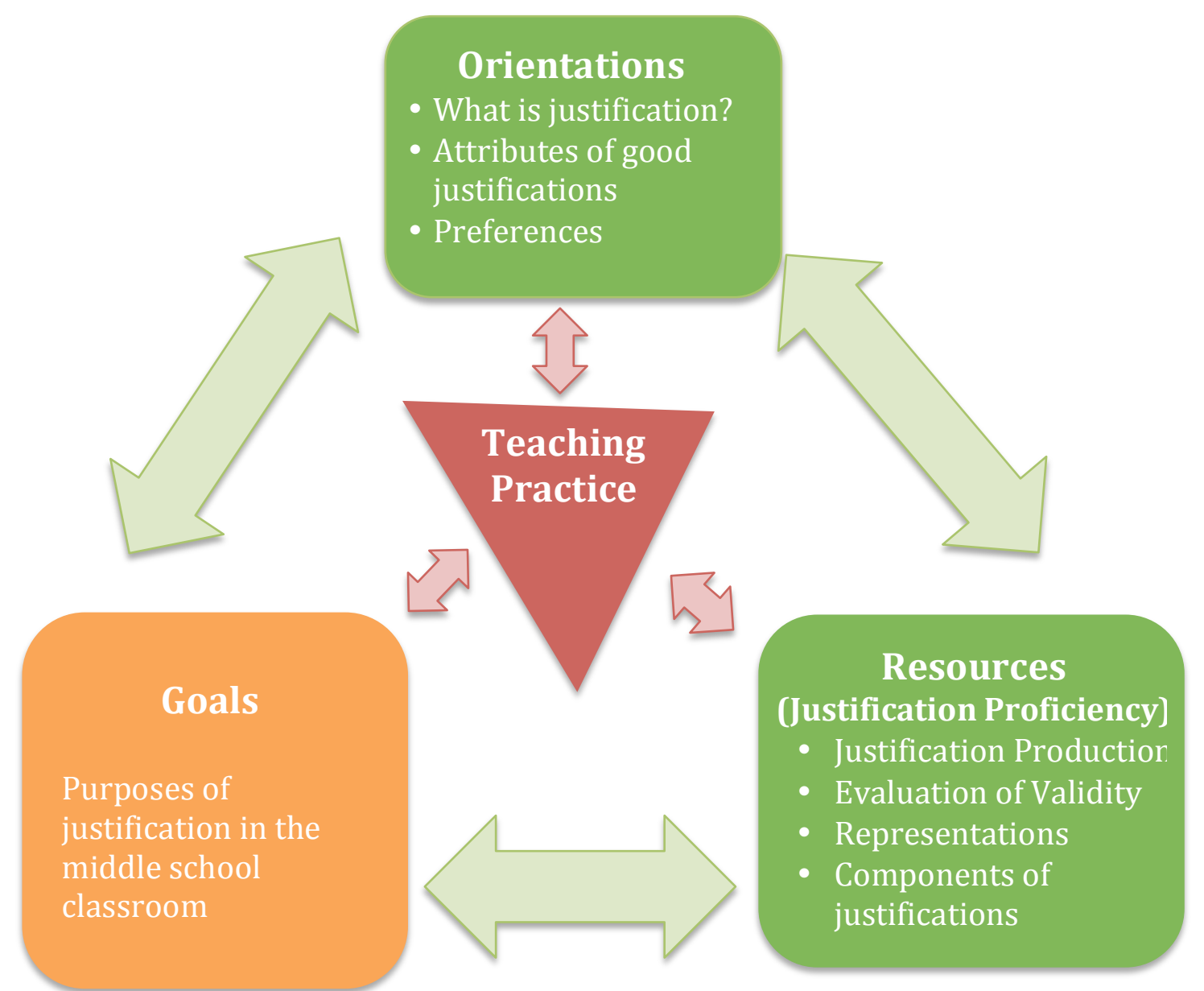

Figure 5: Theoretical framework linking teacher orientations, goals and resources with teacher practice

\section{Research Questions}

This paper serves multiple purposes. At its core, it gives insight into how teachers view justification, providing a robust profile of relationships between a teacher's understanding of justification, view of the purposes of justification, and proficiency with justification. Secondly, this paper demonstrates the development of those conceptions over time. This longitudinal analysis has important implications for teacher growth and can inform future professional development. Finally, the results from in this paper will be used in a larger case study that identifies relationships between teacher conceptions of justification, professional noticing of justification, and pedagogy with respect to 
justification.

Data for this paper was drawn from the JAGUAR project (Justification and Argumentation: Growing Understanding of Algebraic Reasoning): a two-year coinvestigation of justification and pedagogy among a team of middle school teachers and math education researchers. It is important to recognize that the teachers in this study are not representative of typical middle school teachers: the teachers selected for this study already had classroom cultures classified as strategy reporting or inquiry-argument (Wood \& Turner-Vorbeck, 2001), and their participation in the project demonstrated an active interest in improving justification practices. Within the context of the project they spent two years working to improve their understanding of justification and support for justification within their classrooms. The conceptions of justification held by these teachers can be considered productive: all of the teachers in this group had evidence of student justification activity in their classes (see Staples and Newton, in progress).

This paper offers a detailed analysis of conceptions of justification held by teachers who engage in this ambitious practice. The teachers had differences in their conceptions, thus this paper offers multiple models of conceptions necessary to support justification. By comparing the conceptions, this analysis also describes important conceptual elements across the cases. Finally, this set of cases illustrates the development of conception of justification, which can serve as a guide for training teachers in future professional development work.

In this paper I present a description of JAGUAR middle school teacher conceptions of justification, which include teachers' understanding of the definition of 
justification, their purposes for justification, and their proficiency with justification. Specifically, the research questions are:

1. What do JAGUAR teachers think justification is? What attributes of justification do they believe are important? How do their beliefs this shift over time?

2. What do they see as the purposes of justification in their classroom? How does this shift over time?

3. What are teacher proficiencies with justification? What types of justifications do they produce? How do they understand components of justification? How does this shift over time?

The first research question targets teachers' orientations: their beliefs about what justification is, how it relates to proofs and explanations, and what they value in justifications. The second research question targets what teachers see as the goal or purpose of justification within the middle school classroom. The third research question targets their proficiencies with justification, which is one type of resource. Notice that proficiencies is plural, because teachers may demonstrate multiple abilities when demonstrating understanding of justification. This includes the teachers understanding of representations, forms of reasoning, and validity of justifications.

This paper builds on the previous work of Thanheiser et. al (2010) that examined teacher conceptions of justification and Staples, Bartlo and Thanheiser (2011) that examined teacher purposes of justification. Both of these previous studies were based on a portion of the JAGUAR data drawn from the first year of the project. This study completes the picture by examining the full data set over the course of the entire 
JAGUAR project.

\section{Background Literature}

In the following section, I briefly review previous research relating to the definition of justification, the roles of justification, and teacher proficiency with justification. Little work has been done to investigate justification specifically, thus this literature review focuses on both proof and justification. Because teachers tend to view proof as a more formal argument compared to justification, their view of proof and the roles of proof may differ somewhat from their view of justification. We see this in the contrast between teach beliefs about formal and informal proofs, described below.

\section{Definition of Justification}

Very little literature has examined teacher definitions of justification specifically, but a number of studies have looked at preservice teacher (PST) and inservice teacher definitions of proof. In general, elementary PSTs tended to view proof as support for an argument or a convincing argument (Goettlings, 1995; Mingus \& Grassls, 1999). Middle and secondary teachers demonstrated a wider range of conceptions in terms of the focus on validity and mathematics. These conceptions include proof is as a convincing argument, proof as a demonstration of how the math works, and proof as a logical argument that establishes validity (Knuth, 2002a\&b; Thanheiser et. al, 2010; Weiss, Herbst and Chen, 2008). Several studies also indicated that teachers believe a proof or justification should demonstrate a student's understanding (Staples \& Truxaw, 2009; Thanheiser et. al, 2010; Tsamir et. al, 2009).

Knuth (2002b) uncovered an important distinction held by many of the teachers in 
his study: a divide between formal proofs and informal proofs. Formal proofs were characterized as ritualistic arguments, based on conventions of format and language, and were seen as appropriate only for advanced students. Informal proofs, on the other hand, included explanations and empirical arguments that provide reasons or evidence, but may not fully establish the validity of a claim. These informal proofs were viewed as important for all students and vital to mathematics instruction across all grades. This distinction was echoed by one preservice elementary teacher in Mingus and Grassl's (1999) study: "I think that informal proofs can be investigated in elementary school and that formal proofs should be presented in high school. It was hard for me to both learn difficult material and formal proof at the same time" (p. 434). The distinction between formal and informal proof can be compared to the distinction between proof and justification held by some teachers. Informal proofs offer evidence in support of an argument but may lack rigor or formal structure. Similarly, some teachers may view justification as an informal argument that provides evidence without the formality of a proof. An important distinction is that informal proofs may or may not establish the validity of a claim, while in this paper a valid justification indeed use valid forms of reasoning to establish a result.

\section{Purposes of Justification}

De Villiers' (1990) paper on the roles of proof has been influential in shaping how the purpose of proof is framed both within mathematics and within mathematics classrooms (e.g. Hanna, 2000; Herbst, Miyakawa \& Chazan, 2012; Knuth, 2002a \& 2002b). De Villiers' five roles of proof for mathematics consist of (1) proof as a means of verification, (2) proof as a means of explanation, (3) proof as a means of systemization, 
(4) proof as a means of discovery, and (5) proof as a means of communication. A number of researchers have expanded the roles of proof on theoretical grounds to include purposes specific to the classroom community. These additional roles include: exploration and incorporation of ideas into new frameworks (Hanna, 2000), development of conviction for oneself or others (Bartlo 2013; Hersh, 1993), demonstrating a mathematical technique (Herbst et. al, 2010), construction of empirical theory, and incorporation of known facts into new frameworks (Bartlo, 2013; Hanna, 2000; Herbst et al 2010).

In addition to this work, empirical studies have addressed teachers' conceptions of the purposes of proof in mathematics classrooms. Knuth (2002a \& b) found secondary mathematics teachers believed these purposes included verification of truth, communication, displaying thinking, explaining why, and creating mathematical ownership. Additionally, teachers saw proof as part of systemization, but their view of systemization was the construction of building blocks for future mathematics, not the creation of an axiomatic system. Notably absent from the teachers' conceptions was a belief that proof aided in the deepening of mathematical understanding.

Knuth's (2002b) findings contrast with those of Staples, Bartlo, and Thanheiser (2011), who found deepening understanding to be an important purpose for justification according to middle school teachers. The middle school teachers in Staples and colleagues's study (2011) were JAGUAR participants. They articulated a large number of purposes for justification beyond deepening understanding, such as fostering valued math skills and dispositions, fostering valued life-skills and dispositions, assessment, managing diversity, and influencing social relationships. Unlike the teachers in Knuth's (2002a \& 
2002b) studies, the teachers in Staples, Bartlo, and Thanheiser (2011) did not identify verification of mathematical validity as a purpose of justification. One possible explanation for the differences between Staples et. al's (2011) findings and those of Knuth (2002a\&b) was their focus on mathematical justification rather than mathematical proof. As discussed previously, teachers tend to view proof in more formal terms, while they view justification as an argument that explains why. As such, concept of justification may play a greater role in deepening understanding of mathematics, while the purpose of proof might be more closely associated with establishing validity. An additional reason for this distinction might be the teacher sample; since the teachers in Staples et. al's (2001) study were JAGUAR participants, they had focused on developing justification as a pedagogical practice.

\section{Proficiency with Justification}

Much of the work that focuses on teacher proficiency with proof centers on a teacher's ability to construct or evaluate a valid mathematical argument. As a whole, teachers appear to be proficient in the construction of their own proofs, particularly when those proofs are represented via algebraic representations (Barkai et. al, 2002; Tabach et. al, 2009; Tabach et al., 2011; Tsamir et. al, 2009). However, evidence indicates that teachers tend to be too lenient in their evaluation of the validity of proofs, accepting mathematically invalid arguments (Knuth, 2002a; Martin \& Harel, 1989). Staples and Truxaw (2009) found that although teachers were able to shift in their understanding of attributes of justifications, they still struggled to evaluate what makes an argument a strong justification.

\section{Empirical Reasoning and Universality}


One of the most commonly cited errors in teacher treatment of proofs is their acceptance of empirical reasoning arguments in cases for which it is mathematically invalid (e.g. Barkai et. al, 2002; Knuth, 2002a\&b; Martin \& Harel, 1989; Stylianides \& Stylianides, 2009). Teachers may be aware that empirical examples fall short of fully generalized proof, but they may be incapable of constructing a general argument or view examples as a convincing form of evidence (Healy \& Hoyels, 1998; Stylianides \& Stylianides, 2009). Teachers also used examples to increase conviction of the validity of previously proven statements (Knuth, 2002a; Martin \& Harel, 1989). See Chapter 6 of this paper for a more complete discussion of teacher conceptions of empirical reasoning.

Another difficulty teachers have with proof is understanding universality: a valid proof is always true. Once a statement has been proven to be true, teachers may still believe that counter-examples are possible (Knuth, 2002a). Similarly, teachers struggle with the idea that a single counter-example can disprove a universal statement (Barkai et. al, 2002; Tirosh and Vinner, 2004).

\section{Ritualistic Components of Proof}

Evidence also indicates that teachers focus on surface features of proofs, such as type of representation or format, rather than the content of the argument (Knuth, 2000a; Martin \& Harel, 1998; Weiss, Herbst, \& Chen, 2008). Similarly, teachers have focused on the validity of algebraic operations within an argument, rather than whether the conclusions of the argument actually addressed what was to be proven (Tabach et al., 2011). Other features teachers attended to included use of a familiar mathematical technique or argument (Knuth 2002a, Staples and Truxaw, 2009), use of sufficient levels of detail (Knuth, 2002a), use of a predictable sequence of steps (Weiss, Herbst \& Chen, 
2008), and use of the teacher's anticipated form of reasoning (Tsamir et. al, 2009).

\section{Representations in Proof}

A number of studies have focused on the types of representations teachers use in their arguments or prefer from students. Teachers themselves tend to use algebra when producing general arguments, and their algebraic arguments tend to be valid more frequently than arguments utilizing other representations (Barkai et. al, 2002; Tabach et. al, 2009; Tabach, 2011; Tsamir et. al, 2009). When evaluating student work, Healy and Hoyles (1998) found that teachers had strong aptitude in evaluating the validity of algebraically presented arguments. These results contrast with the findings of Tabach (2011), in which about half of the teachers failed to notice when an algebraic argument failed to address the domain that was supposed to be shown. These findings indicate that although teachers are skilled at creating and assessing sequential algebraic equations, they may struggle to assess the underlying premise of arguments.

Some evidence indicates that teachers have less appreciation for arguments given in verbal or pictorial form (Dreyfus, 1999; Healy \& Hoyles, 1998). Teachers struggled with evaluating the validity of verbally produced justifications, because they did not believe that a verbal argument was able to cover the general case (Tabach, 2011; Tsamir et. al, 2009; Barkai et. al,2002). In Dreyfus (1999) some teachers noted that a pictorial proof was valid, but would still give that type of argument a low score on a proving task. Stylianides, Stylianides, and Philippou (2004) had different findings for the specific case of proofs by contrapositive; prospective elementary teachers did significantly better evaluating the verbal proofs over symbolically represented ones. In summary, teachers generally show a preference for algebraic representations, and may not have strong value 
for pictorially represented proofs.

As a whole, the existing body of literature points to a number of deficits in teacher proficiency with justification. Teachers tend to be too lenient in their evaluation of what constitutes a valid proof, often times accepting empirical arguments in cases for which they are inappropriate. Teachers struggle with the universality of proofs, believing that a valid proof may have counter-examples or that a counter-example is insufficient to disprove a universal claim. Teachers in these studies demonstrated limited appreciation for varied forms of argument representation and limited use of different types of representations within their own arguments. Rather than focusing on teacher deficiencies, this paper seeks to understand teacher proficiencies with justification.

\section{Analytic Frameworks}

This paper describes teacher conceptions of justification. Their conceptions include their orientations toward what justification is, their purposes for justification, and their proficiencies with justification. Given the lack of consensus within the literature on the definitions of proof and justification in particular, start with a definition of justification and how that definition is operationalized for the analysis within this paper.

\section{Operationalization of Justification}

The definition of justification used for analysis in this paper is based on the definition of proof offered by Stylianides (2007) (Table 2). This definition of proof was developed specifically to describe proof within school mathematics classrooms. It includes three characteristics: accepted statements, modes of argumentation, and modes of representation. Accepted statements are the basis upon which a justification is built: statements that have been proven or are accepted within the community without further 
explanation. Forms of reasoning are the type of argumentation employed (see Forms of Reasoning, Table 3). Modes of representation include the ways in which an argument is presented (e.g. visual diagrams, tables, graphs, verbal, written, numeric, algebraic).

\section{Table 2: Stylianides' (2007) definition of proof}

Proof is a mathematical argument, a connected sequence of assertions for or against a mathematical claim, with the following characteristics:

1. It uses statements accepted by the classroom community (set of accepted statements) that are true and available without further justification;

2. It employs forms of reasoning (modes of argumentation) that are valid and known to, or within the conceptual reach of, the classroom community; and

3. It is communicated with forms of expression (modes of argument representation) that are appropriate and known to, or within the conceptual reach of, the classroom community.

This definition accounts for the tension between student thinking and mathematical validity commonly present within the mathematics classroom: proofs must be mathematically valid (namely, utilize valid statements and modes of argumentation), while at the same time be accessible to the classroom community.

Stylianides' (2007) definition of justification was an important part of the implementation of the JAGUAR project. In the working sessions, the teachers themselves developed their own definitions of justification based on discussions and mathematical activities. However, as part of the working session activities, teachers were exposed to the components of Stylianides' (2007) definition of justification, and asked to analyze and evaluate justifications based on the components of this definition. This definition serves as a basis for the analysis of the teacher's conceptions of justification, particularly in terms of teacher proficiency with justification. 


\section{Forms of Reasoning Framework}

The second component of Styliandies' (2007) definition, forms of reasoning, requires further elaboration. A taxonomy of forms of reasoning was developed by the JAGUAR project team, which identified forms of reasoning accessible to the middle school community (Larsen \& James, in "preparation”) (Table 3). This forms of reasoning framework was also used, and refined, within the JAGUAR working sessions for evaluating justifications. It served as part of the framework for the analysis of teacher conceptions of justification.

\section{Table 3: Forms of reasoning in middle school classrooms}

\section{Forms of Reasoning}

- Empirical Reasoning

○ Valid forms of empirical reasoning (counter examples, proofs by exhaustion)

- Naïve empirical reasoning (individual or sets of examples used to justify a general case)

- Generic example-based reasoning (a single example is reasoned about in a general way- there is a continuum of sophistication for such proofs)

- Result-pattern reasoning (a pattern is identified. A general rule or claim is formed based on a patterned set of examples) (Harel, 2001)

o Process-pattern reasoning (a pattern is identified and the reason why that pattern must hold is described) (Harel, 2001)

- Transformational Reasoning (dynamic mental or physical operations are used to "run through" or transform the mathematical objects) (Simon, 1996)

- Appealing to known information or model-based reasoning (arguments that rely on known givens or models; such as a "tree-diagram" for factorization)

\section{Methods}

The goal of this study is a detailed description and analysis of teacher conceptions of justification and their shifts over time. This study is part of the larger JAGUAR project 
analysis, which examined teacher development in their understanding of justification, the transformation of that knowledge into classroom practice, and the subsequent impact on student justification activity. The parent project was designed to culminate in accounts of practice (Simon \& Tzur, 1999), specialized case studies that "portray the complex interrelationships among different aspects of teachers' knowledge and their relationships to teaching" (p. 163). As a piece of the larger whole, this study also utilizes a case-study methodology. Each teacher served as a case, and four cases were selected as "replications of each other, contrasting comparisons, or as hypothesized variations" (Yin, 2009, p. 112).

\section{Participants}

All twelve JAGUAR teacher participants were included in the initial analysis. From those twelve, four cases were selected to best represent a wide range of conceptions present from the original group. The themes that emerged from the larger group are represented by those found in these 4 cases. The cases also serve as contrasting cases: they were selected to provide the most diversity in different types of conceptions, all of which remain within the themes of the larger group.

The four case teachers include Kelly Wade, Cythia Littrel, Irene Primm, and Paige Davilla, (all pseudonyms). Ms. Wade taught $8^{\text {th }}$ grade at a small suburban school on the east coast. Ms. Wade had been teaching for 29 years before the start of the program, 28 of which were at the middle school level. Ms. Littrell and Ms. Primm both taught at a 6-8 middle school in a town in the rural west. The student body was primarily white and middle class, with less than 10\% minority, 20\% Free/reduced lunch, and less than 5\% classified as English Language Learners. Ms. Littrell taught $7^{\text {th }}$ grade, and had 
14 years of teaching experience, all of which were at the middle school level. Ms. Primm taught $8^{\text {th }}$ grade, and had 7 years of teaching experience, 3 of which were at the middle school level. Ms. Davilla taught $7^{\text {th }}$ grade at an urban school on the east coast. The student body was $70 \%$ minority, $30 \%$ qualified for free or reduced lunches, and fewer than 5\% were English Language Learners. Ms. Davilla was relatively new to teaching, with only one year of teaching experience prior to the start of the JAGUAR project.

\section{Data Sources}

Data was drawn from the JAGUAR project, which included two years of collaboration with 12 middle school teachers. Each year consisted of a week long summer session, three working sessions in the school year, and four focal lesson observations. The summer and working sessions were collaborative investigations into the development of the understanding of what justification is and the pedagogical practices necessary for supporting it.

Data for this analysis included teacher interviews, verbal and written contributions in working sessions, and two written justification assessments. Interview data included transcriptions from five individual 45-90 minute, semi-structured interviews over the course of the project. The first interview took place before the first meeting, and the last interview took place nearly two years later during the final working session. The interviews included questions specifically designed to elicit teacher definitions of justification such as "If you were to describe justification to a colleague, what would you say." Some questions asked teachers about the purpose of justification in the middle school classroom and in learning math. The interviews also provided opportunities for teachers to demonstrate justification and to evaluate hypothetical 
student justifications. Several interview questions were repeated across each of the interviews to help indicate changes in teacher thinking over time. Other questions were unique to individual interviews (see Appendix $\mathrm{C}$ for sample interview protocols).

Data also included written work and video tape recordings from the working sessions. Teachers completed three written justification assessments: one at the start, one in the middle, and one at the end of the project. The justification survey was developed by the JAGUAR team, which included some original questions and some questions adapted from Healy and Hoyles (2000).

\section{Data Analysis}

A qualitative analysis of the interview and working session data led to the construction of a robust description of teacher conceptions of justification, and how those conceptions changed over time. This analysis focused on teacher definition of justification, proficiency and the purposes of justification, as well as how those understandings shifted over time.

In the first stage of analysis, the author and a second researcher began by independently reviewing interview transcripts and identifying excerpts relating to the following questions that align with the paper's research questions:

Table 4: Questions guiding transcript analysis of teacher conceptions of justification

\section{1: What is justification?}

- How does it relate to explanation? How does it relate to generalization? How does it relate to proof?

- How different for middle school vs. for mathematician community?

- What are attributes of a good justification?

2: What is the role/purpose of justification in the middle school mathematics classroom?

- Why should students do it? 
- How can it help students learn? (More specifically how can it help students learn mathematical concepts?)

- What can it help students learn?

- How does it help the teacher?

\section{3: What are teacher proficiencies with justification?}

- What is needed for a valid justification?

- What are the different forms of reasoning?

How proficient is the teacher at constructing or evaluating justifications?

Each researcher identified passages related to these questions and organized the teacher responses into themes. We then formed evidence-based conjectures with attention to differences between interviews. Next, we compared and revised the conjectures to construct a comprehensive set based on evidence from the excerpts. For example, when collecting evidence about Ms. Primm's definition of justification, the first author formed the conjecture, "Additional elements of her definition of justification emerged over time. In particular, she paid greater weight to the importance of basing the argument on things that are already known or accepted by the community." This conjecture was refined when compared with the second researcher's conjecture, “At the start of the project, Ms. Primm believed the validity of the justification depends on what is expected knowledge for the student's grade level. After the first Summer Session, the validity of a justification instead depends on taken-as-shared/common/agreed-upon understandings among students." Both researchers observed that Ms. Primm placed increasing importance of the role of commonly accepted statements, but when comparing the conjectures a trajectory in the development of this conception was more clearly seen.

Once the set of conjectures was refined, this author revisited the interview data to find confirming and disconfirming evidence in the interview data. The conjectures were 
organized temporally to create a chronicle of teacher conceptions over the course of the project.

In the next stage of analysis, the set of conjectures generated from the interview data was further refined based on the data from the working sessions. First, excerpts in the working session data were identified that pertained to the questions listed previously (see Table 4). Next, the excerpts from the working session data were compared to the conjectures formed from the interview data with the objective of further refining the set of conjectures. In practice, no conflicting data arose from the working session analysis, and the conjecture set was simply refined to include more detail in supporting data.

To address teacher proficiency with justification, research question 3, an additional analysis of the teacher justification surveys and working session work was conducted. The working session data was reviewed to find instances in which the teachers engaged in justification activity. Additionally, every response from the justification survey was analyzed. The teacher justifications from both the written assessments and the working sessions were all analyzed using an analytic framework developed from Stylianides' definition of justification. The justifications were analyzed based on the validity of the argument, the mode of argumentation (form of reasoning) and the representation (See Table 5). The results of the analysis formed a catalogue of teacher responses over the course of the project.

Table 5: Analytic Framework for Justification Proficiency

Analytic Framework for Teacher Justification Proficiency: Based on Stylianides' definition of justification (2007)

Validity: Is the teacher's justification mathematically valid? (Does it address the proper cases? Is it logically sound?) 
Forms of Reasoning: What form(s) of representation are used? (Naive empirical, generic example, process-pattern, result-pattern, model-based, transformational, etc.) Modes of Representations: What mode(s) of representation are used? (Pictorial, algebraic, verbal, numerical, etc.)

After each teacher was analyzed individually, a cross-case analysis was conducted to identify similarities and differences among the four case teachers. The cross case analysis used each teacher's chronicle as a basis for comparison; unifying themes (and variations within those themes) were identified. A final analysis was conducted that focused narrowly on each theme, to ensure that the data from the previously constructed chronicle was both accurate and comprehensive. For example, for the cross-case theme of validity, every transcript was reviewed and every passage that contained the words "true," "truth," "valid," or "validity" was reexamined.

Once a formal draft was complete, I shared the entire draft with the case teachers for a member check. Three of the four teachers responded, each with positive, though limited, feedback. In particular, Ms. Davilla commented that she was impressed by the amount she changed over the two-year project. This member check provided backing of the validity of interpretation as well as the opportunity for teacher reflection.

In summary, the individual cases provide a detailed description of individual conceptions, how those conceptions coexist and evolve, while the cross-case comparison looks across the cases to identify commonalities and differences among this group of JAGUAR teachers.

\section{Results}

The goal of this study is to describe middle school teacher conceptions of justification and the changes in those conceptions over time. I begin with a brief 
description of each teacher's conceptions, including their definition, purposes, and proficiencies, and their development over the project. I conclude the results with a summary of the cross-case analysis that includes a description of themes across the cases.

\section{Case 1: Kelly Wade}

Ms. Wade's definition of justification centered on a student's explanation of his or her thinking or process. At the start of the project, Ms. Wade's definition included a description of what the student did, but over the course of the project her definition grew to include the importance of explaining why a student did what he or she did. Toward the end of the project she explained:

"Justification, to me, would be explaining your reasoning... The step-by-step process might be part of that reasoning, but it's my reasoning more than anything else. Or why I did what I did, and why I got what I got."

Notably absent from Ms. Wade's definition of justification was mathematical validity, although she did include some mathematical reasoning ("how it works") within the final interview. For Ms. Wade, a good justification should demonstrate a student's understanding and include illustrative examples.

According to Ms. Wade, the primary roles of justification were not specifically mathematical; purposes included the development of life and communication skills, such as working well with others and improving thinking or problem solving skills. This aligned well with her definition of justification, which focused on student thinking rather than explicating mathematics. Ms. Wade also maintained justification could be used as an evaluation tool because it helped to demonstrate student understanding. This, too, aligned 
well with her definition of justification, which is an explication of a student's understanding.

The most notable component of Ms. Wade's justification proficiency was her early reliance on naïve empirical reasoning. Over the course of the project empirical reasoning was replaced by more general written arguments; however she continued to value the inclusion of examples to aid clarity in explanation. Again, this aligned with her belief that justification should be an explication of student thinking: even when she recognized that naïve empirical reasoning was invalid, she continued to value examples based on their explanatory power. At the start of the project, Ms. Wade produced and valued verbal arguments most highly, especially those accompanied by examples. As the project continued, Ms. Wade included more varied types of representations within her description of good justifications, including verbal, written, diagrams, computations and algebraic representations.

\section{Case 2: Cynthia Littrel}

Ms. Littrel's definition of justification consistently focused on the communication of a student's thinking. She valued use of multiple representations as a means for communication, particularly early in the project. At the start of the project she stated, "Justification is my view, ... I can verbalize it, I can think it, I can talk it, I can share it." Her explicit definition focused on communication, and based on her reaction to student work Cynthia also implied that students must also have an understanding of the mathematical meaning behind their steps to count as a justification. Over the course of the project her definition expanded to include specific reference to mathematical reasoning and sense-making. She explained, “And so now everything is, 'Does your 
thinking make math sense? Can you justify that thinking? Is there math sense in your justification, not just an explanation?'” Her definition expanded to include an explanation of the "math sense" of one's thinking, which we interpret to mean an explanation of why one's thinking makes sense, mathematically.

Ms. Littrel wrestled with, and never fully resolved, the relationship between generalization and justification: at times, she seemed to think of the terms as nearly synonymous, while at other times, they were related yet clearly distinct. She also wrestled with the validity of justifications that were not grounded in statements that the class understood and agreed on. For example, she believed a student's argument was mathematically correct, but did not categorize it as a justification because the other students would not understand it, stating: "I'm thinking that her justification is not valid because the other kids aren't there."

Consistent with her definition of justification, Ms. Littrel viewed the primary purposes of justification as aiding communication and the development of students as mathematical thinkers. At the very beginning of the project, Ms. Littrel focused on how justification allowed her to evaluate students' thinking. However, as the project continued her focus shifted to how justification helps students evaluate their own and each other's thinking.

Ms. Littrel consistently made strong use of diagrams and exhibited increasing generality in their usage over the course of the project. She consistently maintained that specific examples alone could not justify a general result, because examples alone do not explain why something works. One notable exception was example-based arguments presented in picture form. At the start of the project, she maintained that Fiona's pictorial 
argument showed that the sum of two even numbers was always even, and that it also explained why that sum was even (see Error! Reference source not found.). She stated, In Fiona's I love the representation in which she justifies and generalizes." However, by the end of the project she reversed her position: she decided that Fiona's argument neither showed that the result was always true nor did it explain why, stating that Fiona's picture was not general.

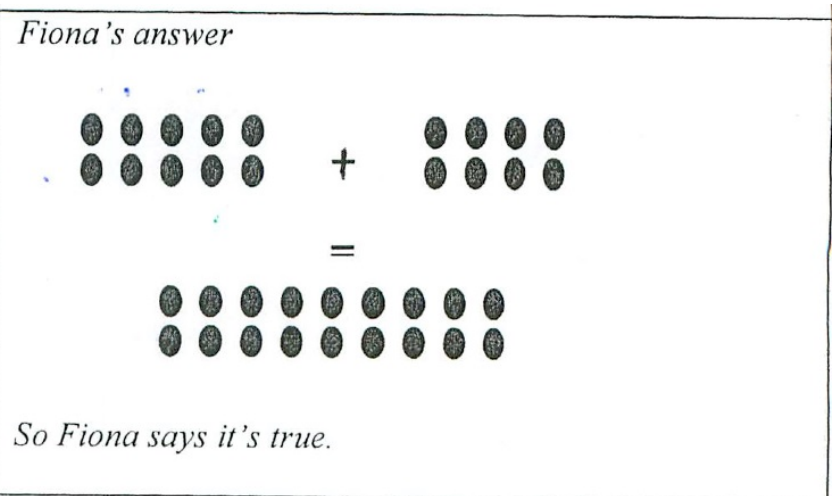

\section{Figure 6: Fiona's pictorial argument that the sum of two even numbers is even}

Ms. Littrel struggled with the validity of generic-example based arguments. Early on, she was conflicted about Sarah's generic example based argument (see Error! Reference source not found.). Sarah's response displayed an understanding of the mathematics, but Ms. Littrel concluded that her argument was not general, and thus not a valid justification: "I would say that Sarah's is not valid ... [Sarah's work] does not push it to, "Oh, this works for every number." By the second year she decided that Sarah's work did address the general case, and was therefore a valid justification. She stated, "I love what Sarah did....I think she generalizes...I would have loved to have seen her say something like 'Well, what if you take $2 x+1$."' Her difficulty analyzing generic example arguments was related to her belief that justifications should demonstrate a general result. Some students were asked to determine whether or not the statement "When you add any 
Some students were asked to determine whether or not the statement "When you add any two consecutive numbers the sum is always odd" is true.

\section{Sarah's response:}

10 and 11 are consecutive numbers so adding them together is like doing 10 plus 10 plus 1.

You really double and add 1.

Since doubles are even, doubles plus one are odd. So the sum of two consecutive numbers is an odd number.

\section{Figure 7: Sarah's generic example argument that the sum of two consecutive} numbers is always odd

Ms. Littler's commitment to communication, multiple representations, and generalization were important elements of her definition of justification, purposes for justification, and proficiency with justification. Her conception of justification underwent a number of transitions over the project: in particular her definition shifted from communication of a person's view to one of mathematical reasoning and sense-making.

\section{Case 3: Irene Primm}

Ms. Primm's definition of justification was stable and clearly stated: she described justification as a student's mathematical reasoning about why something worked or is true. She stated, "So justification would be knowing why something is true mathematically... Justification is using math content to, to prove why something is, mathematically" [emphasis added]. She believed representations were vital for justifications; they served as the vehicle through which students could explain their mathematical reasoning. For Ms. Primm it was also important that justifications be based on valid statements accepted by the classroom community.

According to Ms. Primm the primary purpose of justification was for students to gain a deeper understanding of the mathematics, which included retention and transfer of 
understanding between domains. A secondary role of justification was for students to form connections between representations and to develop student ability to represent thinking with multiple representations.

She was strict in her evaluations of justifications, both in terms of the mathematical validity of the argument and the argument's ability to fully convey why something worked. For example, Ms. Primm maintained that generating a rule from a table was not a valid form of reasoning, because it did not establish why a result was true or why it would work every time. She was a strong justifier herself, making use of multiple representations within her arguments. She was the only teacher in the project to consistently and correctly use fully generalized diagrams within her arguments (see Figure 8).
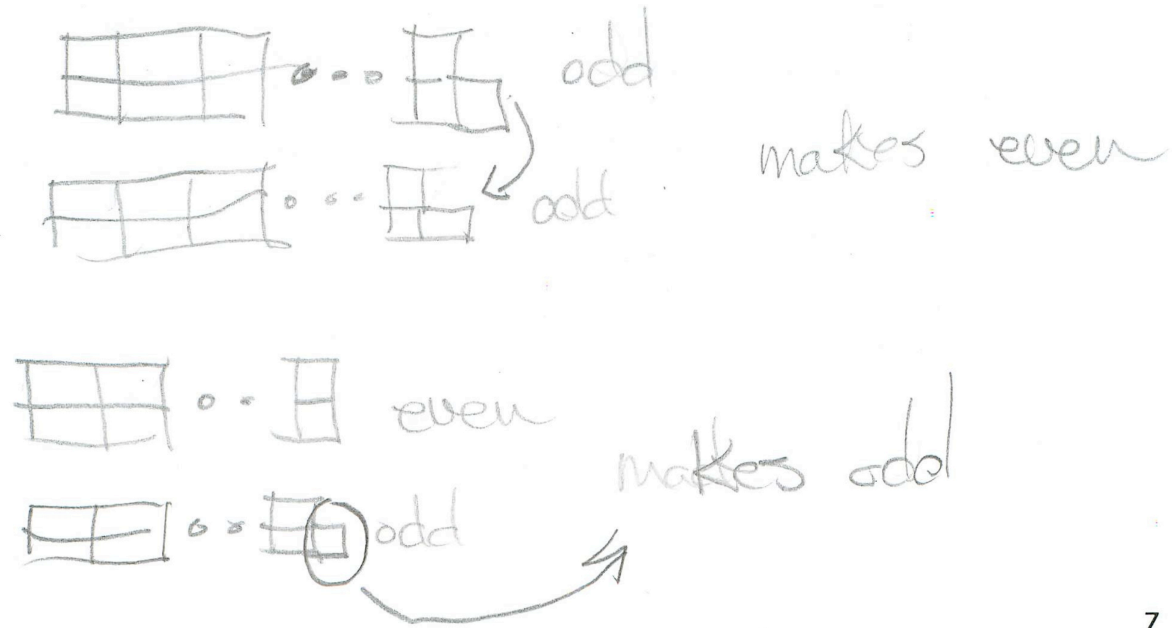

Figure 8: Ms. Primm's generalized pictorial diagram representing that the sum of three odd numbers is odd 


\section{Case 4: Paige Davilla}

Ms. Davilla's conception of justification was detailed, nuanced, and relatively stable over time. According to Ms. Davilla, justifications should contain evidence, reasoning or proof for why an argument works or is true. In order for Ms. Davilla to consider a statement a strong justification, a student must demonstrate his or her conceptual understanding of the mathematics. She admitted that it was easy to conflate a statement of understanding with justification, but a justification should go beyond student understanding and really describe why something works.

Ms. Davilla struggled with her commitment to honoring individual student thinking while simultaneously considering the needs for mathematical validity and community acceptance. She struggled with how to classify incorrect arguments or arguments not accessible to the classroom community. She eventually resolved this tension by positioning such arguments as incomplete justifications, and viewed her role as the teacher to help develop a student's argument so that it was accessible to the class and mathematically valid.

For Ms. Davilla, the primary purpose of justification include shifting the mathematical authority in the classroom from the teacher to the students and deepening students' mathematical understanding. These goals align with her orientation toward justification: a justification should demonstrate a student's understanding, thus the development of a justification would aid in the development of understanding. Similarly, Ms. Davilla's value for student thinking is reflected in her goal of transferring mathematical authority to her students. 
Ms. Davilla herself was highly proficient with justification: apart from minor algebra errors early in the project, she demonstrated the ability to form strong algebraic and verbal arguments. She maintained that generic-example based and pattern-based forms of reasoning were only valid to the degree that they demonstrate why the mathematics works or is true. Of note was her complex (and contradictory) understanding of the relationship between pictorially represented arguments and empirical reasoning. Before the project, Ms. Davilla stated that Fiona's pictorial argument (shown in Figure 9) did not justify the general case, nor did it explain why. In the middle of the project, she still maintained that Fiona's argument did not justify the general case, but that it did explain why the claim is true. However, by the end of the project she ranked Fiona's argument as both verifying the general case and showing why the claim is true. It appears that, at least in this case, Ms. Davilla's appreciation of picture-based representations increased over the course of the project, indicating that pictorial argument of a single example could show that a result was always true.

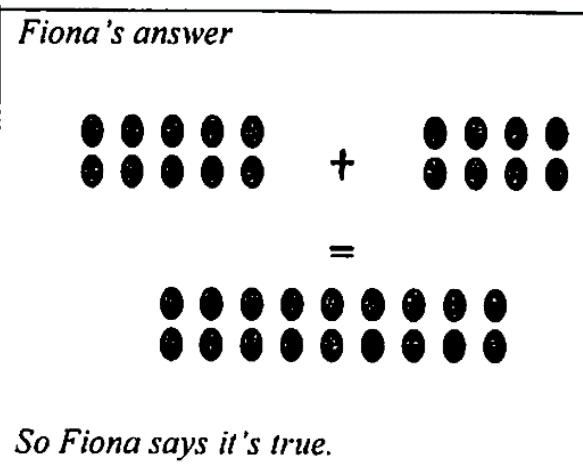

Figure 9: Fiona's pictorial justification that the sum of two even numbers is even

The following table summarizes the important elements of each teacher's conceptions of justification. 
Table 6: Summary of Case Study Teacher Conceptions of Justification

\begin{tabular}{|c|c|c|c|}
\hline & $\begin{array}{l}\text { Orientation to } \\
\text { Justification }\end{array}$ & Goals of Justification & $\begin{array}{l}\text { Justification } \\
\text { Proficiency }\end{array}$ \\
\hline $\begin{array}{l}\text { Ms. } \\
\text { Wade }\end{array}$ & $\begin{array}{l}\text { - Start: "What a student } \\
\text { did" } \\
\text { - Middle: "What a } \\
\text { student did" and "Why } \\
\text { they did what they } \\
\text { did" } \\
\text { - End (briefly): "Why it } \\
\text { works" } \\
\text { - Justifications should } \\
\text { demonstrate a student } \\
\text { understands }\end{array}$ & $\begin{array}{l}\text { - Development of } \\
\text { interpersonal and } \\
\text { communication skills } \\
\text { - Developing of } \\
\text { problem-solving and } \\
\text { thinking skills }\end{array}$ & $\begin{array}{l}\text { - Early reliance on naïve } \\
\text { empirical reasoning } \\
\text { - Rejected naïve } \\
\text { empirical reasoning as } \\
\text { invalid mid-project, } \\
\text { but still valued the } \\
\text { explanatory } \\
\text { component of } \\
\text { examples } \\
\text { - Verbal descriptions } \\
\text { with increasing use of } \\
\text { algebra, limited visual } \\
\text { representations }\end{array}$ \\
\hline $\begin{array}{l}\text { Ms. } \\
\text { Littrel }\end{array}$ & $\begin{array}{l}\text { - Start: Communicating } \\
\text { one's thinking via } \\
\text { representations } \\
\text { - End: Inclusion of } \\
\text { mathematical sense- } \\
\text { making } \\
\text { - Conflation of } \\
\text { justification and } \\
\text { generalization } \\
\text { - Focus on community } \\
\text { acceptance }\end{array}$ & $\begin{array}{l}\text { - Communicate thinking } \\
\text { - Allow teacher, } \\
\text { themselves, and others } \\
\text { to evaluate thinking } \\
\text { - Improved thinking, } \\
\text { understanding, } \\
\text { disposition as } \\
\text { mathematician } \\
\text { - Improved teaching }\end{array}$ & $\begin{array}{l}\text { - Naïve empiricism not } \\
\text { valid and does not } \\
\text { explain why } \\
\text { - Tension regarding } \\
\text { generic examples } \\
\text { - Strong use of visual } \\
\text { representations }\end{array}$ \\
\hline $\begin{array}{l}\text { Ms. } \\
\text { Primm }\end{array}$ & $\begin{array}{l}\text { - Mathematical } \\
\text { reasoning that explains } \\
\text { why something works } \\
\text { or is true } \\
\text { - Importance of } \\
\text { representation and } \\
\text { community acceptance }\end{array}$ & $\begin{array}{l}\text { - Deeper understanding } \\
\text { of mathematics, } \\
\text { particularly connecting } \\
\text { ideas } \\
\text { - Connecting } \\
\text { representations }\end{array}$ & $\begin{array}{l}\text { - Empirical reasoning } \\
\text { was not valid and did } \\
\text { not explain why } \\
\text { - Strong use of algebra } \\
\text { and diagrams, } \\
\text { including fully } \\
\text { generalized diagrams }\end{array}$ \\
\hline $\begin{array}{l}\text { Ms. } \\
\text { Davilla }\end{array}$ & $\begin{array}{l}\text { Evidence for why an } \\
\text { argument works or is } \\
\text { true, increasing focus } \\
\text { on student reasoning } \\
\text { - Includes } \\
\text { demonstration of } \\
\text { student understanding } \\
\text { - Balances mathematical }\end{array}$ & $\begin{array}{l}\text { - Shifting mathematical } \\
\text { authority } \\
\text { - Deepening } \\
\text { understanding } \\
\text { - Social learning } \\
\text { - Life skills }\end{array}$ & $\begin{array}{l}\text { - Empirical reasoning } \\
\text { was not valid. } \\
\text { - Generic examples and } \\
\text { process pattern } \\
\text { reasoning was valid so } \\
\text { long as it explained } \\
\text { why } \\
\text { - Preference for algebra, }\end{array}$ \\
\hline
\end{tabular}




\begin{tabular}{|l|l|l|l|}
\hline & $\begin{array}{l}\text { validity with student } \\
\text { thinking }\end{array}$ & $\begin{array}{l}\text { growing appreciation } \\
\text { of pictorial } \\
\text { representations }\end{array}$ \\
\hline
\end{tabular}

\section{Cross Case Analysis}

In the section that follows, I will report on the results of the cross-case analysis. As brokers between the mathematical community and the classroom community, teachers must balance the principles of the mathematical community with the demands of the classroom. Based on the thematic analysis of the individual case studies, three important themes emerged across the group of cases: validity, explaining why, and attending to student thinking. All of these teachers viewed justification as an important practice, with purposes that ranged from deepening understanding to shifting mathematical authority. They demonstrated a range of proficiencies when justifying, with common use of multiple forms of reasoning and representations.

\section{Question 1: What do JAGUAR teachers think justification is?}

\section{Validity}

In mathematics, a proof demonstrates the validity of a statement. These teachers' primary view of justification was not an argument that established truth, although validity did play a role to a certain extent for all of the teachers. Rather than focusing on establishing mathematical certainty (or existential truth), teachers fell along spectrum of how much they valued validity in terms of mathematical truth versus validity for their community, the middle school classroom.

Ms. Wade was concerned with the truth for an individual student, rather than the 
establishment of ontological truth. For example, she stated, “And so they're more or less testing what they believe to be true." For her, justification demonstrated what the student believed to be true, and did not relate justification to the establishment of mathematical truth.

Ms. Davilla, Ms. Littrel and Ms. Primm were all concerned about what was valid to the classroom community. They all shared similar hesitance in accepting a mathematically valid argument if that argument was not within the conceptual range of the class. Ms. Littrel stated, "If that statement is not valid for the kids it cannot work in that justification ... even though it's a valid wonderful proof or justification statement it's not where the kids are right at that point." Similarly, Ms. Davilla explained, "In the context of the classroom that audience really is important... all the students should be able to at least make sense of the pieces, because we said it should be based on ideas that all had access to...It was important that an argument be accessible to fellow students for it to be valid for the classroom community."

For each of the teachers in this study, truth was dependent on the audience. Ms. Wade viewed each student as an autonomous representative of their own truth, and justification was a means by which students could communicate that truth. The other teachers discussed truth as context or community dependent: while a justification might be true for the mathematical community, it may not be true for the middle school classroom community in which it is presented. This is reflected in Stylianides' definition of proof, in which statements must be "accepted" by the classroom community, and both forms of reasoning and representations must be "known to or within the conceptual reach of the classroom community" (p. 291, 2007). 


\section{Student Thinking}

Within the classroom teachers are challenged to utilize student thinking to build toward understandings consistent with the mathematical community (i.e. Ball, 1993). Both Ms. Wade and Ms. Littrel began the project with a definition of justification that focused heavily on the explication of student thinking. Ms. Wade maintained that a justification was how a student solved a problem, or how they were thinking. By the middle of the project that grew to include why they solved it the way they did. Ms. Littrel also focused on student thinking, but justification was the communication of a student's thinking via multiple representations. Although both teachers' definitions grew to encompass more mathematical aspects of justification, their core definitions focused on a communication of student thinking.

Ms. Davilla struggled to manage the tension between student thinking and the demands of mathematical validity. Although this tension was present for others as well, Ms. Davilla in particular had a clear view of mathematical proof as the establishment of validity, but recognized that incomplete student arguments also had value. She was hesitant to characterize mathematically invalid arguments as invalid justifications because of the pedagogical value in exploring incorrect arguments. She stated, "Well, it's not invalid. It's just not right yet, you know?" She maintained that incomplete or invalid student arguments should be taken up as a whole class. By analyzing and improving them, the incomplete argument could lead to deeper understanding for the whole class.

All the teachers maintained that a justification should demonstrate student understanding. An argument that established the validity of a claim or how something works was frequently not sufficient to suffice as a mathematical justification: students 
had to also demonstrate that they, themselves understand the mathematics behind why the argument works. Ms. Primm explained why simply proving that something works is not sufficient for her: "I don't know if he understands the big idea of fractions or if he is just doing something procedurally. I would press and make sure he understands." This relates directly to the fact that one of the primary purposes of the classroom community is to foster growth of understanding: justifications are one method by which a student can demonstrate that understanding.

\section{Answering “Why?”}

All four teachers focused on the importance of "why" within their definition of justification, but what they meant by "why" differed among the teachers. The differences in what the "why" question focused on illustrates the tension between mathematics and student thinking present within the teachers' conceptions of justification. Ms. Wade's "why" for much of the project was "why a student did what he or she did." She explained, "Justification, to me, would be explaining your reasoning... The step-by-step process might be part of that reasoning, but it's my reasoning more than anything else. Or why I did what I did, and why I got what I got.” Ms. Wade's description of explaining why a student did what he or she did is very close to her original conception of justification: explaining what a student did. By the very end of the project Ms. Wade also mentioned of "why it works." This shift is significant: "why it works" targets the mathematical meaning of a statement. Previously, her focus had been on what the student was thinking or does, while at the end of the project she provided some evidence that a justification should provide a mathematical meaning of a statement.

Ms. Davilla and Ms. Primm, and by the middle of the project Ms. Littrel, all focus 
on "why it works" or "why it is true" as important questions that a justification should answer. "Why it is true" was a less important conception for these teachers; establishing truth was valued but not as important as an explication of a mathematical relationship or process. Ms. Davilla explains that students should "talk about how they knew it was true... what was the thinking that got them there or like, why did they do something? Why does it work?" They valued mathematically correct arguments, but noted that just establishing validity was not enough: a student must include an explanation of why it works to count as a justification.

Both Ms. Davilla and Ms. Littrel shifted from focusing on "why it works" to include "why it makes (math) sense." This shift is significant, because it included attention to student thinking as part of the "why." Rather than just explicating what was happening mathematically, these teachers were attuned to how a justification was part of an individual student's thinking and sense-making process. Ms. Primm was consistent over the course of the project that a justification should demonstrate a student's mathematical reasoning for why something works.

These questions of "why" could be placed along a continuum: "why a student did what he or she did" focuses primarily on the student; "why it works" focuses on the mathematics, and "why it makes (math) sense" combines both student thinking with mathematical reasoning. The relationship between student thinking and mathematical validity within these teachers' conceptions of justification represents one example of a larger teaching practice: classroom mathematics should be grounded in student thinking, but build toward conventional mathematical truths (Ball, 1993). 


\section{Question 2: What do they see as its purpose in their classroom?}

The purposes of justification identified by this set of case study teachers align with the purposes identified by Staples, Bartlo, and Thanheiser (2012). Their analysis was based on the same group of teachers after one year of the project, and the purposes they found included fostering valued math skills and dispositions, fostering valued lifeskills and dispositions, assessment, managing diversity, and influencing social relationships. This analysis included data from both years of the project

\section{Deepening understanding}

One of the purposes of justification that was consistent among the teachers was how justification deepened student understanding. This purpose was primary for Ms. Primm, and important for Ms. Littrel and Ms. Davilla as well. For these teachers, the definition of justification included an explication of why something works or makes sense mathematically, thus it seems reasonable that through justification students gain an understanding of why. Ms. Davilla made this connection clear, "It makes it a stronger understanding for you if you have to think about why it is true and why it works." For Ms. Davilla, a justification is an argument that explains why something works or is true;

thus a student must understand why something is true to be able to explain why it is true. Included within a deepened understanding were the related ideas of retention and transfer.

According to these teachers, justification could also help students form connections between other mathematical ideas, retain knowledge, and apply that understanding in new situations. For example, Ms. Littrel stated that justification "uses their [students'] past learning and understands to make new understandings." Similarly, 
Ms. Davilla stated, "I think that when they make those connections, it just reinforces all of their understandings." For these teachers, a deep understanding is associated with the ability to extend previous knowledge into new contexts and to provide a solid base for future learning.

The exception was Ms. Wade, who did not see deepening understand as a primary purpose of justification. This could be explained by her view of the definition of justification; she viewed justification as an explanation of why a student did what he or she did rather than as an explanation of why something worked. With the relative absence of emphasis on the mathematics within her definition of justification, it is not surprising that deepening understanding of mathematics was equally limited within her perception of the roles of justification.

\section{Developing Mathematical Practices}

Teachers maintained that justification helped to improve math skills such as problem solving and higher-level thinking. Ms. Wade. Ms. Davilla and Ms. Littrel all discussed how justification could help students to become better thinkers. Ms. Wade stated, "Because if you've got the process [of justification], you really become a problem solver." Notice how this role differs slightly from that of deepening understanding of mathematics, which focused on the development of knowledge. In this theme the focus was on the development of a student's mathematical thinking skills independent from mathematical content.

An associated role was the improvement of a student's mathematical disposition; through justification students began to view themselves as effective mathematicians. Ms. Littrel stated, "I can help the kids feel a comfort to think like mathematicians who justify. 
To use math that fits. To talk about conjectures; make conjectures and generalizations. ... to think as mathematicians." Other positive dispositional shifts included a feeling of ownership of the mathematics and enjoyment of mathematics. For these teachers, justification not only changed their content knowledge about mathematics (the "deepening mathematics" role described previously), it also helped students feel more confident or proficient with math. These findings align with those found by Bartlo, and Thanheiser (2012) when examining this teacher group after the first years' data collection.

\section{Assessment}

Early in the project, several of the teachers focused on the importance of justification for assessment purposes: either because justification practices were important for state tests (Ms. Wade and Ms. Davilla), or because justification helped teachers with formative assessment (Ms. Primm, Ms. Littrel, and Ms. Davilla). However, as the project progressed, the focus on teacher and state assessment was no longer emphasized. Instead, teachers focused on how justification could help students assess one another or themselves. Ms. Littrel stated, "One, is that they can kind of hear their thinking, and so they can understand if it is true or not. And the other thing is, is it helps others. And then people can, if there is a misunderstanding or a misconception, sometimes students will catch that." Thus justification could help teachers evaluate their students, and also help students evaluate their own thinking and the thinking of others. In this study, teachers did not rely on justification to establish the truth of a mathematical statement; instead justification demonstrated to the teacher (or other classmates) that the student's reasoning was valid. This distinction between the validity 
of a claim and the validity of a student's argument lies in the distinction between the middle school classroom and the disciple of mathematics. In a middle school classroom, developing and demonstrating understanding is frequently more important than establishing a result as valid: in part because unlike in the math community the results established in the middle school classroom will not typically be used to solve other problems. The teachers' purpose of justification as a means for demonstrating student understanding more than establishing the validity of a result mirrors the teachers' conception of justification. As discussed previously, these teachers defined justification as statements that explain why with a focus on student understanding, rather than statements that establish truth.

\section{Social Learning}

According to these teachers, justification can also help students learn from one another. Justification activity provided opportunities for students to learn from one another by exposing them to each other's ideas. As explained previously, it could also help students learn to evaluate each other's ideas and to gain exposure to different viewpoints. Ms. Wade explained, "I think this, the idea of providing justification, maybe helps to open them up to other ways to do things, other ways to think about things."

Justification can also help students improve their ability to learn from one another by improving their communication skills and representational skills. Three of the teachers discuss explicitly how justification can improve communication skills. Ms. Primm and Ms. Littrel also mention how justification can help students use and understand different forms of representations within their justifications. 


\section{Shifting Mathematical Authority}

Some of the purposes of justification identified by these teachers were specific to the classroom. In particular, the idea of shifting the mathematical authority in the classroom was prominent for Ms. Wade, Ms. Davilla, and Ms. Littrel. These teachers noted that justification helped students to evaluate their own thinking rather than relying on the teacher. Ms. Davilla explained, "Now, I'm relying on math to be the decision maker... So we're not saying, whether I say it's right or I say it's wrong, we'll let math decide, you know?" Justification could also help shift the mathematical authority among students, as ideas were evaluated based on mathematical criteria rather than social status, and quieter students were given more opportunities to participate.

\section{Discussion of the purposes of justification}

One trend found among the teachers was a general increase in the number of purposes of justification identified over the course of the project. These teachers identified only a few purposes of justification in their initial interview before the start of the project, but after the first summer institute the teachers identified many more. It is likely that this increase is due to the summer session, which included a discussion about the possible roles of justification in the classroom. However, new purposes emerged over the entire course of the project: as teachers began incorporating more justification activity in their classes, they may have seen an emergence of new purposes as well.

Another important theme is the connection between a teacher's conception of justification and their purposes for justification. For example, we see that Ms. Primm, Ms. Davilla and Ms. Littrel all viewed justification as an explanation of why something works or makes sense mathematically, and they also found deepening understanding to 
be an important purpose of justification. On the other hand, Ms. Wade focused on justification as an explanation of student thinking, thus her purposes were primarily nonmathematical. Evidence for the connection between the definition and this purpose is particularly strong based on Ms. Wade's final interview. In that interview, she included "Explains why something works" as part of her definition of justification, and correspondingly, that was the first time that she saw deepening understanding as one of the purposes.

However, a teacher's definition of justification was not the sole predictor of a teacher's purposes of justification. For example, Ms. Primm and Ms. Davilla both maintained similar definitions of justification over the course of the project: both teachers focused on explaining why something works or is true mathematically, and both teachers saw deepening understanding (including transfer and building over time) as important purposes of justification. However, for Ms. Primm deepening understanding was almost the exclusive function of justification, while Ms. Davilla was attuned to many more purposes, such as social learning and shifts in mathematical authority.

\section{Question 3: What are teacher proficiencies with justification?}

The teachers in this case study demonstrated a number of proficiencies with justification. The justifications they produced were generally mathematically valid, with a couple of notable exceptions: some justifications did not fully explain the rationale for every result and one of the teachers in particular relied on naïve empirical reasoning to justify the general case. 


\section{Validity}

The justifications produced by the teachers in this project were generally mathematically valid; however, they were not always well explained. Some of the accepted statements used to frame the arguments were not proven, which at times seemed inappropriate given the justification task. Similarly, connections between diagrams and verbal or algebraic explanations were not always clear or present.

A second issue with validity in the teacher's justification was inappropriate use of empirical reasoning. Most of the teachers used examples for illustrative purposes: a general argument was followed by a specific example to clarify the explanation. However all four teachers used single example justifications presented in pictorial form at some point. An exception was Ms. Wade, who used individual examples as her primary argument throughout the project, although with diminishing frequency. This result aligns with previous literature, in which teachers were typically able to produce mathematically valid proofs (e.g. Barkai et. al, 2002; Tabach, 2011; Tsamir et. al, 2009), with the common exception of inappropriate use of example-based reasoning (e.g. Barkai et. al, 2002; Knuth, 2002a\&b; Martin \& Harel, 1989; Stylianides \& Stylianides, 2009).

The literature indicates that teachers tended to be too lenient in their acceptance of proofs, frequently believing that non-proofs were valid in cases they are not (e.g. Knuth, 2002a; Martin \& Harel, 1989). Our teachers stand in contrast with this result: this group of teachers tended to reject mathematically valid arguments because the argument did not sufficiently explain why a result worked or it did not demonstrate sufficient student understanding. For example, three times over the course of the project, the teachers were asked whether Ahmed's argument was a justification (see Table 7). Notice that this 
argument is mathematically valid in the sense that it uses valid claims to deductively arrive at the correct result. However, the argument is missing warrants, statement which justify the connection between data and conclusion, and backing which provides further evidence for the warrant (Toulmin 1969 as cited in Inglis, Mejia-Ramos, \& Simpson, 2007).

Even though this argument uses mathematically valid operations, Ms. Primm, Ms. Littrel and Ms. Davilla all did not see this argument as a valid justification because it did not fully explain why the result held, nor did it sufficiently demonstrate the student's understanding of fractional addition. Ms. Davilla explained, "I don't know that he's necessarily thinking about why it's true... I mean he explained what he did, but not necessarily why." Similarly, Ms. Primm reflected, "It is hard to just look at that and know do they really understand? How much do they really understand?"

This relates to the complicated relationship between validating truth and validating reasoning. Warrants and sufficient backing are necessary for a complete justification. They serve to both establish the validity of a claim, and in doing so they can demonstrate the understanding of the person who constructed the justification. The importance of explaining why and demonstrating understanding both informed these teachers' treatment of validity of the justification. These results are similar to those of Tsamir et. al (2009), who found teachers would reject mathematically valid arguments if they felt the student did not demonstrate sufficient understanding. 


\section{Table 7: Ahmed's response for the sum of 1/2 and 1/4}

Some students were asked to explain how they solved 1/2+1/4.

\section{Ahmed's Response}

I found a common denominator, which was 4 , and then I added $\frac{2}{4}$ and $\frac{1}{4}$ to get $\frac{3}{4}$

$$
\begin{aligned}
& \frac{\frac{1}{2}}{+\frac{1}{4}} \\
& \frac{3}{\frac{3}{4}}
\end{aligned}
$$

\section{Example-Based Reasoning}

By the end of the project, all of the teachers recognized that naïve empirical reasoning was not a valid form of justification, but teachers offered different perspectives on why it was not a valid form of reasoning. One reason was that naïve empirical reasoning was not mathematically valid: single sets of examples can never justify the general case ${ }^{1}$. At some point in the project, all teachers offered this explanation: Ms. Primm and Ms. Littrel at the start, and Ms. Davilla and Ms. Wade by the end. However, Ms. Primm and Ms. Littrel offered a secondary explanation that emerged at the end of the project: naïve empirical reasoning was not a valid justification because it lacked

\footnotetext{
${ }^{1}$ Unless, of course, the general case consists of a finite number of cases
} 
explanatory power. This perspective is fundamental to their conception of justification and its distinction from mathematical proof. For them, a justification must be an argument that explains why something works or is true, what Hanna (1990) refers to as proofs that explain. In contrast, a proof that proves (Hanna, 1990) may logically establish mathematical validity but fail to explain why the result holds. For the teachers in this study, the purpose of justification is primarily pedagogical; they want students to deepen understanding of mathematical ideas. Thus an argument that is not able to explain why cannot be considered a valid justification for these teachers.

A notable exception to the teacher's agreement on empirical reasoning was their evaluation of Fiona's picture-based empirical example (see Figure 9 discussed previously). Notice that Fiona's picture is specific in the sense that it only illustrated the addition of two particular even numbers: $10+8=18$. However, by representing each of the numbers as sets of pairs, it offers insight into why the claim would hold for any two even numbers in a way that numerals do not. This picture could be considered a very weak generic example: although the example is only presented for a single case, the representation as sets of pairs offers some evidence for why the claim would hold in general.

Fiona's picture-based example had the most disagreement among the teachers. Ms. Primm consistently maintained that Fiona's argument was a single example, and thus not a valid justification nor an argument that explained why. However, the three other teachers shifted positions over the course of the project: Ms. Wade and Ms. Davilla initially maintained that Fiona's argument was not a justification, but changed their mind by the end. Their stance may indicate an increased appreciation for generic-example type 
arguments as well as for the explanatory power of pictures. Ms. Littrel had the exact opposite switch: she began believing it was a justification but later decided the single example was not enough.

\section{Representation}

The teachers utilized a wide range of different representations to communicate their justifications, and every teacher used at least two different representations in their constructed justifications. Ms. Primm and Ms. Littrel, in particular, made strong use of visual representations, with the inclusion of increasingly general diagrams. Ms. Davilla and Ms. Primm both valued symbolic arguments using variables as a more sophisticated representation because of its power to describe the general case.

Middle school students are at a stage of mathematical development in which algebra may be beyond their current capabilities, thus it is particularly important for middle school teachers to encourage modes of representation other than symbolic, such as diagrams and verbal arguments. One of the roles of middle school is to help promote algebraic reasoning and understanding which is a difficult challenge (i.e. Nathan \& Koedinger, 2000). Utilizing non-algebraic representations for mathematical argumentation is one way for students to gain access to mathematical ideas and transition to increasingly general representation afforded by algebra.

\section{Conclusions and Further Directions}

Using Schoenfeld's framework of Orientations, Goals and Resources (2011), this study described four different models for middle school teachers' understanding of what justification is, its purposes, and the teachers' proficiency with justifying. Although the 
teacher conceptions were individually unique, several common themes emerged across their orientations, goals, and proficiencies.

One theme was the value of student thinking and understanding. In their definitions of justification the teachers placed increasing value on justification as an explanation of a student's (mathematical) thinking. Similarly, teachers consistently valued the deepening of student understanding and student learning as important purposes for justification. They focused on the importance of student understanding when assessing the validity of justification arguments.

Attention to ways of thinking students is a critical part of effective teaching (e.g. Carpenter, 2004). However, part of a teacher's role is to guide students toward increasingly valid mathematical ways of knowing. Ball has described this dilemma as respecting children as mathematical thinkers:

How do I create experiences for my students that connect with what they know and care about but also transcend the present? How do I value their interests and also connect them to ideas and traditions growing out of centuries of mathematical exploration and invention? (Ball, 1993, p. 375)

This case study in conceptions of justification highlights this tension of respecting children's ways of knowing while valuing mathematical validity. The teachers in this study clearly valued mathematical understanding as part of justification rather than mathematical validity. The validity of a justification was dependent upon many factors beyond the mathematics, such as the context within classroom community, the degree of explication why, and the degree to which a student demonstrated understanding.

A related theme is the importance of justification in establishing why something works or is true. Again, this aligns with the pedagogical role that justification plays 
within the middle school math classroom. These results are not surprising: the primary purpose of a middle school math community is for students to deepen understanding rather than establish mathematical results, thus understanding why and prioritizing student understanding were present as defining characteristics in middle school teachers' conceptions of justification.

This work also identified multiple trajectories in the development of teacher understandings of justification over time. Many of the teachers described more roles for justification over the course of the project and refined their proficiencies including increasing use of representation and attention to generality. Several teachers also underwent a series of transformations in their conception of justification; transitioning from a student-centered definition, to mathematically centered definition, to one that combined both student thinking and mathematics.

Next steps based on this work include further analysis that connects teacher conceptions of justification with teacher practice. This analysis is based on what teachers say about justification outside of teaching settings. More work is needed to connect teacher's conceptions of justification with their justification practices within the classroom. Additionally, this work can help inform the development of a learning trajectory for teachers; now that productive conceptions of justification have been identified they can be leveraged to train others in this ambitious practice.

\section{References}

Ball, D. (1993). With an Eye on the Mathematical Horizon: Dilemmas of Teaching Elementary School Mathematics. The Elementary School Journal, 93(4), 373-397. 
Ball, D. L., Thames, M. H., \& Phelps, G. (2008). Content Knowledge for Teaching What Makes It Special? Journal of Teacher Education, 59(5), 389-407. http://doi.org/10.1177/0022487108324554

Barkai, R., Tsamir, P., Tirosh, D., \& Dreyfus, T. (2002). Proving or Refuting Arithmetic Claims: The Case of Elementary School Teachers. In Proceedings of the twentysixth annual meeting of the International Group for the Psychology of Mathematics Education. Psychology for mathematics education Retrieved from http://eric.ed.gov/?id=ED476089

Bartlo, J. (2013). Why ask Why: An Exploration of the Role of Proof in the Mathematics Classroom. Dissertation, Portland, OR.

Bray, W. S. (2011). A Collective Case Study of the Influence of Teachers' Beliefs and Knowledge on Error-Handling Practices During Class Discussion of Mathematics. Journal for Research in Mathematics Education, 42(1), 2-38.

Carpenter, T. (2004). Using Knowledge of Children's Mathematical Thinking in Classroom Teaching: An Experimental Study. In T. Carpenter, J. Dossy, J. Koehler, E. Fennema, P. Peterson, C.-P. Chiang, \& M. Loef (Eds.), Classics in Mathematics Education Research (pp. 134-151). Reston, VA: The National Council of Teachers of Mathematics.

Chazan, D. (1993). High School Geometry Students' Justification for Their Views of Empirical Evidence and Mathematical Proof. Educational Studies in Mathematics, 24(4), 359-387. http://doi.org/10.2307/3482650 
Cochran-Smith, M., \& Lytle, S. L. (1999). Relationships of Knowledge and Practice:

Teacher Learning in Communities. Review of Research in Education, 24, 249-305. http://doi.org/10.2307/1167272

Council of Chief State School Officers (CCSSO) \& National Governors Association Center for Best Practices (NGA Center) (2010). Common Core State Standards for Mathematics. http://www.corestandards.org/assets/CCSSI_Math\%20Standards.pdf Darling-Hammond, L. (2000). Teacher quality and student achievement: A review of state policy evidence. Educational Policy Analysis Archives, 8(1).

De Villiers, M. (1990). The role and function of proof in mathematics. Pythagoras, 24(1), $17-24$.

Dreyfus, T. (1999). Why Johnny can't prove. Educational Studies in Mathematics, 38(1), $85-109$.

Fennema, E., \& Franke, M. (1992). Teachers' knowledge and its impact. In Handbook of Research on Mathematics Teaching and Learning (1st ed., pp. 147-164). New York: MacMillan.

Floden, R. (2001). Research on Effects of Teaching: A Continuing Model for Research on Teaching. In V. Richardson (Ed.), Handbook of Research on Teaching (4th ed., pp. 3-16). Washington, DC: American Educational Research Association.

Goettling, M. (1995). The college students' understanding of mathematical proof. Unpublished dissertation. University of Maryland, Maryland.

Hanna, G. (1990). Some pedagogical aspects of proof. Interchange, 21(1), 6-13. http://doi.org/10.1007/BF01809605 
Hanna, G. (2000). Proof, Explanation and Exploration: An Overview. Educational Studies in Mathematics, 44(1-2), 5-23. http://doi.org/10.1023/A:1012737223465

Harel, G. (2001). The development of mathematical induction as a proof scheme: A model for DNR-based instruction. In S. Campbell \& R. Zaskis (Eds.), Learning and Teaching Number Theory: Research in Cognition and instruction (Vol. 2, pp. 185212). New Jersey: Ablex Publishing Corporation.

Harel, G., \& Sowder, L. (1998). Students' proof schemes: Results from exploratory studies. Research in Collegiate Mathematics Education III, 7, 234-282.

Herbst, P., Miyakawa, T., \& Chazan, D. (2012). Revisiting the functions of proof in mathematics classrooms: A view from a theory of instructional exchanges Retrieved from http://hdl.handle.net/2027.42/78168.

Hersh, R. (1993). Proving is convincing and explaining. Educational Studies in Mathematics, 24(4), 389-399. http://doi.org/10.1007/BF01273372

Hill, H. C., Blunk, M., Charalambous, C., Lewis, J., Phelps, G., Sleep, L., \& Ball, D. L. (2008). Mathematical knowledge for teaching and the mathematical quality of instruction: An exploratory study. Cognition and Instruction, 26(4), 430-511.

Hill, H. C., Rowan, B., \& Ball, D. L. (2005). Effects of teachers' mathematical knowledge for teaching on student achievement. American educational research journal, 42(2), 371-406.

Hoyles, C. (1997). The Curricular Shaping of Students' Approaches to Proof. For the Learning of Mathematics, 17(1), 7-16. 
Inglis, M., Mejia-Ramos, J. P., \& Simpson, A. (2007). Modelling mathematical argumentation: the importance of qualification. Educational Studies in Mathematics, 66(1), 3-21.

Knuth, E. J. (2002a). Secondary school mathematics teachers' conceptions of proof. Journal for Research in Mathematics Education, 33, 379-405.

Knuth, E. J. (2002b). Teachers' conceptions of proof in the context of secondary school mathematics. Journal of Mathematics Teacher Education, 5, 61-88.

Knuth, E., Choppin, J., \& Bieda, K. (2009). Middle school students’ production of mathematical justifications. In M. Stylianou, M. L. Blanton, \& E. J. Knuth (Eds.), Teaching and Learning Proof Across the Grades: A K-16 prespective (pp. 153170). Mahwah, NJ: Erlbaum. Retrieved from https://urresearch.rochester.edu/institutionalPublicationPublicView.action?institutio nalItemId $=27321$

Lampert, M. (1990). When the Problem Is Not the Question and the Solution Is Not the Answer: Mathematical Knowing and Teaching. American Educational Research Journal, 27(1), 29-63. http://doi.org/10.3102/00028312027001029

Lesseig, K. (2011). Mathematical knowledge for teaching proof. Retrieved from http://ir.library.oregonstate.edu/xmlui/handle/1957/23465

Lewis, J. M., \& Blunk, M. L. (2012). Reading between the lines: Teaching linear algebra. Journal of Curriculum Studies, 44(4), 515-536Martin, T. S., McCrone, S. M. S., Bower, M. L. W., \& Dindyal, J. (2005). The Interplay of Teacher and Student Actions in the Teaching and Learning of Geometric Proof. Educational Studies in Mathematics, 60(1), 95-124. doi:10.1007/s10649-005-6698-0 
Maher, C. A., \& Martino, A. M. (1996). The development of the idea of mathematical proof: A 5-year case study. Journal for Research in Mathematics Education, 194214.

Martin, G., \& Harel, G. (1989). Proof frames of preservice elementary teachers. Journal for Research in Mathematics Education, 20(1), 41-51.

Mingus, T. T. Y., \& Grassl, R. M. (1999). Preservice Teacher Beliefs About Proofs. School Science and Mathematics, 99(8), 438-444. http://doi.org/10.1111/j.19498594.1999.tb17506.x

National Council of Teachers of Mathematics (NCTM) (2000). Principles and Standards for School Mathematics. Reston, VA.

Nespor, J. (1987). The role of beliefs in the practice of teaching. Journal of Curriculum Studies. 19, 317-328.

Reid, D. A. (2002). Conjectures and Refutations in Grade 5 Mathematics. Journal for Research in Mathematics Education, 33(1), 5-29. http://doi.org/10.2307/749867

Ross, K. A. (1998). Doing and Proving: The Place of Algorithms and Proofs in School Mathematics. The American Mathematical Monthly, 105(3), 252-255. http://doi.org/10.2307/2589080

Schoenfeld, A. (1994). What do we know about mathematics curricula? Journal of Mathematical Behavior, 13, 55-80.

Schoenfeld, A. H. (2011). Toward professional development for teachers grounded in a theory of decision making. ZDM, 43(4), 457-469. http://doi.org/10.1007/s11858011-0307-8 
Simon, M. A. (1996). Beyond inductive and deductive reasoning: The search for a sense of knowing. Educational Studies in Mathematics, 30(2), 197-210.

Simon, M. A., \& Tzur, R. (1999). Explicating the Teacher's Perspective from the Researchers' Perspectives: Generating Accounts of Mathematics Teachers' Practice. Journal for Research in Mathematics Education, 30(3), 252-264. http://doi.org/10.2307/749835

Staples, M. E., Bartlo, J., \& Thanheiser, E. (2012). Justification as a teaching and learning practice: Its (potential) multifacted role in middle grades mathematics classrooms. The Journal of Mathematical Behavior, 31(4), 447-462. http://doi.org/10.1016/j.jmathb.2012.07.001

Staples, M., \& Newton, J. (in progress) Student Justification.

Staples, M., \& Truxaw, M. (2009). A journey with justification: Issues arising from the implementation and evaluation of the Math ACCESS Project. In Proceedings of the thirty-first annual meeting of the North American Chapter of the International Group for the Psychology of Mathematics Education (Vol. 5, pp. 827-835).

Stylianides, A. J. (2007). Proof and proving in school mathematics. Journal for Research in Mathematics Education, 38(3), 289-321.

Stylianides, A. J., \& Ball, D. L. (2008). Understanding and describing mathematical knowledge for teaching: knowledge about proof for engaging students in the activity of proving. Journal of Mathematics Teacher Education, 11(4), 307-332. http://doi.org/10.1007/s10857-008-9077-9 
Stylianides, A. J., \& Stylianides, G. J. (2009). Proof constructions and evaluations.

Educational Studies in Mathematics, 72(2), 237-253.

http://doi.org/10.1007/s10649-009-9191-3

Stylianides, A. J., Stylianides, G. J., \& Philippou, G. N. (2004). Undergraduate students' understanding of the contraposition equivalence rule in symbolic and verbal contexts. Educational Studies in Mathematics, 55(1-3), 133-162. http://doi.org/10.1023/B:EDUC.0000017671.47700.0b

Tabach, M., Levenson, E., Barkai, R., Tsamir, P., Tirosh, D., \& Dreyfus, T. (2011). Secondary teachers' knowledge of elementary number theory proofs: the case of general-cover proofs. Journal of Mathematics Teacher Education, 14(6), 465-481. http://doi.org/10.1007/s10857-011-9185-9

Tabach, M., Levenson, E., Barkai, R., Tsamir, P., Tirosh, D., \& Dreyfus (2009). Teachers' knowledge of students' correct and incorrect proof constructions. In Proceedings of the ICMI Study 19 Conference: Proof and Proving in Mathematics Education (Vol. 2, pp. 214-219). Taipei, Taiwan: National Taiwan Normal University.

Thanheiser, E., Staples, M., Bartlo, J., Heim, K., Sitomer, A. (2010). Justification in middle school classrooms: How do middle school teachers define justification and its role in the classroom. Conference Proceedings of Psychology of Math Education- North American Chapter. Cincinnati, OH.

Thompson, A. G. (1992). Teachers' belief and conceptions: A synthesis of the research. In Handbook of Research on Mathematics Teaching and Learning (1st ed., pp. 127146). New York: MacMillan. 
Tirosh, D. \& Vinner, S. (2004). Prospective teachers' knowledge of existence theorems. In Proceedings of the 28th Conference of the International Group for the Psychology of Mathematics Education. Bergen University College.

Tsamir, P., Tirosh, D., Dreyfus, T., Barkai, R., \& Tabach, M. (2009). Should proof be minimal? Ms T's evaluation of secondary school students' proofs. The Journal of Mathematical Behavior, 28(1), 58-67. http://doi.org/10.1016/j.jmathb.2009.04.002

Weber, K. (2001). Student difficulty in constructing proofs: The need for strategic knowledge. Educational Studies in Mathematics, 48(1), 101-119. http://doi.org/10.1023/A:1015535614355

Weiss, M., Herbst, P., \& Chen, C. (2009). Teachers' perspectives on “authentic mathematics" and the two-column proof form. Educational Studies in Mathematics, 70(3), 275-293. http://doi.org/10.1007/s10649-008-9144-2

Wilson, M. (Skip), \& Cooney, T. (2002). Mathematics Teacher Change and Developments. In G. C. Leder, E. Pehkonen, \& G. Törner (Eds.), Beliefs: A Hidden Variable in Mathematics Education? (pp. 127-147). Springer Netherlands. Retrieved from http://link.springer.com/chapter/10.1007/0-306-47958-3_8

Wood, T. (1999). Creating a Context for Argument in Mathematics Class. Journal for Research in Mathematics Education, 30(2), 171-191. http://doi.org/10.2307/749609 Wood, T., \& Turner-Vorbeck, T. (2001). Extending the conception of mathematics teaching. In T. Wood, B. Scott Nelson, \& J. Warield (Eds.), Beyond Classical Pedagogy: Teaching Elementary School Mathematics.

Wu, H. (1996). The role of Euclidean geometry in high school. Journal of Mathematical Behavior, 15, 221-237. 
Yackel, E., \& Cobb, P. (1996). Sociomathematical norms, argumentation, and autonomy in mathematics. Journal For Research in Mathematics Education, 27(4), 458-477.

Yin, R. (2009). Case Study Research: Design and Methods (4th ed.). Thousand Oaks, CA: SAGE Publications. 


\title{
Chapter 6: Middle School Teacher Treatment of Examples in the Context of Justification Activity
}

\begin{abstract}
Although examples alone are not sufficient to prove a general case, specific examples can be useful when engaging in proof-related activity. Examples can be used to develop insight, check conjectures, and leveraged toward more generalized reasoning (e.g. Lockwood, et. al, 2012). This study is based on data from twelve middle school math teacher participants in the JAGUAR project. The analysis focuses on the teachers' conceptions of example-based reasoning, the development of that reasoning, and their treatment of examples within the classroom. Contributions include a framework of middle school teacher treatment of examples within the classroom, as well as three case studies that link teacher conceptions of example-based reasoning with their classroom practice.
\end{abstract}

\section{Introduction}

There is little doubt that proof and justification are fundamental to the discipline of mathematics and have become of increasing interest in school mathematics education as well (Ball et al., 2003; Yackel, 2001; NCTM, 2000; CCSSO, 2010). Some researchers suggest that students' treatments of examples form a key factor in their difficultly with proving (e.g. Ellis et al., 2012; Stylianides \& Stylianides, 2009). However, little research has been done to understand middle school teacher conceptions of empirical reasoning or how they address empirical reasoning in the context of middle school math classrooms. 


\section{Literature Review}

Much of the literature regarding the role of examples in proof and justification activity has focused on deficit models in which teachers or students engage in examplebased reasoning, even when that reasoning is not appropriate for a given mathematical task (e.g. Chazan, 1993; Harel \& Sowder, 1998; Knuth, Choppin, Slaughter \& Sutherland, 2002). In the following section I review current literature on the use of examples, and present evidence for ways in which examples have been used productively to inform or contribute to more general arguments.

Examples can be used at a variety of different levels of sophistication when engaging in proving activity. The most basic form of empirical reasoning is naïve empiricism (Alcock \& Inglis, 2008), in which an individual uses a single example or a small set of examples to prove a general statement. This is generally not a valid approach for proving of a general claim. However, if the claim is about a finite set of objects rather than an infinite set, checking each one of the finite cases constitutes a valid proof by exhaustion. Similarly, a counter-example is a valid proof technique for refuting claim quantified by a universal quantifier whose domain of applicability is larger than the number of cases being checked: the counter-example must satisfy the propositions of a conjecture but fail to satisfy the result, which disproves the conjecture.

It has been well established that both teachers and students frequently engage in naïve empiricism, even when that reasoning is not appropriate for a given mathematical task (e.g. Chazan, 1993; Harel \& Sowder, 1998; Knuth, Choppin, Slaughter \& Sutherland, 2002, Stylianides \& Stylianides, 2009; Simon \& Blume, 1996; Martin \& Harel, 1989). Pre-service teachers have been shown using naïve empirical reasoning, 
such as relying on boundary-cases or sets of examples to provide evidence that a statement is valid (Stylianides \& Stylianides, 2009; Simon \& Blume, 1996; Martin \& Harel, 1989). Buchbinder and Zaslavsky (2011) found secondary school teachers exhibited doubt that a counterexample provided sufficient evidence of the falsehood of a universally qualified claim.

However, research also indicates that many teachers are aware of the limitations of naïve empiricism. The high school teachers in Knuth's (2002) study demonstrated a relatively sophisticated understanding of the limitations of naïve empirical reasoning. This group understood that specific examples do not prove the general case. They also used examples within their proving activity, occasionally utilizing them to improve their conviction of the validity of a previously proven result.

Traditionally, example based reasoning has been thought of as a barrier to valid proof production, because specific examples alone can never be sufficient to prove a general claim. From this perspective, emphasis has been placed on creating an intellectual need for generalized justifications by making explicit the deficiencies inherent in purely example-based arguments. For example, Stylianides and Stylianides (2009) developed an instructional sequence for preservice elementary teachers in which tasks appear to have a regular pattern, but the pattern fails to hold after a finite number of cases. These tasks highlighted the insufficiency of checking individual cases and helped preservice teachers to appreciate the need for general proofs. Sowder and Harel (1998) also maintain that using a set of cases whose pattern fails to hold can be a valuable learning tool for students. However, they maintain that just seeing that the pattern fails is frequently unconvincing for students: students must understand why the pattern does not hold. 
A different instructional approach maintains that proof production starts with specific cases and proceeds toward greater levels of generality (Simon \& Blume, 1996; Knuth, Choppin \& Sutherland, 2002). Knuth, Choppin, and Sutherland (2002) formalize this progression into 6 levels of proving competence, ranging from considering specific examples as sufficient evidence for proof (Level 1), checking targeted examples or use of generic examples (level 2), and increasing ability to follow and generate deductive arguments in familiar and unfamiliar settings (levels 3 through 6). Maher and Martino (1996) demonstrate that over the course of a six-year investigation, one elementary student successfully transitioned from empirical reasoning to more sophisticated generic example-based arguments that justify general results.

Some studies have shown that deep analysis of individual examples can aid in proof production (Weber, Porter, \& Housman, 2008; Mason \& Watson, 2011). For example, Mason and Watson (2001) found undergraduate students' use of boundary cases were helpful in generating intuition about the structure of functions, and Pedemonte \& Buchbinder (2011) found that understanding similarities across examples can lead to deeper conceptual understanding and help generate conjectures. Selden and Selden (2008) suggest using generic proofs (also called generic examples) to unpack the essential elements of a proof, with careful attention to the elements of the example that are generic. Harel (2001) also recommended careful understanding of examples with a focus on why the examples work or hold true.

Several studies have investigated the different ways experts and novices use examples within proving activity. Ellis and colleagues (2012) documented seven different ways middle school students used examples when verifying conjectures. These 
include 1) Check: test whether the conjecture will hold, 2) Support a General Argument: use a generic example to explain a more general phenomenon, 3) Convince: increase conviction of the result, 4) Understand: make sense of the conjecture, 5) Support Empirical Proof: examples used as a justification for the truth of a conjecture, 6) Asked: students use an example because they were asked to do so, and 7) Disprove: students use examples in an attempt to disprove the conjecture.

Mills (2014) and Lockwood et al. (2012) found similarly broad usage of examples in proving activity among mathematicians. Mills (2014) investigated how experienced professors made use of examples within proof presentations in advanced undergraduate courses. She found four primary uses of examples within lecture: 1) to motivate a claim or proof, 2) to persuade students of the plausibility of the claim, 3) to generate proof insight, or 4) to support students' understanding of the claim, proof, or the underlying mathematics content. Lockwood and colleagues (2012) examined how mathematicians used examples in their exploration of conjectures and development of proofs, and their results align with those of the previous two. 1) Check: test whether the conjecture will hold, 2) Break the Conjecture: use examples in an attempt to disprove the conjecture, 3) Make Sense of the Situation: deepen understanding of why the conjecture might be true or false, 4) Proof Insight: seeing examples may inspire a direction for the proof, 5) Generalize: understand the specific to be able to see the general, 6) Understand the Conjecture: understanding of what is being stated in the conjecture.

Taken collectively, the literature indicates that students, teachers, and mathematicians all make use of examples in a variety of productive ways when engaging in proving activity. Empirical thinking can be thought of as a barrier to valid proof 
techniques; however, a great number of studies emphasize how examples can be leveraged to gain understanding and develop more general arguments. Although many studies have considered example usage in the context of proving, none of these studies specifically address how middle school teachers understand example-based reasoning, nor how teacher understanding of examples is manifested in classroom practice.

\section{Theoretical Framework}

Much of the previous work describing teacher understanding of examples focused primarily on teacher knowledge independent from a classroom setting. However, many have argued that investigating teacher conceptions outside of their practice offers an incomplete picture of their understanding (Leatham, 2006; Speer, 2005; Wilson \& Cooney, 2002). Wilson and Cooney (2002) argued this point, writing, "it seems that both observing and interviewing teachers are necessary if one is interested in comprehending how teachers make sense of their worlds" (Wilson \& Cooney, 2002, p. 145).

This study offers an integrated approach in which teacher understanding and classroom practice are examined collectively. I take on a situated view in which "knowledge" and "practice" can be thought of as enacted knowledge in multiple contexts. This perspective aligns with Kazemi and Hubbard's (2008) stance that teacher ways of knowing coevolve across multiple contexts, each one impacting the other. Thus the ways that teachers understand empirical reasoning outside of the classroom and the ways that teachers respond to empirical reasoning inside of the classroom are different manifestations of a single, complicated conceptual structure. 


\section{Operationalization of Empirical Reasoning}

Examples have many different roles in mathematics. My focus here is on the role of examples in mathematical reasoning. I use the terms empirical reasoning and example-based reasoning interchangeably in this paper. In this context, example-based reasoning is reasoning about mathematical concepts based on specific instances of the concept.

The following analytic framework will be used to analyze teacher treatment of empirical reasoning both within and outside of the classroom. These types of examples and forms of reasoning are based upon previous literature results, particularly Ellis et al. (2012) and Larsen and James (unpublished manuscript). These include:

\section{- Valid forms of empirical reasoning}

- Counter examples: a single example is used to disprove a universal claim

- Proof by exhaustion: the statement to be proved is split into a finite number of cases and each one of the cases is addressed

- Naïve empirical reasoning: an invalid proof method in which individual or sets of examples used to justify a general case. However, single examples can increase conviction or generate understanding of the conjecture.

- Boundary case or unusual examples: such examples may test the "boundaries" of a conjecture

○ Randomly selected example: testing a "random" example may increase conviction that the result holds

- Result-pattern reasoning: an invalid form of reasoning in which a pattern is identified and a general rule or claim is formed based on a patterned set of examples (Harel, 2001)

- Process-pattern reasoning: a valid form of reasoning in which a pattern is identified and a mathematical argument for why that pattern must hold is described) (Harel, 2001)

- Generic example-based reasoning: a single example is reasoned about generally. Generic examples lie on a continuum from examples with little generalization to almost fully generalized arguments (Mason \& Pimm, 1984) 
This analytic framework describes different types of examples and example usage within forms of reasoning. On their own, examples may increase conviction of a result or provide insight into what is being proved. Examples are also used within forms of reasoning, or modes of argumentation, that form the reasoning within a proof or justification.

\section{Research Questions}

The central research question for this paper is: How do JAGUAR teachers understand and respond to empirical reasoning in the context of middle school algebra justifications, and how do those understandings and responses change over time? Specifically:

1. How do JAGUAR teachers understand empirical reasoning? How do teachers evaluate empirical reasoning? What kinds of empirical arguments do teachers produce?

2. How do JAGUAR teachers treat examples in the context of classroom justification tasks?

3. What is the relationship between teachers' understanding of empirical reasoning and treatment of empirical reasoning in their classrooms? How does this shift over time?

The contribution of this paper is three-fold. The first contribution is a description of teacher understandings of empirical reasoning. The second is a taxonomy of ways JAGUAR teachers treat examples in during justification tasks in their classrooms. The final and primary contribution is a set of case study profiles linking teacher development of understanding of empirical reasoning with teacher practice. 


\section{Methods}

The primary goals of this study include a description of teacher knowledge of empirical reasoning and how that reasoning relates to treatment of examples in the classroom. This study is part of the larger JAGUAR project analysis, which examined teacher development in their understanding of justification, the transformation of that knowledge into classroom practice, and the subsequent impact on student justification activity. The parent project was designed to culminate in accounts of practice (Simon \& Tzur, 1999), specialized case studies that "portray the complex interrelationships among different aspects of teachers' knowledge and their relationships to teaching" (p. 163). As a piece of the larger whole, this study also utilizes a case-study methodology. Each teacher served as a case, and three cases were selected as "replications of each other, contrasting comparisons, or as hypothesized variations" (Yin, 2009, p. 112). Note that these descriptions "explain the teacher's perspective from the researcher's perspective" (p. 254, Simon \& Tzur, 1999). My role as researcher is to structure the account of teacher practice using a theoretical lens to focus my interpretation. The result is an account of teacher experience that emphasizes aspects with broader theoretical significance.

\section{Context}

Data for this paper was drawn from the JAGUAR project (Justification and Argumentation: Growing Understanding of Algebraic Reasoning). JAGUAR was a twoyear co-investigation of among a team of 12 middle school teachers and math education researchers. One goal of the JAGUAR project was to investigate the development of the knowledge and pedagogy needed by teachers to support student justification. Each year of the two-year project consisted of a week-long summer working session, three weekend 
working sessions during the school year, and four classroom observations of common justification tasks.

Example-based reasoning was a specific content topic in the working and summer sessions of the JAGUAR project. Within the project, the team of researchers designed a number of tasks intended to help teachers identify different types of example-based reasoning and to highlight some of the limitations and affordances of example-based reasoning in justification construction. For example, teachers were given a numbergeneration task in which teachers were asked to generate a conjecture and to explore if the conjecture would hold (see Error! Reference source not found.). Notice that the function output is prime for the first 39 entries, but not the $40^{\text {th }}$ or $41^{\text {st }}$. Other tasks for the teachers included evaluating actual and hypothetical student justifications that included different types of empirical reasoning (see Appendix F for sample justification task and student work). The researchers hoped that through the activities and discussions in the working sessions, teachers would see the mathematical limitations of naïve empirical reasoning while simultaneously gaining an appreciation of the explanatory power of different types of empirical reasoning, including process-pattern and generic-example based reasoning.

\section{Consider the function $f(n)=n^{2}+n+41$.}

What patterns do you notice?

What patterns are provable for all cases?

Table 8: Empirical Reasoning Task 


\section{Methods for RQ1: Teacher Understanding of Empirical Reasoning}

Multiple data sources were used to analyze how teachers understand empirical reasoning, including interview data, summer/working session data, and justification survey data. This included an analysis of what teachers said about empirical reasoning, their evaluation of hypothetical student justifications, and their use of empirical reasoning on justification tasks.

The analysis of teacher conceptions started with what teachers said about their understanding of empirical reasoning. The interview data formed the basis of this analysis because many interview questions were designed specifically to elicit teacher understanding of empirical reasoning. All of the participating JAGUAR teachers were included in the first stage of analysis. In this stage, excerpts in which teachers made use of, discussed, or analyzed examples were identified and briefly described in the form of analytic memos. These excerpts included responses to questions specifically designed to capture teacher understanding of examples and spontaneous responses to open-ended questions (such as "Could you give an example of a justification? When you ask students to justify what do you expect to see?") (See Appendix C for an interview protocol). A second researcher and I independently identified excerpts, organized them into themes, and generated conjectures regarding each of the teachers' conceptions. Next, the second researcher and I compared and revised the conjectures to construct a comprehensive set based on evidence from the excerpts. Finally, we organized the conjectures to create a chronicle of teacher conceptions over the course of the project. This chronicle included a description of teacher treatment of different forms of reasoning over the course of the project. 
In the next stage of analysis, the chronicle generated from the interview data was compared with the data from the working sessions and summer sessions (collectively referred to as the workshops). First, excerpts in the workshop data were identified that pertained to teacher understanding of example based reasoning. Next, the excerpts from the workshop data were compared to the conjectures formed from the interview data, and additional evidence to support or refine the conjectures was added to the chronicle.

Next, the conjectures and supporting data within the chronicle was compared to data from the justification survey. Each teacher completed the justification survey individually at the beginning and the end of the project. Teacher uses of examples in their responses were identified and compared to those from the workshop analysis and added to the chronicle. In the end, the chronicle document was a comprehensive overview of each teachers' treatment of every example type or empirical reasoning, with data illustrating the development within each type over the course of the project. A condensed version of each teachers' chronicle is presented in the results section for research question 1.

\section{Methods for RQ 2: Teacher Treatment of Empirical Reasoning in the Classroom}

The analysis of teacher treatment of empirical reasoning resulted in two products:

(1) a framework of teacher treatment of examples within the classroom and (2) a qualitative description of each case teacher based on the framework analysis. To construct a framework, a thematic analysis approach was taken to identify ways teachers treated empirical reasoning within the classroom (Braun \& Clark, 2006). An initial coding framework was developed based on the results of previous literature (particularly Lockwood et al. (2012), Mills (2014) and Ellis et. al (2012)). The framework was 
continually revised in a constant comparative method (Strauss \& Corbin, 2008), in which categories were adapted or revised based on the data. The resulting framework captured these teachers' treatment of examples within the context of middle school classrooms.

The first stage of analysis consisted of coding of all classroom transcripts of the Number Trick Task for every JAGUAR teacher. The Number Trick Task was chosen first because that task had the most explicit use of examples embedded in the task. Codable instances were identified and tagged with potential codes. A codable instance of a code is a distinct treatment of examples. "Treatment" includes (1) the existence of an example and (2) teacher initiation and use of examples or example-based reasoning, OR teacher response to student use of examples or example-based reasoning. For example, if a teacher uses the same example in the same way over multiple utterances, it is considered a single coded instance. Alternatively, if a teacher responds to the same example in multiple, different ways in a single utterance, it would be coded with multiple codes. For example, in the following instance Mr. Hummel encourages students to test their conjecture using multiple examples:

Try zero, try a fraction maybe, try a decimal, try pi, try a negative number, so try something you haven't tried that seems like it might be a little unusual.

This is coded as a single codable instance because although it includes multiple mentions of different possible examples, the entire passage is encouraging students to use examples to test the conjecture. It is also possible to have multiple instances for the same example. In the following excerpt, Ms. Davilla evaluates a pair of students' work with examples and has the following exchange:

Ms. Davilla: Okay [reading] yes, because it works with decimals, yes, it would work with different numbers, you could give examples of large numbers and 
decimals [end reading]. Okay so that helped you to understand why it works for every example? That tells you why it works?

Alexis: Pretty much.

Ms. Davilla: Okay. And you're content with that.

[Alexis and Nat nod.]

Ms. Davilla: All right. [moves to new group]

In this passage, the green highlighted section was coded as "Explain Why," because the students used examples to understand why their conjecture worked. The green highlighted section was coded as "Examples endorsed as valid” because Ms. Davilla moved to a new group without mentioning to the students that their set of examples did not in fact justify the general claim.

The codes were continually revised based on a constant comparative method (Corbin \& Strauss, 2008), in which all instances that were conceptually similar to preexisting codes were coded, and those that were new were tagged. At the end of each set of transcripts the "tags" were reviewed and given their own code if they were sufficiently conceptually distinct from previous codes or incorporated into preexisting codes.

In the next stage of analysis, themes among the codes were sought out. Similar to axial coding (Corbin \& Strauss, 2008), codes were reorganized to better reflect the internal relationships between the concepts. Previously established codes were refined, either by splitting of one code into multiple codes or joining previously separate codes into one common code. For example, the code initially called "To get a feel for how something works" was eliminated and separated into "Generate Conjectures" and "Explain Why (something works)" Codes with only one or two instances were eliminated or merged into other code categories. Once the codes had stabilized and been named, I returned to the transcripts and recoded all of the documents with the intent to attain 
formal counts of instances of each code for every transcript. The full set of transcripts across all 12 teachers and 3 task implementations was used to give the greatest diversity of possible uses of examples within these justification tasks. A second researcher was trained in the coding, and double coded a representative selection of one-third of the transcripts with $89.5 \%$ reliability.

The quantitative analysis formed the initial basis for the qualitative analysis. Based on the results of the quantitative analysis and results from analysis of teacher conceptions, three teachers were selected as case study teachers. These three teachers were selected because they demonstrated strong understanding of empirical reasoning: they all differentiated between forms of empirical reasoning and their understanding of the validity of naïve empirical reasoning aligned with that of the mathematical community. However, they offered contrasting cases (Yin, 2009) due to the differences in their treatment of empirical reasoning in their classrooms.

For each of the selected case study teachers, the coded instances from the quantitative classroom analysis were reviewed and contextualized within the other events of the lesson. Patterns within and across lessons were identified, as well as differences between the different implementations. Significant themes within the treatment of examples were identified, and the relationships between those themes across the chronology of the lesson were described. For consistency and clarity, excerpts from the number trick task were selected to illustrate those themes when possible.

\section{Methods for RQ 3: Case Study}

The results of research questions 1 and 2 were analyzed to answer the question: What is the relationship between teachers understanding of empirical reasoning and 
treatment of empirical reasoning in their classrooms? How does this shift over time?

Once the analysis of research questions 1 and 2 were completed, a set of three case study teachers were selected to represent the larger group. These case study teachers were representative of the larger group in the sense that the themes identified for these teachers reflected the themes identified for the whole group. However, these teachers were also selected because they offered contrasting results: each of the three teachers offer a different insight into the relationship between teacher understanding of empirical reasoning and practice.

Once a formal draft was complete, I shared the entire draft with the case teachers for a member check. Three of the four teachers responded, each with positive, though limited, feedback. In particular, Ms. Davilla commented that she was impressed by the amount she changed over the two-year project. This member check provided backing of the validity of interpretation as well as the opportunity for teacher reflection.

\section{Results}

Results are presented in two sections. I begin with the framework of middle school teacher uses of examples within the classroom, which partially addresses research question two: How do JAGUAR teachers treat examples in the context of classroom justification tasks? In the second section I present three case study analyses, one for each case teacher. Each case includes three components. The first component is a description of each teachers' understanding of empirical reasoning, which addresses research question one: How do JAGUAR teachers understand empirical reasoning? The case also includes a quantitative and narrative description of teacher treatment of examples, which both pertain to research question 2 . Finally, each teacher case study also includes a 
discussion of the connections between the teacher's understanding of empirical reasoning and his or her treatment of examples in the classroom.

\section{Framework: Teacher Use of Examples in the Classroom}

One of the main results of this paper is a framework that identifies the ways JAGUAR middle school teachers treated examples within the context of justification activity in their classrooms. This framework contains two sections and a total of 13 categories. The first section, Pedagogical Uses of Examples contains 8 categories, which represent the different ways teachers utilized examples to understand or explore the mathematics of the lesson. The Treatment of Validity of Examples section contains 5 categories. It catalogues how teachers addressed the validity of naïve empiricism. The latter section is significant given the propensity for students to rely on faulty empirical reasoning, as described in the literature. I begin with a description of each of the categories in the first section: Pedagogical Uses of Examples.

1. Demonstration: Teacher used an example to demonstrate what was to be justified (or proved) in the task. Conceptually similar to Lockwood and colleague's (2012) category Make Sense of the Situation or Mill's (2014) motivate a claim, the category Demonstration took place when an example was used to clarify the statement of the task.

2. Generating conjectures: For this category, a teacher prompts students to use examples to generate a conjecture about a general relationship. Frequently this code occurs when the teacher asks students to reflect on examples that have already been computed. For example, after working with numbers between 1 and 10, Mr. Hummel addressed his class: “And right now don't worry about why or anything, just describe 
what you're noticing." In this example, Mr. Hummel is asking students to describe what they see occurring in a set of examples.

3. Understanding how or why something works: In this code, a teacher has students explore specific examples to gain a deeper understanding of how or why something works mathematically. Notice that this code differs from the previous code because generating conjectures focuses on what is happening and this code focuses on why it is happening. It includes instances in which the teacher prompts students to look at numerous examples, such as the following from Mr. Hummel: "Use more examples and try to figure out why this works." It also includes instances in which a teacher has students consider a single specific example in great detail. For example, Ms. Littrel has students examine Andrea's example in this whole class discussion. She stated:

"I actually love exactly how he wrote it because that's going to help us understand... when Andrea wrote this up here, I kept this up here for a very specific reason, I think the way he wrote it is kind of a huge answer as to what's happening in this number trick. ... I think if you can see that in there [points where Andrea wrote 2(1+4)], this is going to be a big huge hint and help you figure out how to justify everything in an equation."

This category is similar to Mill's (2014) description "to support student understanding of the claim, proof, or underlying mathematics," but in my framework the focus is exclusively on understanding the mathematics of why the conjecture works.

4. Identifying Patterns: This category includes instances in which a set of examples is used to identify a pattern. This category is a specific subtype of Generating Conjectures, because identifying a pattern can form the basis of a conjecture if that 
pattern were to hold. However, because of the high frequency of this subcategory and its theoretical importance relative to the teachers' conceptions of empirical reasoning, it was given its own category title. Instances of this code typically involved finding patterns based on finite sets of examples without exploring why (the basis of pattern-result reasoning). If students were asked to describe a pattern and why the pattern held, such an instance was double-coded as both identifying patterns and understanding why. For example, Ms. Wade asked two students to identify a pattern based on examples: "If there's a pattern going on, see if you can figure out what the pattern is. Okay?" Notice that this was an instance in which students were asked to form a specific type of conjecture, one based on patterns, but it was only placed within the identifying patterns category.

5. Testing Conjectures: At times teachers asked students to use examples to test their conjectures. For example, Ms. Wade stated, "Try another number or two and see if it works." This category focused on testing the validity of a statement by evaluating specific examples. This category matches Check from both Ellis et. al (2012) and Lockwood et al. (2012).

6. Increase Conviction: This category was conceptually similar to the previous category of Testing Conjectures, but it went beyond simply testing whether a specific case held. This code indicated that specific cases were used to develop a sense of conviction that the result was true. For example, Mr. Hummel addressed the whole class after an initial investigation of the number trick: "Okay so all the different types of numbers you have tried have worked. So you're convinced that it's 
always going to be true.” This code was conceptually similar to Ellis et al.'s (2012)

Convince and Mill's (2014) "to persuade students of the plausibility of a claim."

7. Explaining or demonstrating the general argument: When a teacher or student was providing a general argument, teachers would occasionally ask for the presentation of a specific example to help clarify that argument. For example, in Ms.

Davilla's classroom a student gave a general argument for the number trick. Ms.

Davilla paused the student and stated, “Ok, I don't understand what you're saying.

Can you come up maybe and point to these numbers in one of the examples so everyone else can understand?" Ms. Davilla asked the student to make use of specific examples to help clarify the general argument.

8. Using examples to build a more general argument: In this set of classroom episodes, teachers used specific examples to guide students toward a more general argument by breaking down a single example in an explicit way and leveraging that example toward a general algebraic or pictorial representation. Ms. Davilla explained the process to her class:

"We need to be able to go from these examples, all these different examples, to show that something will work generally. To show that something will work for every number. And the way that we do that is we start using our variables."

Both Ellis et al. (2012) and Lockwood et al. (2012) had similar findings in their frameworks, with Support a General Argument and Generalize, respectively. In addition to the pedagogical uses of examples described previously, I also identified five ways teachers evaluated the validity of example use. These are a special sub-type of the pedagogical treatment of examples described earlier: instances in these 
categories identify the manner in which teachers respond to naïve empirical reasoning. Literature indicates that students tend to view naïve empiricism as a valid form of reasoning (e.g. Chazan, 1993; Knuth, Choppin, Slaughter \& Sutherland, 2002; Hoyles, 1997; Healy and Hoyles, 2000; Harel \& Sowder, 1998). Given this background, it was particularly important to consider how teachers addressed the validity of empirically based mathematical arguments. This analysis resulted in five categories. The first four categories address why single examples are not sufficient to show the general case, and the final category is an endorsement of empirical reasoning.

1. Examples are not enough: No further explanation: In this category, teachers stated explicitly in their classroom that a single example was insufficient evidence to justify a general claim, and they offered no further explanation. For example, the following exchange took place in Ms. Primm's classroom:

Ms. Primm: Can we just choose a couple numbers and see if it works? And then is that enough to say that it would work for any number?

Student: Yeah.

Ms. Primm: No, but that certainly would show that it works for those numbers that you choose.

Notice in this passage Ms. Primm directly addressed the fact that single examples cannot justify the general case: they only prove the result for those examples.

However she did not elaborate as to why the example was not enough.

2. Examples are not enough: Not possible to test all cases: In this category, teachers addressed that examples were not enough to justify the general case, and also included the rationale that it is not possible to test all cases. For example, in his whole class wrap-up Mr. Ferris stated, "Important things to take away: [Student A] said, 'No, we can't try every single number.' We've got to come up with an equation.' In 
this statement, Mr. Ferris described the mathematical impossibility of testing all cases, and offered algebra as an alternative.

3. Examples are not enough: Not practical or efficient to test all cases: Much like the previous category, this category also includes instances in which teachers identifed testing examples as inappropriate for proving the general case. However, unlike the previous code, rather than confirming that testing all cases is impossible, in this category the teachers emphasized the impracticality or inefficiency of testing all cases. For example, Ms. Davilla stated, "If we were checking every number it would take a very long time." Although it is possible that such statements could be intended as hyperbole, it might leave students with the impression that checking an infinite number of examples is a possible method for establishing results.

4. Examples are not enough: Examples don't explain why: The final category in Examples are not enough included statement that examples do not explain why. Notice that rather than focusing on the mathematical validity of using examples as a justification tool, in this category teachers emphasized the fact that individual examples on their own, without explanation, do not communicate the mathematical structure or reasoning why something is true. In this passage Ms. Littrel explained to her class the shortcoming of examples and the importance of explaining why:

"So last period we had a question and with two questions, someone just said, 'Ok well just try some numbers," let's try 99 and prove it, and then let's try 152 and prove it... Alright so we're just kind of like assuming it will work. But how do we, how does it work. That's what we've got to prove. How is this trick working?"

5. Examples Endorsed as Valid: The final code in this category included instances in which teachers implicitly or explicitly endorsed naïve empirical reasoning. This 
typically took place when a student produced a naïve empirical argument and the teacher chose to move on and not comment directly on the argument. For example, in the following interchange one student maintained that equality would always hold in the number trick based on testing a set of examples:

Student: They will always equal out.

Ms. Davilla: Ok, how did you show that?

Student: Um, we did whole numbers between 1 through 10. We did decimals too.

Ms. Davilla: Ok, so we checked, we checked numbers 1 thought 10, and you said we checked some decimals too?

Student: Yeah.

Ms. Davilla: Some decimals, and these were the whole numbers right? Ok, other ways we established this? [emphasis added]

Notice that by continuing the conversation by asking for other ways that the result was established, the teacher implicitly endorsed naïve empiricism as one possible justification form.

Taken together, these categories form framework the identifies 13 different ways that these middle school teachers made use of or responded to example use in their classroom. On its own, this framework is significant because it identifies a wide range of pedagogical uses for examples. This shows that justification work in middle school classrooms can include a rich variety of different ways in which examples are used. Additionally, many of the items in this framework align with those found by either Mills (2014) or Lockwood and colleagues (2012), indicating that the middle school teacher treatment of examples in their classrooms mirrors that of professors when demonstrating proofs in upper division courses and professional mathematicians when working with conjectures. 
A unique component of this framework that had not been captured previously was the ways in which teachers responded to naïve empirical reasoning. These teachers gave a variety of reasons for why examples did not prove the general case. Of note was the reason that checking examples simple was not practical because it would take too long. This rationale reinforces the misconception that naïve empiricism could be a valid proof technique, if only we had the tools or resources to check an infinite number of cases. Mathematically it can never be possible to check an infinite number of cases with brute force.

\section{Case Descriptions of Teacher Treatment of Examples}

In the following section, I describe the treatment of examples for each of the three case study teachers. I include quantitative results of the classroom analysis based on the previously presented framework. Please note that each teacher's class had variable length and these counts should be interpreted within the context of their use; they may indicate patterns and trends but the frequency value in isolation should not be over-interpreted.

\section{Mr. Hummel}

Mr. Hummel demonstrated a robust understanding of empirical reasoning. Within the workshop sessions and interviews, he consistently categorized types of example-based reasoning in the manner intended by the research team. His own justification work relied heavily on algebra, but he also included appropriate uses of examples within his own justifications, including counter-examples, proof by exhaustion, and generic-example based arguments. Mr. Hummel clearly and consistently articulated that individual 
examples could not prove the general result, but he was none-the-less willing to classify naïve empirical arguments as justifications.

Mr. Hummel maintained that single examples could not prove the general case, but he still considered them (weak) justifications. For example, in the pre-project interview Mr. Hummel analyzed the hypothetical student work for the consecutive number task (see Figure 10).

\section{CONSECUTIVE NUMBER TASK}

\section{Determine whether or not the statement "When you add any two consecutive numbers the sum is always odd" is true.}

5 and 6 are consecutive numbers, and $5+6=11$ and 11 is an odd number. 12 and 13 are consecutive numbers, and $12+13=25$ and 25 is an odd number. 1240 and 1241 are consecutive numbers, and $1240+1241=2481$ and 2481 is an odd number.

That's how I know that no matter what two consecutive numbers you add, the answer will always be an odd number.

\section{Figure 10: Consecutive number task with hypothetical student work}

Mr. Hummel concluded the following: "I think it's a justification, but I think it's kind of a limited justification. So it's, it's three specific examples. So kind of, I guess what I see is that, yeah, it's justifying, based on those three examples. That it seems to work." At the end of the project he reflected on the same student work: "So to me [this student] is not proving it with this. But I think that [the student] is lending some justification to what they are thinking by supporting their thinking with examples.” Mr. Hummel drew a distinction between the requirements for proof and those of justification: while naïve example-based arguments could not prove the general case, examples could provide some justification. A partial proof is not something typically highly valued within the 
mathematics community, but in every-day life providing some evidence for a claim is very valuable, in part because rigorous, deductive arguments are typically impossible.

This apparent contradiction is explained in part by Mr. Hummel's definition of justification. He maintained that a justification is a convincing argument that explains why something works. He stated, "[Justification is] a convincing proof or argument for the reasoning behind why what you are doing mathematically works." Thus if students find examples convincing, he was willing to classify that type of argument as a justification.

This view was consistent with his evolving stance on patterned example-based reasoning. Early in the project, Mr. Hummel viewed result-pattern justifications, those that describe a pattern and assume it will hold, as valuable and even superior to other empirical arguments. For example, in the first summer session, Mr. Hummel defended the use of tables in generating justifications, because they can be very helpful in helping students display and discover patterns. In later sessions, Mr. Hummel voiced a greater need for an explanation of why the pattern would hold, but still considered patterned examples justifications. For example, Mr. Hummel reflected on a student's argument that included a table with little explanation: "From that first glance it seems to be [a justification]. It seems to be (Short Pause) - yeah, I think I might want to know - I might want to ask, based on the diagrams or based on what they know about what's happening; why it's going up three every time. But yeah, it's fairly convincing to me." Thus although he would accept it as a justification, he would still want to know more about why the pattern held. 
Throughout the project, Mr. Hummel consistently appreciated generic examples and saw the importance of their structural elements. For example, in the first summer session Mr. Hummel categorized a student's reasoning as a justification because although the student was using examples, the student reasoned about the examples in a general way that explained why the result was true.

In summary, Mr. Hummel had a unique perspective on the role of example-based reasoning within justifications. He had a strong grasp of the different types of examples, and although he understood that single examples or sets of examples could not prove the general result, he valued them as justifications. His view of naïve empirical reasoning could be in part because examples do indeed provide evidence, even if they do not prove a claim. Additionally, he believed students found examples convincing, and for him a justification was by definition a convincing argument.

\section{Mr. Hummel: Classroom Treatment of Examples}

In the following section, I describe Mr. Hummel's treatment of examples numerically and qualitatively. Table 9 offers a quantitative summary of Mr. Hummel's treatment of examples for the three focal tasks over two years. The following section describes Mr. Hummel's treatment of examples and connects the numerical data to classroom context.

Table 9: Mr. Hummel's treatment of examples by task and year

\begin{tabular}{|l|c|c|c|c|c|c|}
\hline & \multicolumn{6}{|c|}{ Bruce Hummel } \\
\hline & \multicolumn{2}{|c|}{ Hexagon Task } & \multicolumn{2}{c|}{ Number Trick } & \multicolumn{2}{c|}{ Scaling Task } \\
\hline & Year 1 & Year 2 & Year 1 & Year 2 & Year 1 & Year 1 \\
\hline \hline Demonstration & 1 & 0 & 5 & 2 & 5 & 4 \\
\hline Generating Conjectures & 1 & 0 & 12 & 8 & 12 & 2 \\
\hline Understanding how or & 13 & 4 & 9 & 6 & 9 & 37 \\
\hline
\end{tabular}




\begin{tabular}{|c|c|c|c|c|c|c|}
\hline why something works & & & & & & \\
\hline Identifying Patterns & 2 & 0 & 2 & 0 & 2 & 1 \\
\hline Testing Conjectures & 6 & 0 & 5 & 7 & 5 & 1 \\
\hline Increase Conviction & 0 & 1 & 1 & 1 & 1 & 0 \\
\hline $\begin{array}{l}\text { Explaining or } \\
\text { demonstrating the general } \\
\text { argument }\end{array}$ & 2 & 9 & 1 & 1 & 1 & 4 \\
\hline Build a general argument & 3 & 3 & 3 & 4 & 3 & 2 \\
\hline Examples are not enough & 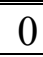 & 0 & 0 & 1 & 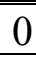 & 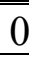 \\
\hline $\begin{array}{l}\text { Not possible to test all } \\
\text { cases }\end{array}$ & 0 & 0 & 0 & 1 & 0 & 0 \\
\hline $\begin{array}{l}\text { Not practical to test all } \\
\text { cases }\end{array}$ & 0 & 0 & 0 & 1 & 0 & 0 \\
\hline $\begin{array}{l}\text { Examples don't explain } \\
\text { why }\end{array}$ & 0 & 0 & 0 & 0 & 0 & 0 \\
\hline Endorsed as valid & 0 & 0 & 0 & 3 & 0 & 0 \\
\hline Counter-example & 0 & 0 & 0 & 0 & 0 & 0 \\
\hline
\end{tabular}

I characterize Mr. Hummel's approach to empirical reasoning as an "adding why" model. Mr. Hummel consistently acknowledged that examples were convincing for students and encouraged students to explore many types of examples when forming and testing conjectures. However, he also directly confronted the conception that examples alone were enough: he insisted that in addition to examples, students must also explain "why" something was true. Testing out examples was an important part of his students' mathematical investigation, but for him a justification should also include a description of why the result holds beyond the examples.

\section{Focus on Examples to Build Conviction, Generate Conjectures and Test Conjectures}

Mr. Hummel asked students to use examples to generate conjectures, test

conjectures, and to develop a sense of conviction that a result would hold. In particular, in the first year's implementation of the number trick, Mr. Hummel frequently directed students to use examples to gain a sense of conviction that the "number trick" would work in all cases. In the first year's implementation of the task, Mr. Hummel asked the 
students if trying out examples helped convince them that the result holds for integers 1-

10.

Mr. Hummel: Okay so did everybody in here who plugged in a number, you got the same thing here as you did here?

Students: Yeah.

Mr. Hummel: Alright are you convinced that it works for all numbers from one to ten?

Students: Yeah.

Building on this conversation, Mr. Hummel acknowledged that given the

students' work with examples, they were likely to be convinced that the general result would hold. He stated, "Okay so you're pretty convinced that that's going to work, no matter what?"

His focus on examples to increase conviction links directly to his conception of justification. Mr. Hummel described justification as "creating a convincing proof or argument for the reasoning behind why what you are doing mathematically works" [emphasis added]. Within his interviews, Mr. Hummel described an increasing emphasis on the convincing nature of a justification, so much so that by the end of the project he preferred the term convincing argument over the term justification. He explained: "I think that a lot of the students still feel when they hear justification that it just means to explain what they did and not necessarily to get to why it works or a convincing way that it makes sense." Given his conception of justification, it is not surprising that he might utilize examples in his classroom practices to help students increase their conviction. What is surprising, perhaps, is that his use of examples to increase conviction is not more present, and on the whole tends to decrease over the two year implementations of justification tasks. 
Another trend in Mr. Hummel's treatment of examples was a consistent decrease in the use of examples to test conjectures. For example, in the first implementation of the number trick task students used examples to generate conjectures, and spent much of the first class period testing a wide variety of different examples to see if their conjectures would hold. In the (first) year, Mr. Hummel polled the class to see what types of examples the students have tried.

OK, raise your hand if you've tried a decimal. [Several hands go up] OK... uh, fraction? Any fractions? Could be kind of the same, yeah. Negatives? [Several hands go up] Irrational numbers? Anyone? OK. So just some ideas, to try some different ones.... Okay will that work in all cases? So try a different number.

This aligns with Ellis and colleagues' finding that students use dissimilar sets of examples to help increase conviction that a result will hold.

His focus on examples for generating and testing conjectures generally decreased over the two-year project. Particularly in the scaling task, the exploration of lots of examples was replaced by a deep exploration of a single example to understand what was happening for that single case. (See Chapter 7 for a more detailed exploration of that task.)

\section{Examples to Explain the General Argument}

Compared to the other case teachers in this study, Mr. Hummel used examples to help explain the general argument at a greater frequency, as indicated by 17 instances over the six task implementations. For the majority of these instances, Mr. Hummel asked students to explain their general rule or argument using a specific example given in the form of a picture or diagram. For example, in the scaling task Mr. Hummel explored with a student: "Here you have a general rule... So how can you show that general rule with a picture?" Similarly, in the hexagon task he asked, "OK, can you explain how the four ties 
in this example with the picture?" This may also explain why Mr. Hummel's use of examples to explain the general case was relatively rare in the Number Trick task that did not readily lend itself toward pictorial representations. It also explains in part why the instance of this code increased over the two years of the scaling task: in the second year Mr. Hummel placed much greater emphasis on connecting to diagrams (see Chapter 7 for more on the scaling task).

\section{Examples are not enough}

The Number Trick task was the only task in which Mr. Hummel directly addressed the validity of naïve empirical reasoning. In both implementations of the Number Trick task, Mr. Hummel explained to the class that testing individual examples is never sufficient for proving a general claim. In both years Mr. Hummel focused on the limitations of examples and on the possibility that a set of examples may lead a person to a false conclusion. In the following passage taken from a whole class discussion in the second year, Mr. Hummel explained that testing examples doesn't prove a general result.

Mr. Hummel: One thing you want to avoid is to try and prove something by saying, 'Well it works with this number and it works with this number and it works with this number, so it must always work.' Because, how many numbers are there out there?

Several students: A lot.

Mr. Hummel: Yes, lots of them. So, can you try every possible number?

Several students: No.

Mr. Hummel: No. there's always gonna be another number you can try. So, it's hard to prove something's true, because it's worked with all the examples you've tried so far.

In this passage, Mr. Hummel helped to explain to the class that testing examples is not sufficient to validate a general claim. This connects with his understanding of the limitation of naïve empirical reasoning as demonstrated in the interviews and working sessions. 
However, even though he told students directly that examples cannot prove the general case, he still chose not to confront naïve empirical reasoning in the moment when working with groups. Consider the following interchange in the second year of the number trick task. Mr. Hummel visited a group and asked them to share whether they believe the number trick will always work.

Student 1: I do think it will work for any number because we tried different numbers and they all worked.

Student 2: I think it will work with different other numbers because we've tried it with different numbers and it worked.

Mr. Hummel: All right. [Walks to next group.]

This excerpt is typical of the way that Mr. Hummel implicitly endorsed naïve empirical reasoning. By choosing not to correct the argument, he allows students to continue to believe that their reasoning is reasonable. This may link back to Mr. Hummel's strong belief that a justification should be a convincing argument, and he recognized that for these students testing a set of examples is indeed convincing.

\section{Adding "why"}

A common pattern for Mr. Hummel's implementations was to have students work with examples to generate conjectures, test those conjectures, and build conviction that the conjecture was true before moving on to answering why the conjecture was true. In fact, Mr. Hummel intentionally delayed having students share an explanation as to why the task worked to allow the rest of the class the opportunity to explore examples first: “Don't worry about 'the why' too much here because that's actually, you're going to get to that here, but do you think you might have figured out 1?" He made the same suggestion in the second year's implementation of the task, "And right now don't worry about why or anything, just describe what you're noticing." Thus Mr. Hummel appeared 
to value the exploration of examples as an initial introduction to the task, and he delayed asking about why until student had become more familiar with the mathematics of the task.

Once the students felt convinced that the result was reasonable, he would turn the class's attention to answering why it worked. For example, in the second year's implementation of the number trick task, Mr. Hummel explained to the whole class how he wanted students to proceed in verifying their conjectures:

So, for number four, I want you to work together to come up with a convincing argument for how this works and why it works. OK, so if you're all convinced that it works, without using a bunch of examples, try and show how and why it's working.

In this passage, Mr. Hummel focused student attention away from listing additional examples and redirected it toward understanding why. However, in other instances specifically directed student attention toward examples to help students understand why. In the following passage, Mr. Hummel pointed to specific places in the student's worked example in an attempt to have the student explain more fully why the result held.

Mr. Hummel: Okay so I want you to figure out why it's working. Student: Because every number I tried worked.

Mr. Hummel: Yeah, but why? So figure out what's happening here: so what's happening here [points to part of the example] and what's happening here [points to the other part of the example], and why does that make that the same at the bottom?

Similarly, Mr. Hummel asked students to use examples as a starting place for thinking about a more general argument:

Now, what are you thinking for why it always works? [5 second pause] And, like, I don't want you to dismiss the whole thing that it works for the examples. So think about why it's working for the examples. Like, what's happening to make it work for every one of these examples? 
Mr. Hummel made it clear to his students that he expected the argument to go beyond a set of examples. Mr. Hummel also asked students to build on the work they did with the specific examples to construct a more general argument.

In summary, Mr. Hummel had a strong understanding of different forms of empirical reasoning, but a unique perspective on naïve empirical reasoning. $\mathrm{He}$ maintained that although single examples insufficient to establish the validity of a general claim, they did provide some evidence for the claim, and thus he considered them justifications. In his classroom, he frequently asked students to explore examples to generate and test conjectures. Once students developed conviction that a result held, he then directed them toward answering why the result held.

\section{Ms. Primm}

Throughout the project, Ms. Primm's evaluation of example-based reasoning was based on the degree to which the argument explained why. She consistently maintained that naïve empirical reasoning could not justify because single examples did not have the explanatory power to describe why something works mathematically. For example, before the start of the project when evaluating the naïve empirical argument (see Figure 10) she stated, "So this one here is just where you have an example, so this is not a justification... there is no mathematical reasoning about why you have this."

Although Ms. Primm classified naïve empirical reasoning as invalid, she did view certain types of example-based reasoning as better than others, depending on their ability to address why. For example, she valued a patterned set of examples over seemingly random examples, because the patterned examples were closer to describing why, according to Ms. Primm. With regards to a patterned example she stated, "At least she 
has some sort of systematic pattern. Whereas Micah's [in Figure 10] was just some-- they seemed to me to be random choices. At least Erica has some sort of pattern, so I think that it is a better justification why... But it still seems to be just examples". From a mathematical standpoint, patterned sets of examples by themselves do not actually offer explanations; but for Ms. Primm example-based arguments that relied on a pattern were preferable to random examples because they were closer to unpacking the mathematical why. Ultimately, both random and patterned sets of examples were not valid justifications according to Ms. Primm.

Ms. Primm recognized that a single counter-example was sufficient to prove that a general result does not hold, but she still favored a more explanatory justification that described why. She stated, "I just know the difference between just showing that something doesn't work... like this isn't true because this example doesn't work and showing why it doesn't work." Unlike some other teachers in the project, Ms. Primm understood that a single example could be a useful tool in establishing that something is not true, but she maintained that it may not explain why something is not true, which was important for her definition of justification.

Similarly, Ms. Primm's opinion regarding the validity of generic example based arguments depended upon the degree to which the argument explained why. At times Ms. Primm favored some generic examples because they demonstrated why something was true mathematically. However, at other times she questioned whether the certain generic example argument were valid because of how well they described why something held for the general case. 


\section{Ms. Primm: Classroom Treatment of Examples}

Ms. Primm's treatment of examples was more limited than that of the other focal teachers in this study. Within her task implementations she used several specific examples early in the launch of the task, with the purpose of giving the students a chance to understand the exact directions of the task. She also had students consider examples represented in pictorial form to help them understand why a task worked. However, she typically redirected students away from looking at examples and had students focus instead on representing their thinking using algebraic and graphical representations.

Table 10 displays the counts for Ms. Primm in each of the coding categories, organized by year and by task.

Table 10: Ms. Primm's treatment of examples by task and year

\begin{tabular}{|l|c|c|c|c|c|c|}
\hline & \multicolumn{7}{|c|}{ Irene Primm } \\
\hline & \multicolumn{2}{|c|}{ Hexagon Task } & \multicolumn{2}{c|}{ Scaling Task } & \multicolumn{2}{c|}{ Number Trick } \\
\hline & Year 1 & Year 2 & Year 1 & Year 2 & Year 1 & Year 2 \\
\hline Demonstration & 1 & 2 & 2 & 1 & 3 & 2 \\
\hline Generating Conjectures & 1 & 0 & 3 & 3 & 2 & 0 \\
\hline $\begin{array}{l}\text { Understanding how or } \\
\text { why something works }\end{array}$ & 10 & 2 & 16 & 0 & 8 & 2 \\
\hline Identifying Patterns & 2 & 1 & 2 & 2 & 4 & 1 \\
\hline Testing Conjectures & 2 & 0 & 7 & 4 & 1 & 0 \\
\hline Increase Conviction & 0 & 0 & 0 & 0 & 0 & 0 \\
\hline $\begin{array}{l}\text { Explaining or } \\
\text { demonstrating the general } \\
\text { argument }\end{array}$ & 0 & 0 & 0 & 0 & 0 & 0 \\
\hline Build a general argument & 6 & 2 & 4 & 0 & 1 & 0 \\
\hline Examples are not enough & 1 & 0 & 1 & 0 & 5 & 3 \\
\hline $\begin{array}{l}\text { Not possible to test all } \\
\text { cases }\end{array}$ & 0 & 0 & 0 & 0 & 0 & 0 \\
\hline $\begin{array}{l}\text { Not practical to test all } \\
\text { cases }\end{array}$ & 0 & 0 & 0 & 0 & 1 & 0 \\
\hline Examples don't explain & 0 & 0 & 0 & 0 & 0 & 0 \\
\hline
\end{tabular}




\begin{tabular}{|l|l|l|l|l|l|l|}
\hline why & & & & & & \\
\hline Endorsed as valid & 0 & 0 & 0 & 0 & 0 & 0 \\
\hline
\end{tabular}

\section{Insufficiency of Empirical Reasoning}

Ms. Primm was consistent and direct in her evaluation that naïve empiricism was not a valid form of reasoning. She was one of the few teachers who never implicitly or explicitly endorsed naïve empirical reasoning as valid, as indicated by the empty bottom row of Table 10. Additionally, she was one of the few teachers who discussed the insufficiency of naïve empirical reasoning outside of the Number Trick task.

When Ms. Primm evaluated naïve empirical reasoning, she focused on the fact that it was not a valid form of reasoning, but she generally did emphasize that examples alone do not have explanatory power to demonstrate why something was true. For example, early in the first year of the Number Trick task, one student suggested trying out several examples to show that the two rules were valid. Ms. Primm rejected the student's method:

Matty: On number one, can we just pick like a few random numbers, and try the rule or do we?

Ms. Primm: So good question, so what Matty just ask is, can we just choose a couple numbers and see if it works? And then is that enough to say that it would work for any number?

Student: Yeah.

Ms. Primm: No, but that certainly would show that it works for those numbers that you choose. But how could we show that it would work for any number? Okay, that's the big question.

In this passage Ms. Primm pointed out that a single example did not show that the result would hold for all numbers. This is an interesting contrast to her description of naïve empirical reasoning within the interview setting. During her interviews, she was explicit that single examples were insufficient not only because they cannot address the general 
case, but also because they fail to explain why the result works or is true. In her interview, she explained, "So this one here is just where you have an example, so this is not a justification... there is no mathematical reasoning about why you have this." However, within her classroom she did not explicitly explain that single examples fail to explain why a result holds.

\section{Focus on representations to explain why}

When addressing empirical reasoning, Ms. Primm did not highlight an example's insufficiency in explaining why. However, she frequently directed students to explain why, and relied on pictorial representations of examples to do so. Evidence for her focus on using examples to explain why is found in the relatively high number of counts in the category Understanding how or why something works. When working with students, she frequently pressed students to explain how and why something was true, such as, "Why would it always be the same? If we add eight after we've doubled the number, why is that always the same?" and "Why are the pictures the same? Why is this picture the same as that picture?"

Ms. Primm consistently pressed students to explain how and why they knew something was true by asking students to consider using multiple representations rather than numeric examples. She stated, "And when you show how you know, what I mean by that, is I need you to use words, pictures, numbers, and symbols, to show how you know." Additionally, when students had trouble understanding how to answer why something was true, rather than directing them toward numerical examples, she would prompt them to draw a picture to understand the relationship. A picture can be used to 
represent a specific example, but unlike the numeric counterpart, Ms. Primm emphasized a picture's ability to help students understand why.

\section{Focus on patterns}

Although Ms. Primm guided her students away from most forms of empirical reasoning, result-pattern reasoning was present, particularly in the second year's implementation of the number trick task. Ms. Primm did not confront this as invalid reasoning in her class, and at times she directly stated that result-pattern arguments were valid justifications.

For example, in the second year of the number trick task Ms. Primm encouraged students to organize their investigation to look for patterns. She stated, "Remember, mathematicians always organize their work so they can see patterns." The result was that some students found a pattern that the outputs of both number tricks increase by two for a one unit increase in the input. Students reasoned that the trick would hold because of a pattern, but they did not explain why that pattern exists or why it would continue to hold. Based on the pattern, students formed linear equations. Ms. Primm accepted these equations as valid justifications, even though the students had not justified the origins of the pattern itself. In response to one of these arguments, Ms. Primm stated: "That's a great justification right there. Perfect, you found the y-intercept and the coefficient and you found that they're the same. Good job." In this case, the student generated linear equations using pattern-result reasoning.

Ms. Primm did not accept naïve empirical reasoning as a justification in her classroom, but more subtle forms of empirical reasoning were validated. In this case, students supported their arguments using patterned sets of examples and formed algebraic 
rules based on those patterned examples. Rather than pressing the students to explain why the pattern held, Ms. Primm endorsed the pattern-result argument. This exchange took place toward the very end of the project, in the second to last classroom observation.

This finding stands in contrast to that of her work within the interviews and working sessions. Within the third interview, she clearly articulated that a result-pattern argument was not a justification. She explained, "There's no "why it works... they're just looking at the table and saying, 'well it increases by three each time'." Thus although she seemed to characterize result-pattern reasoning as insufficient when placed in contrast to other justifications in an interview setting, that same type of reasoning was endorsed as valid within her classroom after the interview had taken place.

\section{Redirect Toward Algebra}

Rather than using specific examples to have students explore the tasks, as was the case for many of the other teacher's implementations, Ms. Primm preferred to have students use algebra. For example, in the first year's implementation of the number trick task, Ms. Primm demonstrated an example for the class with a starting number of 5, but then immediately moved to algebraic notation as she worked through the specific example. She stated:

So we'll start with that same number, five. So we've worked with variables in that last book we were in, right? ... We can just replace that with the variable, $n$, and that means whatever number we choose. Okay, so, $n$ equals five, [writes five on the poster].

While Ms. Primm is demonstrating the example for $n=5$, she is also preparing the students to consider the general case. 
This method was echoed throughout other task implementations, in which she encouraged students to move away from specific examples and toward algebraic representations, as we see in the Build a General Argument category. For example, in the hexagon task she prompted students, "You can explain how you got [Figure number] 50, and then we can make that a [algebraic] rule." At times she was explicit about asking students to replace single numbers with variables in order to generalize their equations. For example, Ms. Primm guided students to construct an equation for the perimeter of a polygon train composed of $n$ polygons, each with $k$ sides.

Ms. Primm: Could you figure out an equation for a 10-sided figure?... So I heard you say 8 ? So do you know how to write that mathematically?

Veronica: So $k$ minus 2?

Ms. Primm: Yeah. Mmhm. Exactly. Exactly! Yeah. And then I heard you say multiply by $n$. Yeah.

In this exchange, Ms. Primm helped students transform their equation for a specific example into a more general algebraic equation. This aligns with Ms. Primm's stance from the interviews that fully generalized algebraic arguments are preferable to specific examples.

Ms. Primm was consistent in her evaluation that naïve empiricism was an invalid form of reasoning. In her interviews she emphasized that single examples were not mathematically valid nor did they explain why. When she did focus on examples in her class, she most often did so using pictorial representations: she frequently asked students to use pictures or diagrams to explain why. In her classroom, she tended to redirect students away from using examples, and focused on finding patterns or alternate representations such as algebra or diagrams. 


\section{Ms. Davilla}

Ms. Davilla's thinking about empirical arguments underwent a number of changes over the course of the project. At the start of the project, she was uncertain if naïve empirical reasoning could be considered a justification. When evaluating the student work for the consecutive number task (see Figure 10), she stated, “I don't know... [the student] did look pretty globally I mean they looked at small numbers and big numbers. So that's not a bad thing.... But I still feel like they are reasoning through this. They are not... they are not just following any algorithm." However, in later interviews she was certain that this student's naïve empiricism was not a justification because it did not show that the conjecture was always true. She explained, "You've looked at three cases. That doesn't prove it to me for all numbers." Note that her objection to the argument was on the grounds of its mathematical validity and not that the argument did not explain why.

Ms. Davilla described a shift in her own thinking about the differences among naïve empirical arguments. When she reflected on her own thinking, she realized that early in the project she preferred arguments that used a wide variety of example values over arguments that used small consecutive values. However, after the first summer session she placed both arguments on equal footing because they were both empirical arguments that did not prove the general case.

Over the course of the project Ms. Davilla also displayed a growing understanding of generic example reasoning. For example, in the first summer session she initially classified [FoR \#5 from SS1] as a naïve empirical reasoning, but through discussion saw that the student was representing the specific example generally. She explained, "I think I missed the piece about generic representation using a specific 
example, but then they are reasoning about it generally. I agree [that it is generic example]." Later in the project, Ms. Davilla was clear about her appreciation of generic example reasoning. When evaluating a generic example, she stated: "I mean she does it with a concrete example, but I think that's okay because then she makes it a little bit more generic or general ... And that's the statement that I think we're trying to get to.”

Although Ms. Davilla appreciated generic examples, she frequently stated that they could be improved by including a more general, algebraic, argument. She stated, "She starts off her argument with two concretes, so she could probably represent that more generally... represent that algebraically for all numbers.” Ms. Davilla maintained that arguments must also include strong connections between the specific example and the general case, preferably using algebra.

\section{Ms. Davilla: Classroom Treatment of Examples}

Ms. Davilla provided a mixture of different messages to her students regarding the role of examples in justification. On the one hand, she valued examples as a good place to start, and numerous times throughout both years' implementations of the number trick task she implicitly endorsed naïve example-based arguments when sharing student solutions. However, she also made it clear that students must provide more explanation than examples alone. A common element in her instruction was extended use of a specific example to either explain an underlying mathematical property or as the starting point to build a more general (algebraic) argument. Table 11 displays the results for the analysis of Ms. Davilla in each of the coding categories, organized by year and by task. 
Table 11: Ms. Davilla's treatment of examples by task and year

\begin{tabular}{|l|c|c|c|c|c|c|}
\hline & \multicolumn{5}{|c|}{ Paige Davilla } \\
\hline & Hexagon Task & \multicolumn{2}{c|}{ Scaling Task } & \multicolumn{2}{c|}{ Number Trick } \\
\hline & Year 1 & Year 2 & Year 1 & Year 2 & Year 1 & Year 2 \\
\hline Demonstration & 0 & 0 & 12 & 6 & 3 & 2 \\
\hline $\begin{array}{l}\text { Generating } \\
\text { Conjectures }\end{array}$ & 1 & 1 & 8 & 0 & 0 & 1 \\
\hline $\begin{array}{l}\text { Understanding } \\
\text { how or why } \\
\text { something works }\end{array}$ & 20 & 31 & 9 & 20 & 6 & 7 \\
\hline $\begin{array}{l}\text { Identifying } \\
\text { Patterns }\end{array}$ & 2 & 1 & 0 & 2 & 1 & 1 \\
\hline $\begin{array}{l}\text { Testing } \\
\text { Conjectures }\end{array}$ & 4 & 1 & 5 & 1 & 4 & 0 \\
\hline $\begin{array}{l}\text { Increase } \\
\text { Conviction }\end{array}$ & 0 & 0 & 0 & 1 & 4 & 0 \\
\hline $\begin{array}{l}\text { Explaining or } \\
\text { demonstrating the } \\
\text { general argument }\end{array}$ & 0 & 0 & 4 & 3 & 2 & 3 \\
\hline $\begin{array}{l}\text { Build a general } \\
\text { argument }\end{array}$ & 2 & 3 & 3 & 1 & 3 & 3 \\
\hline $\begin{array}{l}\text { Examples are not } \\
\text { enough }\end{array}$ & 0 & 0 & 0 & 0 & 2 & 0 \\
\hline $\begin{array}{l}\text { Not possible to test } \\
\text { all cases }\end{array}$ & 0 & 0 & 0 & 0 & 1 & 0 \\
\hline $\begin{array}{l}\text { Not practical to } \\
\text { test all cases }\end{array}$ & 0 & 0 & 0 & 0 & 2 & 3 \\
\hline $\begin{array}{l}\text { Examples don't } \\
\text { explain why }\end{array}$ & 0 & 0 & 0 & 0 & 5 & 0 \\
\hline Endorsed as valid & 0 & 0 & 0 & 0 & 5 & 7 \\
\hline
\end{tabular}

\section{Implicit endorsement of nä̈ve empiricism}

Multiple times throughout both years' implementations of the number trick task,

Ms. Davilla did not directly confront the validity of naïve empirical reasoning when it

was suggested in her classroom. As shown previously, the following passage was a typical example of a whole class discussion in which one student gave an argument based on a set of examples, and Ms. Davilla did not refute it. 
Student: They will always equal out.

Ms. Davilla: Ok, how did you show that?

Student: Um, we did whole numbers between 1 through 10. We did decimals too.

Ms. Davilla: Ok, so we checked, we checked numbers 1 thought 10, and you said we checked some decimals too?

Student: Yeah.

Ms. Davilla: Some decimals, and these were the whole numbers right? Ok, other ways we established this? [emphasis added]

Notice that rather than directly confronting the student, Ms. Davilla instead asked the class for other ways that the result was established. The implication was that counting examples was a way to establish the result, and other ways were also worth discussing. Later in the course of the lesson, Ms. Davilla explicitly explained that examples cannot verify a general claim, but in the moment students might be left with the impression that checking examples was one way to prove a result.

Similar instances of not confronting or commenting on empirical arguments occurred throughout both years of the number trick task. This classroom work did not align with Ms. Davilla's conception as stated in the interview and workshop settings: after the first summer session she was consistent in her evaluation that naïve empirical reasoning was not valid. It is likely that Ms. Davilla prioritized the pedagogical concern of honoring student thinking rather than the mathematical concern of validity. This tension relates to Ms. Davilla's ongoing struggle regarding incorrect student answers. On the one hand, she deeply valued student participation and student autonomy in the development of their own thinking, which sometimes stood in contrast to her obligation to upholding mathematical truth. In this case, rather than confronting students in the moment with their naïve empirical reasoning, she waited until a different whole-class discussion to address the fact that examples alone are not sufficient. 


\section{Examples need explanation}

Ms. Davilla frequently encouraged students to use examples as a good starting place for mathematical exploration, but she also emphasized that examples should be accompanied by further explanation. For example, in the first year's implementation she stated, "[The problem] says, 'explain your reasoning," Okay? You may be able to show some examples, and that's just fine, but you also need to write an explanation. Okay?” She communicated that she expected students to present more than examples: "Just don't show me a bunch of examples. You need to answer the question: 'Will it always work for every ...Will it always work?" Although she allowed students to present example-only arguments to the class and not confront them in the moment, she did state later that she expected students to include further explanation with the examples. In these cases it may not be clear to students whether the inclusion of an explanation is a mathematical necessity for establishing a general result, or if it is simply her preference as a teacher for showing one's work.

\section{Building toward Algebra}

Across every task implementation, Ms. Davilla leveraged specific examples toward more general, frequently algebraic, arguments. For example, in the first year of the hexagon task, she explored in detail the specific case of a train with 100 hexagons. She continued on by stating, "So I want to be able to describe it as $n$, where we know that $n$ means any number of hexagons. We want to be able to describe it so that I can pick a number and plug it in there [points to equation for specific example], and find the right answer." 
Similarly, in the first year's implementation of the number trick task, she explicitly contrasted the power of single examples with the power of algebra to address the general case. She stated:

So if we want to be able to prove something true for every number, we need to be able to go from these examples, all these different examples, to show that something will work generally: to show that something will work for every number. And the way that we do that is we start using our variables. We start using a variable, it means for any number, I can, this will work, and I can prove it.

Much like Ms. Primm, Ms. Davilla pointed out that algebraic arguments could prove the general case. Also similar to Ms. Primm, Ms. Davilla made use of specific examples as a basis to build more general arguments.

However, unlike Ms. Primm, Ms. Davilla described the algebraic method as easier than an example-based method, because an algebraic method did not require checking every example. In one conversation a student, Addison, suggested creating an algebraic rule. Ms. Davilla contrasted this with checking an infinite number of cases: "Do people like Addison's homework better than my homework which was to do all the examples, infinite number? ... I think we might like Addison's idea better." In this instance, students may be left with the idea that checking an infinite number of examples is a tedious way to verify a result, but not that it is mathematically impossible. Ms. Davilla implied that forming an algebraic rule was a useful alternative to checking examples, in part because it is faster than having to check an infinite number of possibilities.

\section{Generic Example Arguments}


Ms. Davilla's practice was characterized by extended whole-class

discussions that focused on a deep understanding of one particular example. In these discussions, Ms. Davilla greatly emphasized understanding why the mathematics worked in the specific example, and the conversations typically culminated in a co-created generic-example justification.

For example, in the second year of the number trick task, Ms. Davilla helped orchestrate the construction of a generic-example argument by having students unpack the structure of one particular example. In this example, the original number is 9, and Ms. Davilla pressed the students to articulate where they saw each of the operations of the number trick within the computations of the specific example. For example,

Ms. Davilla: Ok, so where is the 4 being doubled? Can you just repeat that one more time?...

Student 8: Because you're add 9 and 4 which is 13 and then doubling 13 so. Ms. Davilla: So the 4 gets doubled...

Student 8: Because you're doubling the 13. And it's part of 13.

Ms. Davilla: Can somebody else tell me why 4 is part of 13 . Why is 4 part of 13 ? Because he is saying that the 4 is getting doubled here (points to the 13). Why is 4 part of 13 ?

Student 9: Because 4 plus 9 is 13 . And 9 is the number we started out with.

Notice the Ms. Davilla highlighted an important piece of the mathematics within the students' reasoning about the example and had the students in the class clarify which operations were related to each number. In particular, Ms. Davilla made students "break down" each of the numbers to see exactly where the "doubling 4" was happening. This conversation eventually resulted in a co-constructed generic-example justification. (Refer to Table 12 for the equations in the trick.) 
Table 12: Number Trick example with starting value of 9

\begin{tabular}{|ll|ll|}
\hline \multicolumn{3}{|c|}{ Number Trick Example } \\
\hline & PART 1 & PART 2 \\
$9+4=13$ & & $9 \times 2=18$ & \\
$13 \times 2=26$ & & $18+8=26$ & \\
\hline
\end{tabular}

Ms. Davilla: Can somebody else tell me where the two 4's are? ...

Student 1: Um, in this one with the two 4's, the first one is when you add 4 and then you multiply by 2 so that makes two 4's. And in this one you're adding 8 because 4 times 2 is 8 .

Ms. Davilla: Ok, so that's my two 4's there. So I want to make sure we're really solid on she said the 4 gets doubled here. Can somebody remind me again, I just want to make sure we're clear on that. How are we saying that the 4 is getting doubled? I see a 9. Where the 4 is getting doubled I see a 13, I don't see a 4 . So where's that 4 again. Where's that 4 ?

Student 2: Since the 4 is part of the 13 you're doubling the 4 too.

Ms. Davilla: Ok, is everybody ok with that? Is there any questions on that, that the 4 is part of this 13 and the 4 is part of this 9? Yes, no? So we've heard from a couple people that seem ok with that. Ok. And then can somebody then show me, does the other part of the whole sequence have 2 of the original number. Can somebody show us that? What do we mean by that? That there is 2 of the original number in each? Can you show that? Jiana, can you show that?

Hana: So the original number is 9 , right? So, when you multiply it by 2 there are two 9's in 18.

Ms. Davilla: Ok, so that's part 2. Can you do the same thing for part 1? Show me that they're two 9's there.

Hana: So 9 is part of the 13, because yeah. And since you're doubling the 13, 9 is still a part of that so there's 2 of them, so it's doubled.

Ms. Davilla: Ok, can we explain the "because yeah" part? So, you said 9 is part of the 13 because yeah. Could we elaborate on that part a little bit?

Hana: Because 9 plus 4 equals 13, so...

Ms. Davilla: So the 9 is part of the 13?

Hana: Yeah.

Ms. Davilla: And you said there is 2 because why?

Hana: Because the 13 is doubled.

Ms. Davilla: Ok, 13 is doubled. Ok, so in both parts we have two 4's and two of the original number.

In this passage, Ms. Davilla helped guide students toward an explanation of how the number trick worked for the specific example starting with the original number of 9. 
Students were led to see how the doubling process took place in each of the rules, which formed the basis of a generic-example argument.

I consider Ms. Davilla's case to be one of "moving toward the general." She exhibited development in her understanding of empirical reasoning. By the end of the project she articulated strong understanding of various forms of reasoning and an insistence that naïve empirical reasoning was not valid. However, in her classroom she frequently chose not to confront students when they used examples to justify the general case. She also encouraged students to use examples as a starting place for their thinking, but consistently reminded them of the importance of explaining why. Unlike the other case teachers, Ms. Davilla's classes frequently included sustained, detailed whole-class discussions in which a single example was analyzed in great detail, leading to generic example or fully algebraic argument.

\section{Discussion and Conclusions}

One of the primary contributions of this paper was a framework illustrating 13 ways teachers utilized examples within the context of justification activity. These uses included Pedagogical Uses of Examples, which represent the different ways teachers utilized examples to understand or explore the mathematics of the lesson, and Treatment of Validity of Examples, which catalogues how teachers addressed the validity of naïve empiricism. This framework shows that JAGUAR middle school teachers utilize examples in a number of rich and productive ways, many of which mirror the ways mathematicians use examples within lecture or proving activity.

This paper also described three different teachers' conceptions of empirical reasoning along with their treatment of examples in their middle school classrooms. All 
three case teachers had well-articulated and sound understanding of the limitations of naïve empirical reasoning from a strictly mathematical standpoint: a single example is insufficient to prove the general case. However, even with this commonality the three teachers had a variety of understandings of empirical reasoning and differences in their treatment of empirical reasoning within their classrooms.

Mr. Hummel valued naïve empirical reasoning as a valid form of justification for his middle school students, because he maintained that examples were convincing for students, and a justification should be a convincing argument. Within his classroom, students were encouraged to explore examples at length in developing and testing conjectures, and to gain conviction of the result. However, after students worked with examples, he encouraged them to "add why:" to describe mathematically why the examples work.

Ms. Primm consistently stated that naïve empirical reasoning was insufficient for a justification. Early in the project her focus was on the mathematical insufficiency for addressing the general case; however, she soon included the criteria that individual examples alone do not explain why, which was her primary criteria in evaluating the validity of a justification. In her classroom, Ms. Primm was consistent that single examples were not a valid form of reasoning, and she redirected students toward other representations, such as diagrams, graphs, or algebraic equations, to explore and express their understanding.

Ms. Davilla exhibited some growth in her thinking about example-based arguments over the course of the project. At first she was conflicted about the validity of naïve empirical reasoning, because it demonstrated student thinking but did not address 
the general case. Later she resolved that examples alone were not justifications, but other forms of reasoning that include examples, such as generic-example based arguments, could be valid justifications. Her classroom practice included some implicit validation of example-based arguments, likely because of her stated value in honoring student thinking. Her classroom practice was also characterized by extended classroom discussions focused on single examples both to develop student understanding of the mathematics and to build toward a more general argument.

This study found that teacher treatment of examples in the classroom can be tied to a constellation of different factors, including a teacher's content knowledge, definition or purpose of justification, and beliefs about teaching and learning. In particular, teacher content knowledge of empirical reasoning was evident across all cases. All three teachers agreed that naïve empirical reasoning did not address the general case, and all three teachers pointed out the limitations of such reasoning within their classrooms. Similarly, all of the teachers recognized that algebraic arguments were able to prove general case, and to a certain degree all of the teachers pressed their students to construct algebraic arguments.

While content knowledge of empirical reasoning was important, the enactment of that knowledge in the classroom was mediate by teacher understanding of the definition of justification as well as their view of the purpose of justification in the classroom. For example, Mr. Hummel's definition of justification was “a convincing argument." His belief that examples were convincing may have influenced his choice to have students explore examples before answering why. Similarly, all of the teachers believed that a justification should explain why and all of the teachers consistently leveraged examples to 
have their students understand why. This is reflected in the dominant presence of the code Understanding how or why something works, which accounted for over a third of all codable instances of examples for these teachers. The teachers' beliefs about what a justification is related to their treatment of empirical reasoning while teaching.

Related to this, the teachers' beliefs about the purpose of justification impacted their treatment of examples in the classroom. All of these teachers were unified in their belief that one of the primary purposes of justification was to deepen student understanding. Just as the mathematical community's primary goal is (arguably) the generation of valid results, the middle school math community's primary goal should be student learning. These teachers used examples to meet their instructional goals, which included deepening understanding of why something was true or worked.

Finally, the their unique approaches to empirical reasoning in the classroom were also influenced by their individual beliefs about students and learning. For example, Ms. Davilla's strong commitment to honoring student thinking and valuing student contributions may have led her to choose not to directly confront student's examplebased arguments during whole-class discussions.

Similarly, each teacher's belief about their role as a teacher in the classroom influenced how tightly they coupled their press for examples with student thinking. For example, when Ms. Primm asked students to explain why with an example, it was typically in passing and did not link directly to a specific example or student thinking. A typical example was when Mr. Primm asked a student: "Can you explain why? Maybe by using a picture?" Ms. Primm's role in the classroom was an orchestrator of proscribed routines: she relied on social protocols and general, mathematical prompts to advance the 
mathematical agenda. In contrast, Ms. Davilla was more likely to use Understanding Why in extended, specific, connected work, such as her development of generic-example based arguments described previously. Thus although the teachers all valued using examples to explain why, the degree to which they linked that work to student thinking or directed investigation differed among the teachers.

This paper offers a significant contribution in understanding middle school teacher understanding of empirical reasoning, treatment of examples and the relationships between the two. This study found that knowledge of empirical reasoning was evident in teacher treatment of examples in their classes, however that treatment was influenced by a number of other factors, including their definitions and purposes for justification and their beliefs about students and teaching. These findings are consistent with the literature that teacher beliefs, goals and knowledge all have influence on one another and teacher practice (Aguirre \& Speer, 2000; Bray, 2011; Leatham, 2006).

This study provided evidence of teacher use of examples in the context of justification activity, but did not address the impact of examples on student learning. Future studies could consider the effects of using different types of examples in varied ways on subsequent student justification production. Similarly, this study provided evidence of teacher change in their development of their understanding of empirical reasoning, more work could be done to capture the nature of that growth, particularly in relation to the development of teacher practice.

\section{References}

Alcock, L., \& Inglis, M. (2008). Doctoral Students' Use of Examples in Evaluating and Proving Conjectures. Educational Studies in Mathematics, 69(2), 111-129. 
Ball, D. L., Hoyles, C., Jahnke, H. N., \& Movshovitz-Hadar, N. (2003). The teaching of proof. arXiv:math/0305021. Retrieved from http://arxiv.org/abs/math/0305021

Buchbinder, O., \& Zaslavsky, O. (2011). Is this a coincidence? The role of examples in fostering a need for proof. $Z D M, 43(2), 269-281$. doi:10.1007/s11858-011-0324-7

Chazan, D. (1993). High School Geometry Students' Justification for Their Views of Empirical Evidence and Mathematical Proof. Educational Studies in Mathematics, 24(4), 359-387. doi:10.2307/3482650

Corbin, J., \& Strauss, A. (2008). Basics of Qualitative Research: Techniques and Procedures for Developing Grounded Theory (3rd ed.). Thousand Oaks: SAGE Publications.

Council of Chief State School Officers (CCSSO) \& National Governors Association Center for Best Practices (NGA Center) (2010). Common Core State Standards for Mathematics http://www.corestandards.org/assets/CCSSI_Math\%20Standards.pdf

Ellis, A., Lockwood, E., Williams, C., Dogan, M. F., \& Knuth, E. (2012). Middle school students' example use in conjecture exploration and justification. In Proceedings of the 34th Annual Meeting of the North American Chapter of the Psychology of Mathematics Education. Kalamazoo, MI.

Harel, G. (2001). The development of mathematical induction as a proof scheme: A model for DNR-based instruction. In S. Campbell \& R. Zaskis (Eds.), Learning and Teaching Number Theory: Research in Cognition and instruction (Vol. 2, pp. 185-212). New Jersey: Ablex Publishing Corporation. 
Harel, G., \& Sowder, L. (1998). Students’ proof schemes: Results from exploratory studies. Research in Collegiate Mathematics Education III, 7, 234-282.

Healy, L., \& Hoyles, C. (2000). A Study of Proof Conceptions in Algebra. Journal for Research in Mathematics Education, 31(4), 396-428. doi:10.2307/749651

Hoyles, C. (1997). The Curricular Shaping of Students' Approaches to Proof. For the Learning of Mathematics, 17(1), 7-16.

Kazemi, E., \& Hubbard, A. (2008). New Directions for the Design and Study of Professional Development Attending to the Coevolution of Teachers' Participation Across Contexts. Journal of Teacher Education, 59(5), 428-441. doi:10.1177/0022487108324330

Knuth, E. (2002). Secondary School Mathematics Teachers' Conceptions of Proof. Journal for Research in Mathematics Education, 33(5), 379-405. doi: $10.2307 / 4149959$

Knuth, E., Choppin, J., Slaughter, M., \& Sutherland, J. (2002). Mapping the conceptual terrain of middle school students' competencies in justifying and proving. In Proceedings of the 24th annual meeting of the North American Chapter of the International Group for the Psychology of Mathematics Education (Vol. 4, pp. 1693-1670). Athens, GA: Clearinghouse for Science, Mathematics, and Environmental Education.

Larsen, S. \& James, C. (unpublished manuscript). From empirical reasoning to general arguments: Forms of reasoning in middle school mathematics

Leatham, K. (2006). Viewing mathematics teachers' beliefs as sensible systems. Journal of Mathematics Teacher Education, 9, 91-102. doi:10.1007/s10857-006-9006-8 
Lockwood, E., Ellis, A., Dogan, M., Williams, C., \& Knuth, E. (2012). A Framework for Mathematicians' Example-Related Activity When Exploring and Proving Mathematical Conjectures. In Proceedings of the 34th annual meeting of the North American chapter of the international group for the psychology of mathematics education (pp. 151-158).

Maher, C. A., \& Martino, A. M. (1996). The development of the idea of mathematical proof: A 5-year case study. Journal for Research in Mathematics Education, 194214.

Martin, G., \& Harel, G. (1989). Proof frames of preservice elementary teachers. Journal for Research in Mathematics Education, 20(1), 41-51.

Mason, J., \& Pimm, D. (1984). Generic Examples: Seeing the General in the Particular. Educational Studies in Mathematics, 15(3), 277-289.

Mason, J., \& Watson, A. (2001). Getting Students to Create Boundary Examples. MSOR Connections, 1(1), 9-11. doi:10.11120/msor.2001.01010009

Mills, M. (2014). A framework for example usage in proof presentations. The Journal of Mathematical Behavior, 33, 106-118. http://doi.org/10.1016/j.jmathb.2013.11.001

National Council of Teachers of Mathematics. (2000). Principles and standards for school mathematics. Reston, VA: National Council of Teachers of Mathematics

Pedemonte, B., \& Buchbinder, O. (2011). Examining the role of examples in proving processes through a cognitive lens: the case of triangular numbers. $Z D M, 43(2)$, 257-267. doi:10.1007/s11858-011-0311-z

Selden, A., \& Selden, J. (2008). Overcoming students' difficulties in learning to understand and construct proofs. In M. P. Carlson \& C. Rasmussen (Eds.), 
Making the Connection: Research and Teaching in Undergraduate Mathematics Education (pp. 95-110). MAA.

Simon, M. A., \& Blume, G. W. (1996). Justification in the mathematics classroom: A study of prospective elementary teachers. The Journal of Mathematical Behavior, 15(1), 3-31. doi:10.1016/S0732-3123(96)90036-X

Simon, M. A., \& Tzur, R. (1999). Explicating the Teacher's Perspective from the Researchers' Perspectives: Generating Accounts of Mathematics Teachers' Practice. Journal for Research in Mathematics Education, 30(3), 252. http://doi.org/10.2307/749835

Sowder, L., \& Harel, G. (1998). Types of students' justifications. The Mathematics Teacher, 91(8), 670-675.

Stylianides, G. J., \& Stylianides, A. J. (2009). Facilitating the transition from empirical arguments to proof. Journal for Research in Mathematics Education, 40(3), 314352.

Weber, K., Porter, M., \& Housman, D. L. (2008). Worked examples and conceptual example usage in understanding mathematical concepts and proofs. In M. Carlson \& C. Rasmussen (Eds.), Making the Connection: Research and Teaching in Undergraduate Mathematics Education (pp. 245-252). Washington, DC: MAA.

Wilson, M., \& Cooney, T. J. (2002). Mathematics teacher change and development: The role of beliefs. In G. C. Leder, E. Pehkonen, \& G. Törner (Eds.), Beliefs: A hidden variable in mathematics education? (pp. 127-147). Dordrecht, The Netherlands: Kluwer Academic. 
Yackel, E. (2001). Explanation, Justification and Argumentation in Mathematics Classrooms. In Proceedings of the Conference of the International Group for the Psychology of Mathematics Education (25th) (Vol. 1-4). Utrecht, The Netherlands.

Yin, R. (2009). Case Study Research: Design and Methods (4th ed.). Thousand Oaks, CA: SAGE Publications. 


\title{
Chapter 7: Scaffolding Mathematical Tasks to Support Student Justification
}

\begin{abstract}
Justification and argumentation have been identified as important elements of school mathematics at all grades (CCSSO, 2010; NCTM, 2000), however designing and implementing open-ended tasks that support student justifications is challenging work (i.e. Bieda, 2010). This case study explores two different implementations of a single task over the course of two years by the same teacher. In the first year, the task was structured as an exploration of patterns, which led to limited student justifications. In the second year the task was redesigned and led to generic example and model-based justifications. This case study describes how task scaffolds impact student reasoning: scaffolds that focus students toward numerical patters can led to result-pattern reasoning, while scaffolds that focus on key relationships early in a task and developing common models can support the development of stronger student justifications.
\end{abstract}

\section{Introduction}

Reform efforts in math education have focused on student-centered approaches in which students construct their own understanding under the guidance of a capable teacher. In this model students build upon their current ways of understanding toward a more sophisticated type of mathematical reasoning. "Open-ended" or "exploratory" tasks give students the opportunity to investigate problems utilizing their own mathematical thinking and the thinking of their peers, rather than "closed" problems for which the procedure is proscribed, typically by the teacher. In the absence of prescriptive rules set by the teacher, students are given greater opportunities for generating and testing their 
own conjectures and supporting those conjectures through justifications. Teaching in this model requires a shift in pedagogical practices as well as a reformulation of curriculum to support student inquiry (Gravemeijer, 2004).

Open-ended mathematical tasks allow for multiple solution strategies, draw upon different areas of math content knowledge, and allow varied types of student mathematical engagement (such as conjecturing, generalizing, and justifying). The nature of open-ended tasks provides opportunities for student justification. When no fixed procedure is specified and students can approach the problem using varied strategies, a greater burden is placed on students to assess the mathematical validity of their chosen problem-solving approach and subsequent solution. Dewey described the benefits for students in exploring open-ended tasks:

This creates the openness that is essential for examining and improving the methods and for becoming full participants in the community. One of the most important factors in preventing an aimless and discursive recitation consists in making it necessary for every student to follow up and justify the suggestions he offers... Unless the pupil is made responsible for developing on his own account the reasonableness of the guess he puts forth, the recitation counts for practically nothing. (Dewey, 1933, p. 271, emphasis in original)

This sentiment was substantiated by the work of Martin, McCrone, Wallace and Dindyal (2005), who found that open-ended tasks coupled with classroom discourse norms helped promote student conjecturing and justification activity. Justifications can take place outside of open-ended tasks, and not all open-ended tasks explicitly require justification, but they offer a starting place for greater student engagement in justification. In addition, tasks can be specifically design to prompt for justification. 
It has been well documented that the pedagogies required for successful implementation of open-ended tasks are different from traditional lecture, and they can be difficult to master (e.g., Cohen, 1990; Simon \& Tzur, 1999; Speer \& Wagner, 2009; Wood, Cobb \& Yackel, 1991). Encouraging justification in the context of these tasks adds an additional dimension of difficulty. Franke and colleagues (2008) found that simply asking students to explain their thinking does not consistently lead to explanations, and Martino and Maher (1999) found that students do not typically provide justifications when interacting with one another. Bieda (2010) found that even tasks that ask for justification rarely result in mathematically sound justifications. Bieda's work is a more targeted exploration of a general phenomena described by Stein and others (2000): tasks written at a high level of cognitive demand frequently devolve into less challenging activity during the implementation of the task. Stein and her group examined 144 tasks as implemented in middle school classrooms and characterized the level of cognitive demand over the implementation of the task. They found that one tool teachers employed to maintain the level of cognitive demand was effective scaffolding of the task (Henningsen \& Stein, 1997).

\section{Definitions of Scaffolding}

The term scaffolding was first introduced in 1976 by Wood, Bruner and Ross, and continues to be a popular metaphor to describe support of student learning through intentional structuring. Over time, the term "scaffolding" has taken on a number of different definitions and connotations. Scaffolding has been characterized as a teacher directed activity, in which the teacher builds scaffolds for a student (Tharpe \& Gallimore, 
1998; Wood, Bruner \& Ross, 1976), as well as a discursive activity, in which the teachstudent pair co-construct scaffolds (i.e. Rogoff, 1995).

In math education, scaffolding has been both broadly and narrowly defined. For example, Anghileri's (1995) characterization goes beyond the traditional metaphor of task scaffolding to account for a large array of classroom artifacts and activity that promote student learning. I consider Wood's (1994) distinction between funneling and focusing to be a helpful characterization of different forms of scaffolding. Funneling includes teacher questioning that guides students toward a particular solution or way of thinking about a topic. Focusing, on the other hand, involves teacher interactions that highlight particular aspects of the student's thinking or problem features that are mathematically relevant. It remains honest to the child's thinking and places continued responsibility on the student for resolving the situation.

Staples (2007) identified several types of teacher focusing behaviors that helped to guide students without limiting student's thinking. To help students better share their ideas, the teacher might provide structure by posing questions based directly on a student's thinking. These questions "provide a kind of cognitive, structural support while maintaining space for the student to contribute and develop his or her ideas" (p. 178). Similarly, a teacher might offer food for thought to help students persevere through difficult tasks by commenting on a particular aspect of student work or asking new questions related to their current thinking. These types of scaffolding activities are consistent with Henningsen and Stein's (1997) conception that "scaffolding occurs when a student cannot work through a task on his or her own, and a teacher or more capable peer provides assistance that enables the student to complete the task alone, but that does 
not reduce the overall complexity or cognitive demands of the [intended mathematical] task" (p. 527). Scaffolding can help direct student attention to the important aspects of the task, reducing the cognitive load without compromising the intellectual agency of a student.

In this paper, scaffolds are defined as mathematical resources that provide structure or information to guide the task. This paper does not focus on social scaffolds: the scaffolding of social interaction is a critical part of classroom instruction, but it is beyond the scope of this paper. While it is possible to present differentiated scaffolds based on the needs of specific groups or individuals, this paper is only concerned with those scaffolds delivered to the whole class. In this way, I use the terms "scaffolding" to describe the mathematical structuring of task as delivered to the whole class.

\section{Research on the Impact of Task Structuring}

Evidence indicates that completely unstructured tasks can have limited impact on student learning (Alfieri, 2010; Kirschner, 2006; Mayer, 2004; Stein, Henningsen \& Silver, 2000). Alfieri and colleagues (2010) conducted a comprehensive meta-analysis of 164 studies comparing unassisted discovery learning, assisted discovery learning and explicit instruction. They found that unassisted discovery was less effective than direct instruction in most cases, although assisted or structured exploration was associated with greatest learning outcomes. These findings complement the findings demonstrated by Mayer (2004), that students demonstrate faster learning outcomes, more elegant solutions, and better retention when given some structure as opposed to independent reinvention. Henningsen and Stein (1997) also found that "unsystematic exploration" was a common cause for devolution of the cognitive demand of a task, accounting for the 
decline in 11 of the 36 of the middle school classrooms that shifted from doing mathematics into a less cognitively demanding activity over the course of a task.

Evidence indicates that tasks with proper scaffolding have a favorable impact on student learning when compared to unstructured tasks. Henningsen and Stein (1997) found that $73 \%$ of the tasks that maintained a high level of cognitive demand included scaffolding; for this study, scaffolding included structuring the task in a way that directed student attention to important aspects of the task without lowering the cognitive demand by "giving away" the solution method. Cognitive load theory (Sweller, 1994) provides theoretical support for appropriate task structuring: intentional task design can help reduce the cognitive load of a task by focusing cognitive activity directly on the meaningful elements of the task. By reducing distractors, more of a student's cognitive capacity can be directed toward the important elements of the task without compromising the problem-solving activity associated with the task.

On the other hand, providing too much information or inappropriate scaffolds can undermine a student's inquiry. Hsu, Kysh, Ramage and Resek (2009) found that overstructuring algebra tasks led to lesser student learning. This group found that by "unstructuring" algebra tasks, the pass rates of students (particularly at-risk students) improved. Similarly, Stein, Grover and Henningsen (1996) found that one of the primary ways that teachers contributed to cognitive decline of a task was by providing too much information and eliminating the challenging aspects of the task. Indeed, the point of student-centered instruction is to allow students to construct understanding through exploration and argumentation. As Mayer states, "Students need enough freedom to become cognitively active in the process of sense making, and students need enough 
guidance so that their cognitive activity results in the construction of useful knowledge" (p. 16, 2004). Research indicates that some structuring is warranted, but too much structuring can be detrimental. What is lacking in the current research is a description of how much or which types of scaffolds are effective in supporting justification activity.

\section{Linking Scaffolding to Forms of Reasoning}

When students engage in justification, they employ forms of reasoning, or modes of argumentation, within their justifications. A form of reasoning is the type of argument used in a proof or justification. For example, generic-example based reasoning is a form of reasoning in which a specific example is reasoned about in a general way to make salient the features of the example that generalize. Generic-example arguments can have varying degrees of generality. Other forms of reasoning include result-pattern reasoning, in which a pattern is identified and assumed to hold, and process-pattern reasoning, in which a pattern is identified and the process that generated the pattern is explained. Particular features of the task design or implementation of the task may have an impact on how students reason about the task and what forms of reasoning they employ in those justifications.

Lannin's (2005) work with $6^{\text {th }}$ grade students found that result-pattern reasoning frequently emerged when working with numerical values found in a table. When numbers were displayed as a list in a table, students attend to the patterns in the numbers rather than the underlying mathematical processes that generated those numbers. While resultpattern reasoning can be extended to process-pattern reasoning that explains why a pattern holds, on its own result-pattern reasoning is not a valid form of reasoning. Lannin (2005) also found that spreadsheets could be leveraged to promote generic-example 
justifications, although the role of the teacher was pivotal in directing students toward the generic aspects of their arguments.

Other researchers have also found that elements of a task impact how students reason about the task. Simon (1996) found that preservice teachers were likely to engage in transformational reasoning when working with area models in a geometry task.

Transformational reasoning is a form of reasoning in which a student performs dynamic physical or mental operations on objects to transform the objects. High school students exhibited transformational reasoning when manipulating triangles while using dynamic geometry software (Sherman, 2012). It seems likely that the type of task, the representation of the task, and the scaffolds used to support the task might all impact the forms of reasoning students use as they engage with the task.

\section{Theoretical Framework}

The theoretical framework underlying the analysis of this paper is the Mathematical Task Framework developed by Stein, Grover and Henningsen (1996). In this framework, a mathematical task is a classroom activity designed to focus student attention on a specific mathematical idea. Mathematical tasks can be characterized as having high or low cognitive demand, although the level of cognitive demand is likely to vary through the phases of task implementation. Cognitive demand can vary between individual learners, but for this work it is analyzed at a classroom level based on the previous experiences of learning community. There are two types of low-level cognitive demand tasks: memorization and procedures without connection to understanding, meaning, or concepts (referred to as procedures without connections.) A memorization task requires simple recall of a fact or definition, while procedures without connections 
tasks typically take the form of applying a known procedure to a routine problem, and explanations are typically confined to a description of the procedure. High-level cognitive demand tasks include procedures with connections to understanding, meaning or concepts (referred to as procedures with connections) and doing mathematics.

Procedures with connections tasks ask students to utilize a known procedure in a way that builds on conceptual understanding or meaning, such as connecting algebraic computation to pictorial representations. When doing mathematics, students are asked to explore relationships or draw mathematical conclusions based on tasks for which no procedure is known. Students must apply previous understandings in new ways and rely on sense-making to guide their problem solving process.

The mathematical task framework also describes three phases of task implementation (see

Figure 11): tasks as they are written, either by the teacher or in curricular materials; tasks as set up or described by the teacher; and tasks as they are enacted by students in the classroom, which ultimately lead to student learning. The connections between each of these phases are mediated by additional factors. Factors influencing the set-up include teacher goals, teacher content knowledge, and teacher knowledge of students. In this study, because the teachers themselves were responsible for the design of the written task, those factors also influenced the written tasks. The factors that influence implementation include classroom norms, task conditions, teacher habits and dispositions and student habits and dispositions. One major finding in Stein, Grover, and 
Henningsen's (1996) work was the frequent decline in cognitive demand of tasks over the phases of implementation.

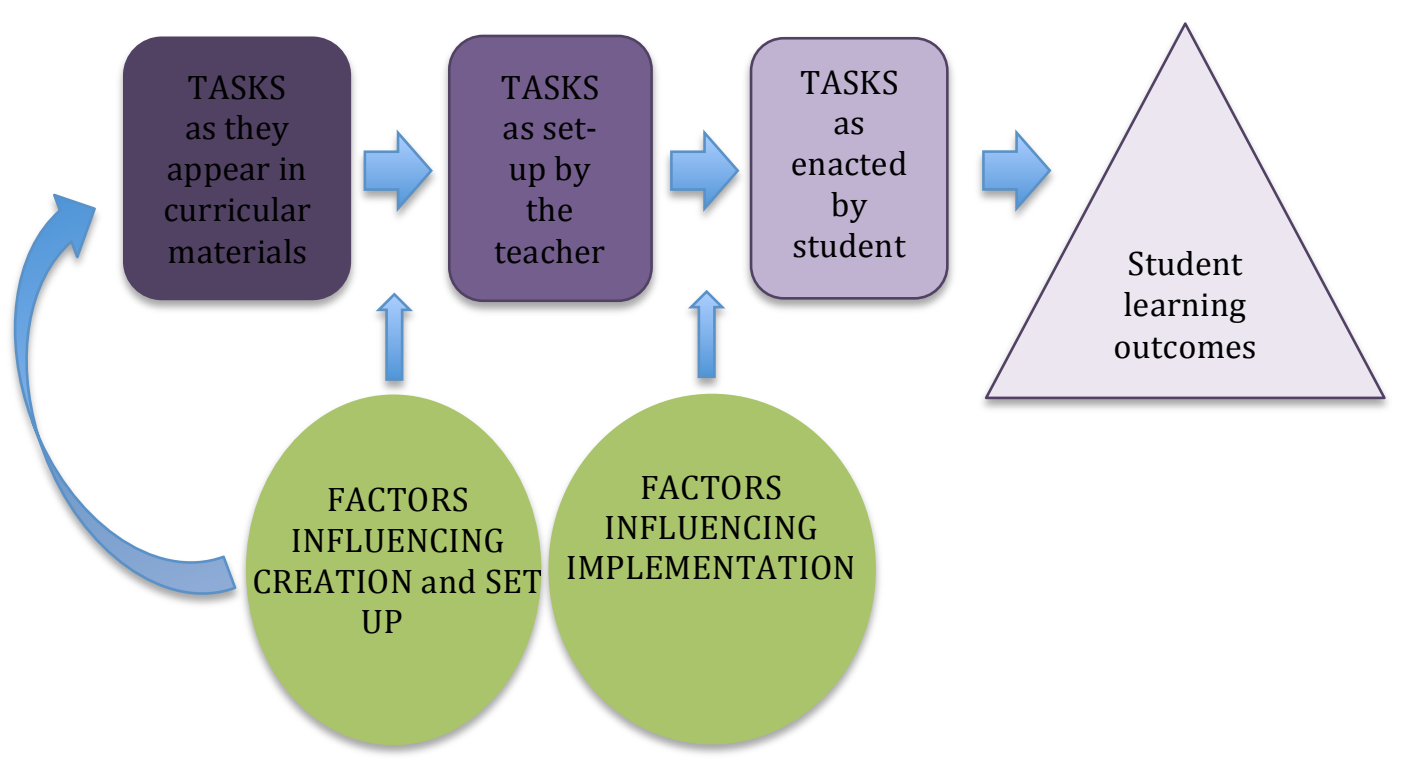

Figure 11: The stages on implementation for the mathematical task framework (Stein, Grover \& Henningsen, 1996)

This study examines all four phases of task implementation (tasks as they were written by the teachers, tasks as set up in their classrooms, tasks as implemented by students, and the subsequent student justifications). Analysis also includes the factors that influenced the creation of the written tasks, the set up of the written tasks, and the implementation of the written tasks. This study tracks the cognitive demand of the tasks over the phases of implementation with attention to how scaffolds impact the cognitive demand and forms of reasoning within student justifications.

\section{Research Questions}

This case study investigates the relationship between task scaffolding and subsequent student justifications. How does teacher scaffolding of open-ended, 
justification tasks relate to student forms of reasoning as they engage with the task? In particular, what are the relationships between tasks as written, tasks as set up by the teacher, and student forms of reasoning? Although it is recognized that scaffolds are helpful in structuring open-ended tasks, this targeted analysis will describe in more detail the types of scaffolds used in written task construction and implementation and the resulting student justifications. By linking scaffolds to forms of reasoning exhibited by students, this research could help inform the conjectured learning process by illustrating student justification activities associated with particular instructional tasks. Although this study is not intended as design research, it builds a base of knowledge to inform future development of instructional design to help guide teachers in supporting student construction of justification (Gravemiejer, 2004).

\section{Methods}

This investigation used a single case study design (Yin, 2009). One single teacher, Mr. Hummel, serves as the case. The case includes a description of his task implementation and revision over two years. The purpose of this study is explanatory; the detailed account of this particular case offers a compelling example of the relationships between task design, implementation, and subsequent student reasoning.

Mr. Hummel was a teacher participant in the Justification and Argumentation: Growing Understanding in Algebraic Reasoning (JAGUAR) project. The JAGUAR project was a bi-coastal research and professional development project that investigated the development of knowledge and pedagogy of middle school teachers to support justification practices in their classes. There were 12 teachers who participated in two years of the project. Each year consisted of a week-long summer workshop, three 
working-sessions during the school year, and four classroom implementations of common justification tasks.

Mr. Hummel taught $8^{\text {th }}$ grade in a midsized town in the northwest. The school population was approximately $75 \%$ minority, nearly $80 \%$ receiving free or reduced lunch, and $50 \%$ of the students at his school were classified as English Language learners, primarily native Spanish speakers. His classes were heterogeneously grouped. Prior to the start of the project, Mr. Hummel had taught 10 years all at the middle school level, the first two were middle school science and the rest were math. Mr. Hummel had participated in a number of previous professional development trainings, including development focused on promoting student discourse and training for students with English as a second language.

The questions for this research were initiated by Mr. Hummel himself. Given his experience with the first years' implementation of the task, he was very reflective regarding how the structure and implementation of the task contributed to student justifications. After the completion of the second year of the project, he collaborated with the author of this paper to formalize his reflections regarding the scaling task. This collaboration resulted in the submission of a practitioner article. This paper builds on the themes of the practitioner paper, but formalizes the investigation into an empirical study.

Mr. Hummel's Scaling Task was selected because of the strong relationship between task design and student reasoning. He revised the task in substantial and intentional ways between the two years. Both written tasks contained scaffolds to guide the students, but the nature of those scaffolds were very different. Additionally, these tasks both included strong student participation, which was necessary to evaluate the 
student reasoning. Although Mr. Hummel serves as the illustrating case for this paper, the empirical investigation for this paper took place among seven of the participating JAGUAR teachers. While his case presents the strongest evidence for connections between student reasoning and task scaffolds, the types of scaffolds demonstrated in this paper were consistent with the other participating teachers.

\section{Written-Task Analysis Methods and Data Sources}

The general statement of the Scaling Task was: "How does scaling various 2dimensional [and 3-dimensional] figures impact the perimeter, area, and volume? Why?" Notice that perimeter of a figure scales proportionally with its side-lengths (i.e. if the side lengths double, the perimeter doubles); however, the area of a figure is proportional to the square of the side lengths (i.e. if the side-lengths triple, the area increases 9 times). The central question for this task was open-ended: there was no prescribed method for students to investigate this relationship. Depending on a teacher's mathematical or justification goals, the task could be structured in many different ways to explore proportional reasoning, geometric representations, or algebraic modeling.

Although the central question of the task was prescribed, Mr. Hummel was able to design the written task around the central question himself based on the content goals of his classroom. Additionally, he was given the opportunity to revise and refine his task in the second year of the project, based on how students engaged with the task in the previous year's implementation and class composition.

The first stage of analysis focused on the task as written. Data for this stage included the written copies of the tasks given to the students in the classroom. The analysis was based on Stein, Grover and Henningsen's (1996) concept of task features, 
which are elements of a task that develop mathematical understanding and reasoning, and include the use of multiple solution strategies, multiple representations, and prompts for explanations. The goal of the task analysis was to describe the task features, particularly those related to promoting justification. For this analysis I generated an analytic framework of task features that pertain specifically to justification tasks. These task features included: (1) Examples - are students asked to explore individual examples, sets of examples, or general examples? (2) Representations - are students asked to consider specific types of representations or the links between representations? And (3) Justification - are students specifically prompted to justify? These task features are summarized in Figure 12.

Figure 12: Framework for analyzing task features of the written task

1) Examples: Does the task ask students to demonstrate an idea using examples?

a. Specific examples

b. Generalized examples

2) Representation: What types of representations (tables, graphs, diagrams, equations, narratives) are required for the task?

a. Does the task require a specific representation?

b. Does the task ask students to link representations?

3) Justification: How are students prompted to justify?

a. Does the task specifically ask for a justification?

b. At what stage(s) in the task are students asked to justify?

c. Does the task provide criteria for that justification? (Specific items that need to be included in the justification?)

In addition to the task features, the Factors Influencing the Creation and Set Up

were also analyzed. These factors include teacher goals, teacher content knowledge, and teacher knowledge of students (Stein, Grover \& Henningsen, 1996). The primary data source for this analysis was Mr. Hummel's reflective journal (See Appendix D for full 
reflective journal protocol). Prompts for the reflective journal included, "What is the primary goal for this lesson" and "What kinds of justifications do you expect students might produce as they work on the task for this lesson?" Data for this analysis also included discussions within the working sessions and interview questions pertaining to the task creation. The data sources were reviewed to locate passages concerning Mr. Hummel's designing of the scaling task. Instances within those passages were identified that pertained to the goals of the lesson, knowledge pertaining to the lesson, or knowledge about students relevant for the lesson.

\section{Task Set Up and Implementation Methods}

The second stage of analysis focused on the task as set-up in the classroom. Data for this stage of the analysis included classroom transcripts of the classroom implementation of the task. The analytic framework used for this analysis was based on Jackson and colleague's (2013) work on setting up complex tasks in middle grades classrooms. They identified four key elements of effective task set-up:

1. Key contextual features of the task scenario are explicitly discussed.

2. Key mathematical ideas and relationships, as represented in the task statement, are explicitly discussed.

3. Common language is developed to describe contextual features, mathematical ideas and relationships, and any other vocabulary central to the task statement that might be confusing or unfamiliar to students.

4. The cognitive demand of the task is maintained over the course of the setup.

Excerpts in the classroom transcript were identified that pertained to the set-up of the task. These excerpts were typically at the start of the class: however, because each task had multiple stages, the set-up for each stage was analyzed. The transcripts of each excerpt were reviewed and elements from the above framework were identified. 
Beyond the task set-up, the analysis also included a review of the factors influencing implementation. These included classroom norms, task conditions, and teacher and student habits and dispositions. The goal of this analysis was not a comprehensive description of classroom culture: instead the analysis was a comparison of the classroom cultures across the two years' implementations of the task. Rather than conducting an independent analysis, the results from Staples' (unpublished manuscript) previous analysis were summarized. Staples' work included a description of Mr. Hummel's general pedagogy and approach.

\section{Tasks as Enacted by Students and Student Learning Outcomes Analytic Methods}

The final phase of analysis focused on both the task as enacted by students and student learning outcomes. Many of the student justifications (which are considered "student learning outcomes") were presented during the enactment of the task. The student justifications (an outcome) impacted future enactments, thus the enactment and outcomes were analyzed collectively.

The scaffolds present during the enactment by students were analyzed in an iterative fashion. First, instances of whole-class scaffolding were identified. These scaffolds consist of instances in which Mr. Hummel provided students with mathematical resources that gave structure or information to guide the task. This could be done directly himself or by intentionally selecting students to present mathematical ideas. Next, the content of each scaffold was analyzed in terms of its use of examples, representations, or press for justification, as described previously.

Student justification activity was analyzed for each of the task implementations. Student justification activity was identified by the verbal justifications in the lessons and 
also included the written student work. The work was analyzed along two dimensions: (1) the form(s) of reasoning present in the work and (2) the completeness and validity of the argument.

The analytic framework for forms of reasoning used for this analysis was based on Larsen and James (manuscript in progress). These include:

- Single empirical examples

- Naïve empirical reasoning: invalid reasoning that a general result can be proven based on the existence of an individual case

- Counter-examples: a single counter-example disproves a general statement

- Sets of examples

- Dissimilar set of examples: invalid reasoning that a general result can be proven based on the existence of a set of "random" or "different types" of examples

○ Proof by exhaustion: every possible example is considered

- Result-pattern reasoning: a pattern is identified in a set of examples and assumed to hold

o Process-pattern reasoning: a pattern is identified in a set of examples and an explanation is given as to why the pattern must hold

- Generic Examples: a single example that is reasoned about generally. Generic examples lie on a continuum from examples with little generalization to almost fully generalized arguments.

- Transformational Reasoning: reasoning about mathematical objects by performing dynamic physical or mental transformations of objects

- Appealing to Known Information: appealing to arithmetic facts, algorithms, equivalent statements, or mathematical metaphors.

- Model-Based Reasoning: a specific sub-type of Appealing to Known Information, model-based reasoning is based on an agreed upon mathematical model, such as the long division algorithm.

\section{Results}

In this section I present the results of the analysis. I begin with a description of the results for the first year, which includes the written-tasks analysis, the set-up analysis, and the analysis of the implementation and student outcomes. Next, I present the same sets of analyses for the second year. 


\section{Results Year 1}

In the first year, students explored the side-lengths and areas for many different figures and many different scale factors (see Figure 13). According to Mr. Hummel, the primary mathematical goal was for the students to use numeric patterns to understand the relationship between scale factor and area of similar shapes. He stated, "Justification will give students the opportunity to elaborate on observations they make about numeric patterns, in order to construct the relationship between scale factor and area of similar shapes. Justification will also help students build the bridge between generalization and application." In addition, students were expected to generalize the relationship to any 2dimensional figure.

When reflecting on his expectations for how students would approach the task, he stated, "I believe students will mostly use examples when justifying ... using illustrations or diagrams. If they are comfortable working with algebraic expressions, they might use the area formulas for various 2D shapes to justify their reasoning.” Mr. Hummel anticipated the possibility of multiple representations of student reasoning within their justifications (diagrams, algebraic equations), and he believed that most students would use example-based reasoning in their justifications. 
Similar Shapes... of Fun!

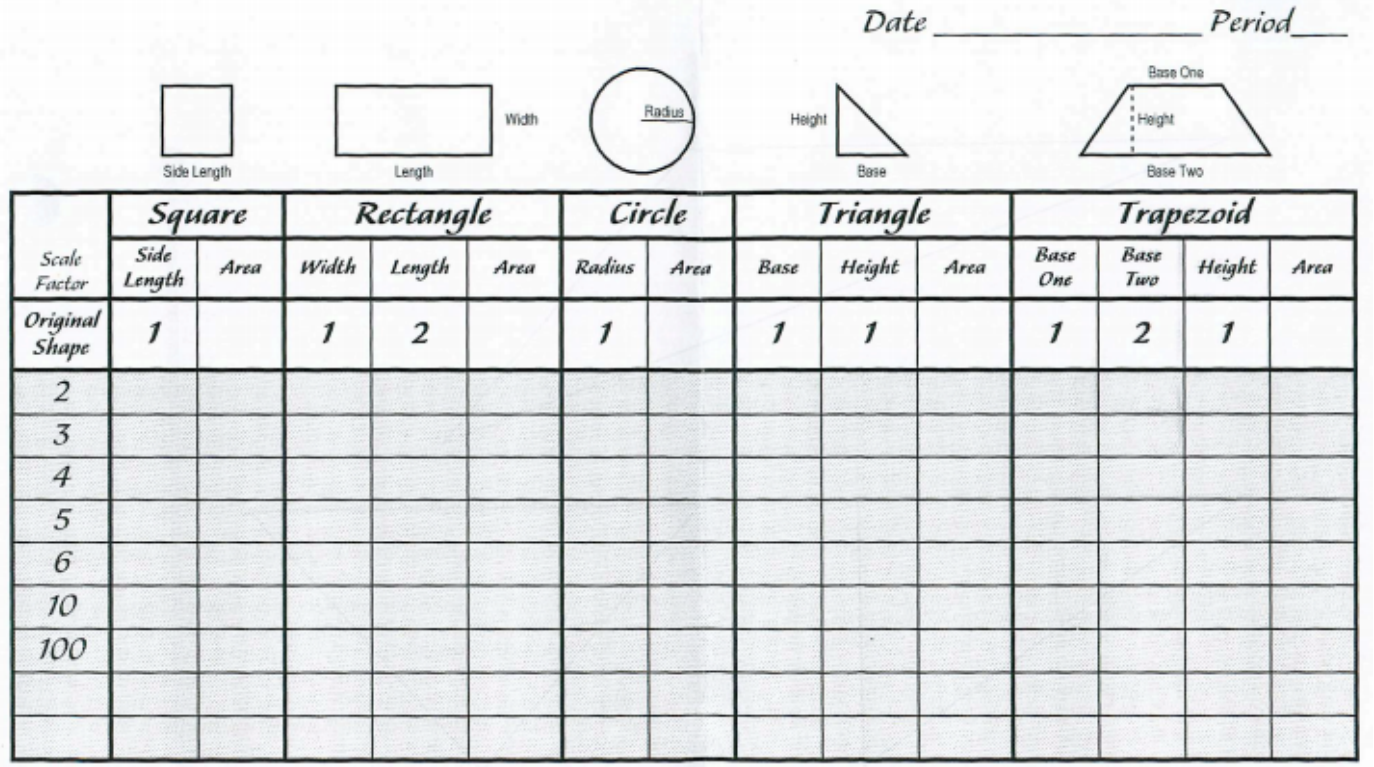

What relationship(s) do you notice between the scale factor and how the arca changes from the original shape to each new shape?

Explain how (and why if you can!) this relationship works. Use the back if necessary. 


\begin{tabular}{|c|c|}
\hline Souk Fator & $\begin{array}{c}\text { Triangle } \\
\text { Arca }\end{array}$ \\
\hline $\begin{array}{c}\text { Originad } \\
\text { Shrope }\end{array}$ & .5 \\
\hline 2 & 2 \\
\hline 3 & 4.5 \\
\hline 4 & 8 \\
\hline 5 & 12.5 \\
\hline 6 & 18 \\
\hline 7 & \\
\hline 8 & \\
\hline
\end{tabular}

1) Make an cbservation between seale factor and how the ares of the new shepe comperes to the area of the orioinal triengle

\begin{tabular}{|c|c|}
\hline Sack fioto & $\begin{array}{c}\text { Trapezovid } \\
\text { Area }\end{array}$ \\
\hline $\begin{array}{c}\text { Oriqued } \\
\text { Shaye }\end{array}$ & 1.5 \\
\hline 2 & 6 \\
\hline 3 & 73.5 \\
\hline 4 & 24 \\
\hline 5 & 37.5 \\
\hline 6 & 54 \\
\hline 7 & \\
\hline 8 & \\
\hline
\end{tabular}

1) Malve an observation batween scale facter and how the area of the new shepe compares to the ares of the criginal trapezcid.

2) Fil in the missing aress based on the relationship.

SUMMARY: Explain in your own words the relationship between the scale factor and area for any shape?

APPLICATION: Find the area of the shape below if it is enlargod by a scale facter of 4 . show your wark.

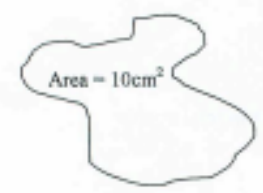

Figure 13: Task as written in year 1

The written task was intentionally designed to assist students in finding

relationships among numeric patterns, which aligned with the goal of the task (Figure 13 displays the task as written for the first year's task). The first part of the task led students to explore a patterned set of examples: each row on the spreadsheet corresponds to a specific scale factor and each section of columns corresponded with a specific shape. Once students completed the table, students were then asked to form a generalization. 
Students were asked to apply their conjecture to a generalized shape in the final stage of the task.

The written task never explicitly asked for a justification: instead students were instructed, "Explain how (and why if you can!) this relationship works." This prompt did not explicitly require students to justify the relationship: instead the prompt requires students to "explain how" the relationship works.

Stein, Smith, Henningsen and Sliver (2009) would consider the task as written to be "procedures with connections," which is a high-level cognitive demand task.

Procedures with connections tasks "focus students' attention on the use of procedures for the purpose of developing deeper levels of understanding of mathematical concepts and ideas." In this case, the procedure was using familiar formulas to calculate areas of twodimensional figures. Students then used those calculations to connect the relationship between the area of a figure and the area of a congruent, scaled up figure and to apply that reasoning to a general shape.

\section{Task Set-Up Year 1}

In the first year of the task, Mr. Hummel spent nearly 15 minutes setting up the task. Much of the scaffolding Mr. Hummel introduced in his set-up aligned with Jackson and colleagues' (2013) framework for high-quality set-ups for complex tasks he collaborated with students to establish common understanding of vocabulary, procedures, and ideas needed for the task. At the start of the set-up for the Scaling Task, he reminded students of their experience scaling figures in a previous scaling task of 2-D figures. In that conversation, he guided students toward the definitions of similar and scale factor, two key vocabulary terms needed for the task. 
Next, Mr. Hummel demonstrated how to scale up a rectangle. He explained, "If I have a scale factor of 4 , I make everything 4 times as big. So this gets 4 times as tall, and this gets 4 times as long.... So we are going to explore what happens to the area when we increase things by a scale factor." To which a student responded, "Oh, I get it." The student's indication of understanding demonstrated that demonstrating scaling was likely an appropriate scaffold: the student developed understanding of a necessary skill to access the task.

Finally, to be sure that the class had access to the procedures necessary for the task, Mr. Hummel reviewed the area formulas of each of the shapes in the Scaling Task. The following interchange was typical of the interaction:

Mr. Hummel: Ok, our first rectangle, our original rectangle is a 1 by 2 . So fill in the area of that first rectangle. So Greg, what is the area of that first rectangle?

Greg: 2

Mr. Hummel: 2. Why?

Greg: Um, you multiply the one times 2.

Mr. Hummel: Yeah, one times 2. So the first rectangle is just one times two, would be two.

The review of area formulas included student explanations of steps in their procedures. These elements of high quality set-up may be in part due to his extensive experience and training when working with English Language Learners. While all of the students in his class were no longer receiving support as non-native speakers, the majority of the students in his class did not have English as their native language. Mr. Hummel's direct and intentional focus on mathematical vocabulary and context features when setting up 
the task were especially helpful for students who did not speak English as a native language.

Although Mr. Hummel's set-up included many of the elements of strong set-ups identified by Jackson and colleagues (2013), his set-up also included over-scaffolding that contributed to the decline in the cognitive demand of the task. Once students were given a copy of the task and asked to begin working, Mr. Hummel saw a common student error and chose to intervene. He saw that students were computing the area of the scaled up figure by multiplying the area of the original figure by the scale factor rather than computing the new area using the scaled up side lengths (see Figure 14).

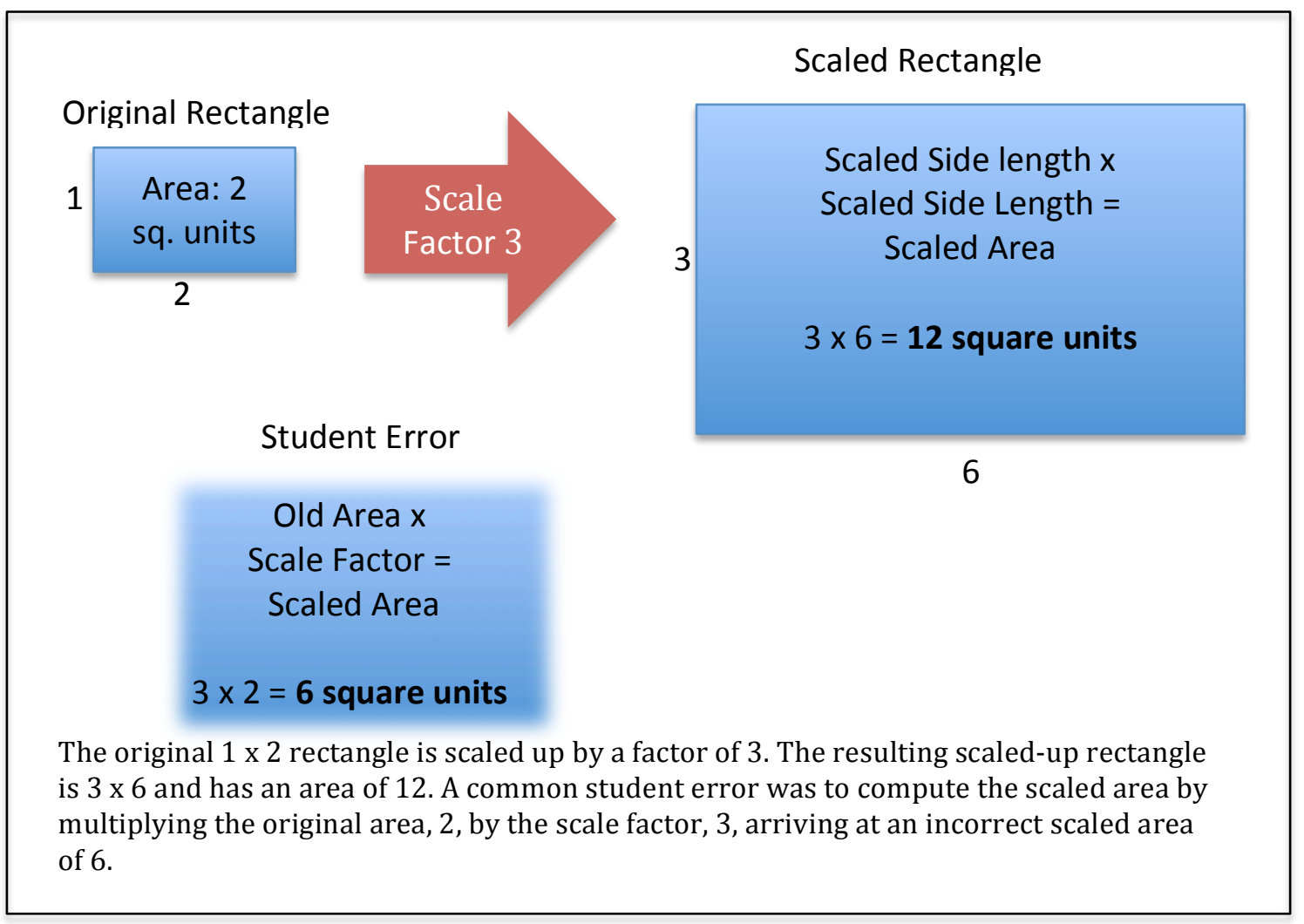

Figure 14: Illustration of common student misconception. 
Mr. Hummel knew that if the students computed the scaled-up area incorrectly, they would not be able to discover the correct relationship based on a pattern of incorrect values in their table. He instructed the class in the following way:

Just to be really, really, really clear. Every eye up here please. Stop whatever you are doing. I need your eyes up here. Just to be really clear. You can't just multiply the areas by the scale factor. It is not right. Ok. Whatever you have for the areas, you can't just multiply by 3 for the third row and 4 for the fourth row. You actually have to calculate the areas given those side lengths. Does that make sense?

The relationship between scale-factor and area was a critical mathematical idea for the scaling task. By directly telling students how to calculate the scaled-up area, the cognitive demand of the primary task declined from procedures with connections to procedures without connections. As written, the task was one of "Procedures with Connections" (Stein, Grover \& Henningsen, 1996), because although students needed to use proscribed procedures, the procedures were being used to develop conceptual understanding of the relationship between scaling and area. However, by restricting students to follow a particular procedure without a strong explanation why, the use of procedures became "opaque with respect to the underlying concepts" (p.6, Stein et al., 2000), and thus reduced the cognitive demand of this portion of the task to "Procedures without Connections." Instead of telling them the procedure, he might have maintained the cognitive demand of the task by instead taking up their misconception and asking them to verify it using a different approach, such as through the use of a diagram. 


\section{Factors Influencing Implementation Year 1}

According to Stein, Grover and Henningsen (1996) the primary factors that influence task implementation are classroom norms, task conditions, and teacher and student habits and dispositions. While a detailed description of these factors is beyond the scope of this paper, a brief synopsis provides both a context for the enactment of the task and evidence of the consistency of classroom culture between both years of the task. These results align with those found by Staples' (unpublished manuscript).

Mr. Hummel's classroom was arranged with desks in groups of four, and he used both whole-class and small-group formats. The first year's implementation of the Scaling Task took place over 136 minutes of instructional time, with more time spent in groups than whole class.

In the small group time Mr. Hummel worked directly with students' mathematics. He commonly focused on an individual student for an extended period of time, questioning and helping to develop a particular student's idea. He occasionally asked other students at the table to weigh in on the idea or to share their own ideas. His work with students focused closely on the written task: he rarely discussed mathematical ideas outside of the specific task questions, with the exception of explicating background content needed to access the task. Students in the class generally exhibited a high level of engagement, and worked both individually and collectively to complete the written task. Students had access to and made use of calculators while completing the task.

After the initial set-up, whole class time was used primarily to "share-out" student strategies, making use of a document camera to display student work. In this lesson, Mr. Hummel had several whole-class "sharing" sessions in which students described the 
results they found in their tables and how they arrived at their results. Mr. Hummel asked students whether they agreed with the results, but did not use whole-class time for lengthy discussions or to improve incomplete solutions.

\section{Task Enactment and Student Outcomes Year 1}

Many students in the class arrived at a conjecture for the relationship between areas of scaled up figures and the original areas, however none of the students offered a valid justification for this relationship. For example, in one extended interaction Mr. Hummel helped facilitate a discussion that led a pair of students to a correct conjecture, but the students were not strongly pressed to explain why their conjecture held. At the start of the interaction, the pair of students noticed that the original area divided evenly into all of the scaled-up areas:

Mr. Hummel: Okay, so you guys have filled out the whole table? Alright. So now, so what about the first question. So what did you notice? What relationship?

Student 1: The original area is factors of all of the other areas.

Mr. Hummel: Ok, so what do you mean?

Student 2: So 1 [points to the area of the original square] is a factor of all of these [points to the column that contains the areas for the scaled up squares]. 2 [points to the area of the original rectangle] is a factor of all of these [points the to column that contains the areas for the scaled up rectangles]. 3.14 [points to the area of the original circle] is a factor of all of these [points to the column that contains the areas for the scaled up circles], .5 [points to the area of the original triangle] is a factor of all of these [points to the column that contains the areas for the scaled up triangles]., and 1.5 [points to the area of the original trapezoid] is a factor of all of these [points to the column that contains the areas for the scaled up trapezoids].[Figure 15 illustrates the regions of the table to which the student is referring.]

Mr. Hummel: Nice! 


\begin{tabular}{|c|c|c|c|c|c|c|c|c|c|c|c|c|c|c|c|}
\hline \multirow{3}{*}{\multicolumn{2}{|c|}{$\begin{array}{l}\text { Sealt } \\
\text { Factor } \\
\end{array}$}} & \multicolumn{2}{|c|}{$\operatorname{son} 4 \cos$} & \multicolumn{3}{|c|}{ Lever } & \multirow{2}{*}{\multicolumn{5}{|c|}{ Circle }} & \multirow{2}{*}{\multicolumn{4}{|c|}{ Trapezoid }} \\
\hline & & \multicolumn{2}{|c|}{ Square } & \multicolumn{3}{|c|}{ Rectangle } & & & & & & & & & \\
\hline & & $\begin{array}{l}\text { Sild } \\
\text { Length }\end{array}$ & Area & widh & Length & Area & Rudius & Areat & Base & Height & Area & $\begin{array}{l}\text { Basse } \\
\text { Ome }\end{array}$ & $\begin{array}{c}\text { Base } \\
\text { Tweo }\end{array}$ & Height & Areat \\
\hline & $\begin{array}{c}\text { Original } \\
\text { Shape } \\
\end{array}$ & 1 & | & 1 & 2 & 2 & 1 & 3.14 & 1 & 1 & .5 & 1 & 2 & 1 & 1.5 \\
\hline 4 & 2 & 2 & 4 & 2 & 4 & 8 & 2 & 12.56 & 2 & 2 & 2 & 2 & 4 & 2 & 6 \\
\hline 9 & 3 & 3 & 9. & 3 & 6 & 18 & 3 & 28.26 & 3 & 3 & 4.5 & 3 & 6 & 3 & B.5 \\
\hline 8 & 4 & 4 & 16 & 4 & 9 & 32 & 4 & 50,24 & 4 & 4 & 8 & 4 & 8 & 4 & 24 \\
\hline 25 & 5 & 5 & 25 & 5 & 10 & 50 & 5 & 78.5 & 5 & 5 & 12,5 & $S$ & 10 & 5 & 37.5 \\
\hline 36 & 6 & 6 & 36 & 6 & 12 & 72 & 6 & 113,04 & 6 & 6 & 18 & 6 & 12 & 6 & 54 \\
\hline 100 & 10 & 10 & 100 & 16 & 20 & 200 & 10 & 314 & 10 & 10 & 50 & 10 & 20 & 10 & 150 \\
\hline 14000 & 100 & 100 & 10,000 & 160 & 200 & 20,000 & 100 & 31400 & 106 & 100 & 5000 & 100 & 200 & 100 & 15,000 \\
\hline 400 & 20 & 20 & 400 & 20 & 4 & 800 & 20 & 1256 & 20 & 20 & 200 & 20 & 46 & 20 & 660 \\
\hline 2,500 & 50 & 50 & 2500 & 50 & 100 & 5000 & 50 & 7850 & 50 & 50 & 1250 & 50 & 100 & so & 3750 \\
\hline
\end{tabular}

Figure 15: Student work for scaling of shapes. The yellow highlighted regions are the original areas, and the red highlighted columns are the areas for the scaled figure.

Notice that these students are relying on result-pattern based reasoning. They see a pattern in the table of values (as indicated by their description of the columns), and they conclude that the pattern will hold.

Continuing in the conversation, Mr. Hummel directed the pair's attention to the row in the table of scale-factor 2, and by examining the entries in the table the students concluded, "That the scale factor of 2 , the area is 4 times bigger than the original area." Next Mr. Hummel directed their attention to other scale factors, resulting in the following exchange. (The student work being referred to is color coded in Figure 16.)

Mr. Hummel: So what did you guys notice?

Student 2: That this number [points to scale factors in green] squared equals that one [points to column in blue]. And this [scale factor squared in blue] multiplied by the original area equals the new area.

Mr. Hummel: Alright, so explain how, how does it work, like for 10 for like a trapezoid?

Student 1: So 10 squared equals 100 . Multiply that by 1.5 , is 150 .

Mr. Hummel: Alright, so in your own words, what is the pattern. What did you notice? What is the relationship? 
Student 2: That whatever you are increase the scale factor by, you square that number, multiply by the original area, and that gives you the new area of the new shape.

Mr. Hummel: Alright! (said in a complimentary tone)

\begin{tabular}{|c|c|c|c|c|c|c|c|c|c|c|c|c|c|c|c|}
\hline & \multirow[b]{3}{*}{$\begin{array}{l}\text { Seatle } \\
\text { Finctor }\end{array}$} & \multicolumn{2}{|c|}{ son ung } & \multicolumn{3}{|c|}{ unve- } & \multicolumn{5}{|c|}{-} & \multirow{2}{*}{\multicolumn{4}{|c|}{ Trapezoid }} \\
\hline & & \multicolumn{2}{|c|}{ Square } & \multicolumn{3}{|c|}{ Rectangle } & \multicolumn{2}{|c|}{ Circle } & \multicolumn{3}{|c|}{ Triangle } & & & & \\
\hline & & $\begin{array}{c}\text { Side } \\
\text { Length }\end{array}$ & Areat & width & Length & & & & & & & $\begin{array}{c}\text { Base } \\
\text { Bunce }\end{array}$ & $\begin{array}{l}\text { Base } \\
\text { Twe }\end{array}$ & Height & Areat \\
\hline \multirow[b]{2}{*}{4} & $\begin{array}{c}\text { Original } \\
\text { Shape }\end{array}$ & 1 & & & & 2 & ime & sth & origir & nal ar & a 5 & 1 & 2 & & 1.5 \\
\hline & 2 & & & 2 & 4 & 8 & 2 & 12.56 & 2 & 2 & 2 & 2 & 4 & 2 & 9 \\
\hline \multirow{2}{*}{ a } & 3 & & & 3 & 6 & 18 & 3 & 28.26 & 3 & 3 & 4.5 & 3 & 6 & 3 & BS \\
\hline & 4 & & $66^{2}$ & 4 & 9 & 32 & 4 & 50,24 & 4 & 4 & 8 & 4 & 8 & 4 & $2 t$ \\
\hline 8 & & 5 & 25 & 5 & 10 & 50 & 5 & 78.5 & 5 & 5 & 12,5 & 5 & 10 & 5 & 35 \\
\hline 25 & 6 & 6 & 36 & 6 & 12 & 72 & 6 & 13,04 & 6 & 6 & 18 & 6 & 12 & 6 & 5 \\
\hline \multirow[t]{2}{*}{100} & 10 & 10 & 100 & 16 & 20 & 200 & 10 & 314 & 10 & 10 & 50 & 16 & 20 & 10 & 150 \\
\hline & 20 & 160 & 10,000 & 160 & 200 & 20,000 & 100 & 31400 & 106 & 100 & 5,000 & \multirow{2}{*}{\multicolumn{4}{|c|}{ Equals new area }} \\
\hline $40 x$ & \multirow{2}{*}{\multicolumn{4}{|c|}{ Scale factor squared }} & C & 800 & 20 & 1256 & 20 & 20 & 200 & & & & \\
\hline $0 \mathrm{~cm}$ & & & & & 0 & 5000 & 50 & 7850 & 50 & 50 & 1250 & 50 & 100 & so & 3750 \\
\hline
\end{tabular}

Figure 16: Student work of the scaling of shapes. The green column indicates the scale factor. The blue column is the scale factor squared. The brown cells and arrows display the steps in the computation of the area of a scaled up trapezoid.

This was another example of result-pattern reasoning. Like the students in Harel's study, these students were "relying on the regularity of the results of their calculations" (p. 11, 2001) to explain their claim, which he classified as resultpattern reasoning. Their results were based on a computation, but the computation originated from observing a regular pattern within the table. This is not considered process-pattern reasoning because the students do not display an understanding of how their computation connects to an underlying process independent from their set of examples.

To follow up this pair's claim, Mr. Hummel asked them why the relationship held:

Mr. Hummel: So now I'm going to challenge you to see if you can figure out, uh, why. (looks at both students) 
Student 1: What? [laughs]

Mr. Hummel: (to a third student in the group) So, did you understand the relationship? What they are saying it is?

Notice that rather than spending focused time pressing the pair to explain why the computation was valid and generate a complete justification, he instead turned to the third group-member to see if that student understood the conjectured procedure. In this way, Mr. Hummel focused on having a community understanding of the conjecture, but did not focus on pressing the students for a more complete justification.

Several other groups arrived at an alternate, valid procedure for finding the area of the scaled up figure. Rather than considering the scale-factor squared multiplied by the original area, students multiplied the scale-factor by the original area and then again by the scale factor. A student explains the procedure to find the area of a rectangle (of original area 2) that has been scaled by 15 :

Mr. Hummel: If I gave you like the $15^{\text {th }}$ [scale factor], what would you do?

Student 7: The 15th, times-

Student 8: [simultaneously] 15 plus 15.

Student 7: Well, yeah, 15 times 2, which would be whatever that other number would be, and then 15 times that number which would give you the answer.

In particular, Student 8 has abstracted the process so that it is no longer "scale factor times original area time scale factor." In this special case where the original area is 2 , the student conceptualized the computation as "(scale factor plus scale factor) times scale factor." This procedure was invented by looking at patterns in the numbers of the table, because they cannot be connected in meaningful ways to either geometric or algebraic properties of scaling. This reasoning is a weak form of result-pattern reasoning: the 
students see a regular pattern in the results of their computations and assume it must hold. The reasoning is weak because they never fully state a generalized version of their claim.

In their written work, very few students offered any explanation for the relationship between scale factor and area. Of the 24 students, 7 left the explanation portion blank. 12 students gave partial explanations such as "they both increase" (See Figure 17).

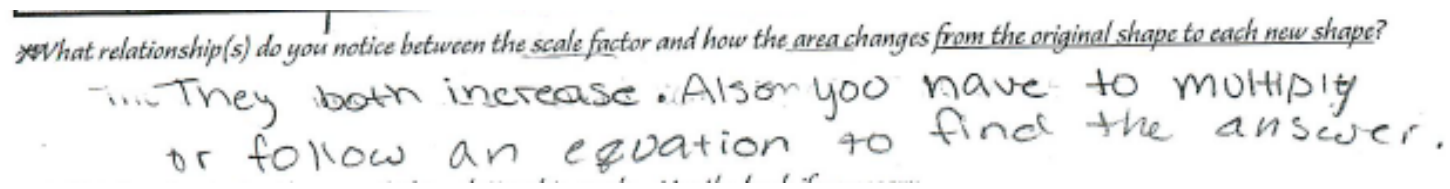

Figure 17: Student partial explanation for relationship between area and scale factor 
Five students stated the correct procedure to find a new area, but none of those gave a justification for the relationship. For example, the student below recognized that the area of the scaled up figure would be equal to the area original figure multiplied by the square of the scale-factor (see Figure 18). However, the student did not support his reasoning with either a geometric or algebraic argument.

SUMMARY: Explain in your own words the relationship between the scale factor and area for any shape?

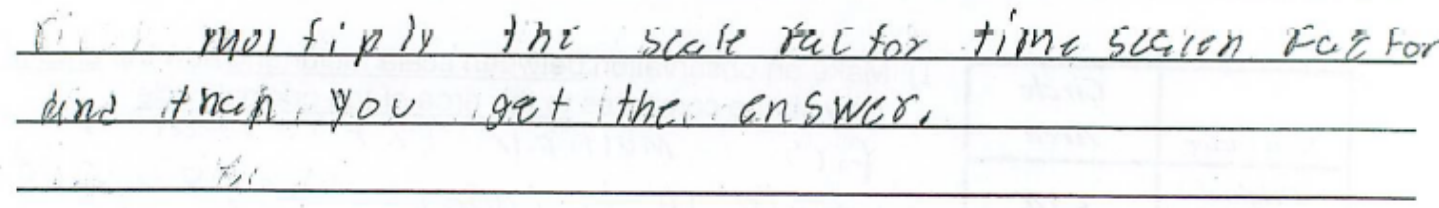

APPLICATION: Find the area of the shape below if it is enlarged by a scale factor of 4 . Show your work.

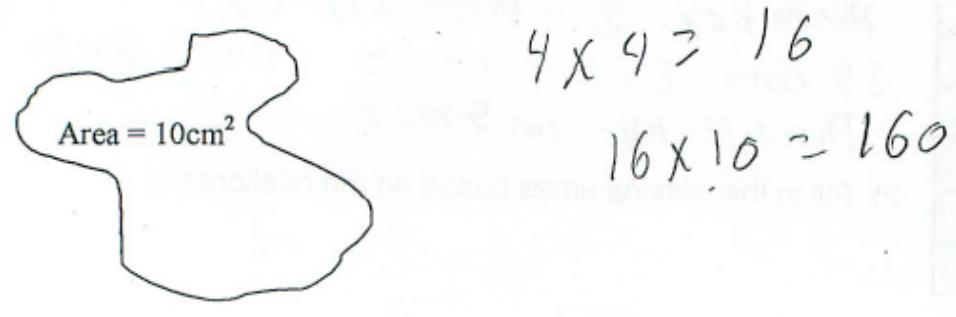

Figure 18: Student statement of the relationship between area and scale factor

In summary, in the first year of the Scaling Task the written task was scaffolded so that students filled out a table for the areas and perimeters of different shapes with different scale-factors. In the set-up of the task, Mr. Hummel provided further scaffolding that caused a decline in the cognitive demand of the task: he directed students to find a scaled up area using a particular procedure to ensure they arrived at the correct value. Many students were able to find a pattern within their table, but they were not able to justify why the pattern held. Much of the student reasoning was typified by result-pattern 
reasoning: identifying a computational pattern based on examples and assuming that the pattern would hold.

\section{Results: Year 2}

After the first implementation of the task, Mr. Hummel reflected, "I think that ... the task was too guided and not open-ended enough for these justifications to occur... I felt like I moved on from the squares (and rectangles) too quickly and the way that we designed and implemented this task didn't allow for enough exploration and discussion about why the scale factor/area relationship works." Based on his experiences with the task in the first year, Mr. Hummel made a number of revisions to the written task to encourage students to better justify why the relationship between the scale factor and the area held. The revisions began with a shift in the mathematical goals away from generalizing based on number-patterns and toward understanding why the pattern existed using both algebraic and geometric representations. Mr. Hummel commented, "The goal last year was for students to be able to generalize this relationship, and the focus this year will be more on students understanding the relationship" [emphasis added].

To this end, the written task for the second year included scaffolding that helped students understand the scaling of a single shape, Squary, for various scale factors. Students were asked to justify every answer, even in the early, computational stages of the task. Additionally, students were explicitly required to provide a convincing argument as to why their rule for scale factor always worked. Students were prompted to include a picture or diagram to help support their arguments.

After the investigation with Squary, students were asked to explore other shapes. Mr. Hummel explained, "The second part of the lesson will then build upon what they've 
discovered with Squary to extend their reasoning to other 2D shapes (with a 3D option)." A copy of the written task for the second year is in Figure 19. 


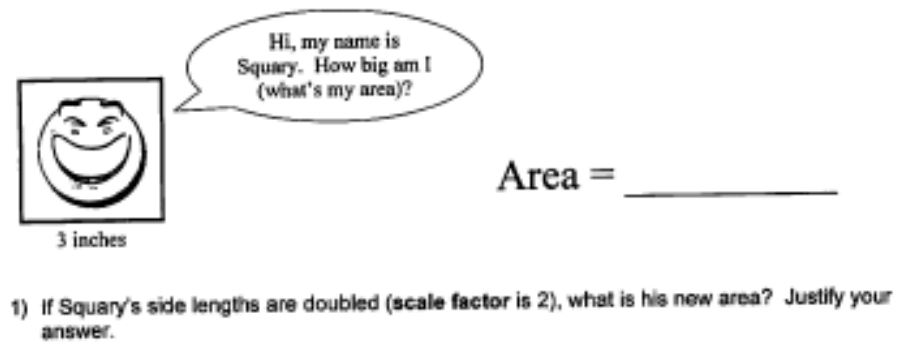

2) If Squary's original side lengths are tripled (scale factor is 3), what is his new area? Justify your answer.

3) Whoth your group's assigned scale factor, calculate Squary's new area and add it to the table below. Justify your answer.

Original Area:
\begin{tabular}{|c|c|c|c|c|c|c|c|c|c|}
\hline $\begin{array}{c}\text { Scaiale } \\
\text { Factor }\end{array}$ & 2 & 3 & 4 & 5 & 6 & 7 & 8 & 9 & 10 \\
\hline $\begin{array}{c}\text { Squarys } \\
\text { Neww Area }\end{array}$ & & & & & & & & & \\
\hline
\end{tabular}

4) What is the relationship between Squary's original area, the scale factor, and his new area?

5) Write a rule for how to find Squary's new area for any scale factor. Explain how your rule works.

6) Provide a convincing argument that clearly shows $\underline{w h y}$ it always works. Include a picture or diagram that helps support your argument.

7) Summarize - Complete the sentence below:

To obtain the new area of any square, increased by any scale factor you have to

Figure 19: Written task for the Scaling Task in Year 2 (questions 5-7 were written on the back of the sheet)

The task as written in the second year could also be classified as "Procedures with Connections." Again, students were asked to use known procedures for scaling figures and area formulas for computing area with the goal of gaining a deeper understanding of a relationship between area and scale factor. However, the scaffolding to support this 
exploration differed significantly from the first year's task. The second year's task had explicit scaffolds to guide the exploration of a single example in detail rather than focusing on finding relationship in numerical patterns.

\section{Task Set-Up Year 2}

The task set-up in the second year was minimal compared to the first year. Unlike the first year, Mr. Hummel did not set-up the mathematical ideas or relationships needed to access the task. Mr. Hummel had a couple of brief discussions about the definitions of some key terms, such as justify and affect. Unlike the previous task, he did not explicitly review area formulas, but instead responded to students in the moment when they were working with a particular figure. In terms of Jackson et al.'s (2013) framework, Mr. Hummel included only a minimal number of elements associated with high-quality set-up of a task: his inclusion of the defining of specific vocabulary terms.

In the second year's set-up of the Scaling Task, there was no decline in the level of cognitive demand of the task during the set-up. In the first year he directly told students that the scaled-up area could not be computed by multiplying the previous area by the scale factor. In the second year his approach was more student-led. After students had done a single example on their own of doubling the side lengths and computing the area of a square with side-length 3 , he had the following conversation:

Mr. Hummel: Okay. Don't look at your papers right now. Just look up here. If somebody asked me and I had to answer right away- and somebody said you're going to take the side lengths and double it. What's going to happen to the area? My response might be?

Student: It doubles.

Mr. Hummel: Right. Why?

Student: Cause you just doubled it.

Mr. Hummel: Cause you just doubled it. Was this area 18? [The original area was 9.]

Class: No. 
Mr. Hummel: No. What if I said you're going to the take the side length and triple it. I might say well, the new area is going to be three times, right? But is it?

Class: No.

Mr. Hummel: No. It's not. Okay, so you're finding that the areas are not just doubled and tripled. So something's happening here. So when you have a scale factor of 2, it's not twice as big as far as area goes. Scale factor of 3 isn't 3 times as big.

In this passage Mr. Hummel addressed the common misconception from the previous year, but unlike the previous year he did not give a proscriptive procedure to address the

problem. Instead he had students refute the faulty conjecture with their own evidence and positioned the question as one for further exploration. With this scaffold he was able to direct student attention to a common misconception while still maintaining the level of cognitive demand of the task.

\section{Factors Influencing Implementation Year 2}

The classroom norms, task conditions, and teacher and student habits and dispositions were similar to the previous year's task implementation. Class time was still split between whole-class and group-work time, with more time in group-work. The total amount of class time spent on the scaling task in the second year was 136 minutes, compared to 134 minutes in the first year. Like the previous year, Mr. Hummel focused on developing students' mathematics during group work. He would work for extended periods with a single student or a group of students, often asking for input but not directly scaffolding conversations between students. His whole-class time was spent reporting student solutions. These results align with those identified by Staples' (unpublished manuscript). 


\section{Task Enactment and Student Outcomes Year 2}

The justifications students produced during the second year of the task were more varied and complete than those of the first year. Although there were only a handful of complete justifications in the second year, they included a variety of different forms of reasoning, including generic examples of different degrees of generality, model-based reasoning and transformational reasoning.

One student, Nate, generated a generic-example justification that utilized transformational reasoning. Nate's pictorially represented argument for the relationship between the area of the original square and a scaled-up square is presented in Figure 20. The original square was in the bottom left corner of his diagram, and Nate explained that when scale it up by seven, "It will be seven times as big in both directions" and thus the total new area will be seven times seven, or 49 times the original area. This justification relied on generic-example based reasoning, because although he illustrated his argument using a single example of a scale-factor of 7 , he reasoned generally about how the relationship would hold for any scale factor. His justification also relied on transformational reasoning: he envisioned the expanding square and conceptualized the copies of the original square within the scaled-up square as it expanded.

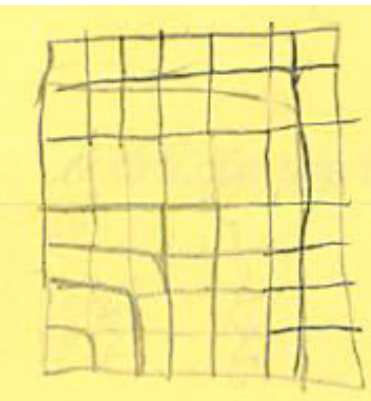

Figure 20: Nate's generic-example argument for the area of a scaled-up square 
This justification served as an important model for subsequent justification activity of other students in the class. Mr. Hummel intentionally selected Nate to present his argument to the whole class. He explained his rationale: "[Nate] not only had a general rule, but was also able to present a convincing argument to the class with a picture and explanation to support why the rule worked. I really liked this because I felt it was key to be able to extend the task into different shapes for the entire class to be on board with this generalization and to have a good visual representation for why it worked." Mr. Hummel's choice to have Nate share his justification was a way for Mr. Hummel to scaffold future student justifications.

For example, in the second phase of the task students chose a shape other than a square in their exploration. Kay modeled his justification for the scaling of a parallelogram directly from Nate's justification from the previous day of class (Figure 21).

Kay: Alright, I got original area times scale factor squared.

Mr. Hummel: Okay. And can you explain your picture? Why that works there?

Kay: Uh- this is the original one right there [pointing to the bottom left parallelogram]. That one is the original and then times 2, 3, 4... [outlining each scaled up parallelogram on his drawing as he counts] And then times 3 squared would be 9 .
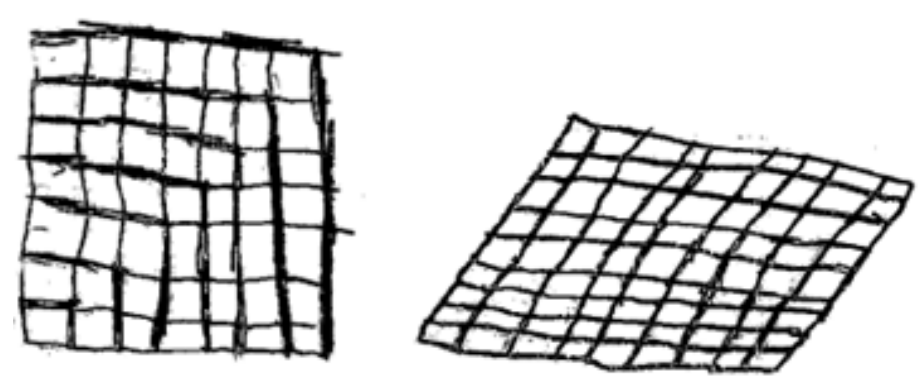

Figure 21: Kay's picture of a scaled up square and parallelogram 
This student also displayed transformational and generic-example forms of reasoning in his argument that the area of a parallelogram scaled by a factor of three would have 9 times the area. This justification was also model-based: Kay was basing his justification on the model that was constructed by Nate in the previous class period. In this case the justification was based on both the scaffolding of the written task and the scaffolds that occurred in the implementation. Kay based his justification on his understanding of how scaling affected the area of the square: thus an important component was previous exposure to the square in the flow of the written task. Also, Kay's work was based on scaffolds during the implementation of the task: Nate's presentation became a model for Kay's justification of the parallelogram.

The strength of the justifications in class was mirrored by stronger written justifications compared to the first year's written justifications. Of the 31 students who submitted work, only 3 students left the justification portion blank. Of the remaining, 14 gave incomplete or incorrect arguments (8 of which were "pseudo" algebraic arguments that contained a valid algebraic expression but insufficient reasoning for a justification). Nine students gave a algebraic argument with a form of reasoning best characterized as “Appeals to known information.” The student in Figure 22 provided a typical justification of this kind, in which she described the process for computing the area of a scaled-up square whose original side length was 3 . It was general in the sense that it held for any scale factor, and it appealed to known information because relied on the formulas for scaling side-lengths and area as its warrant. 

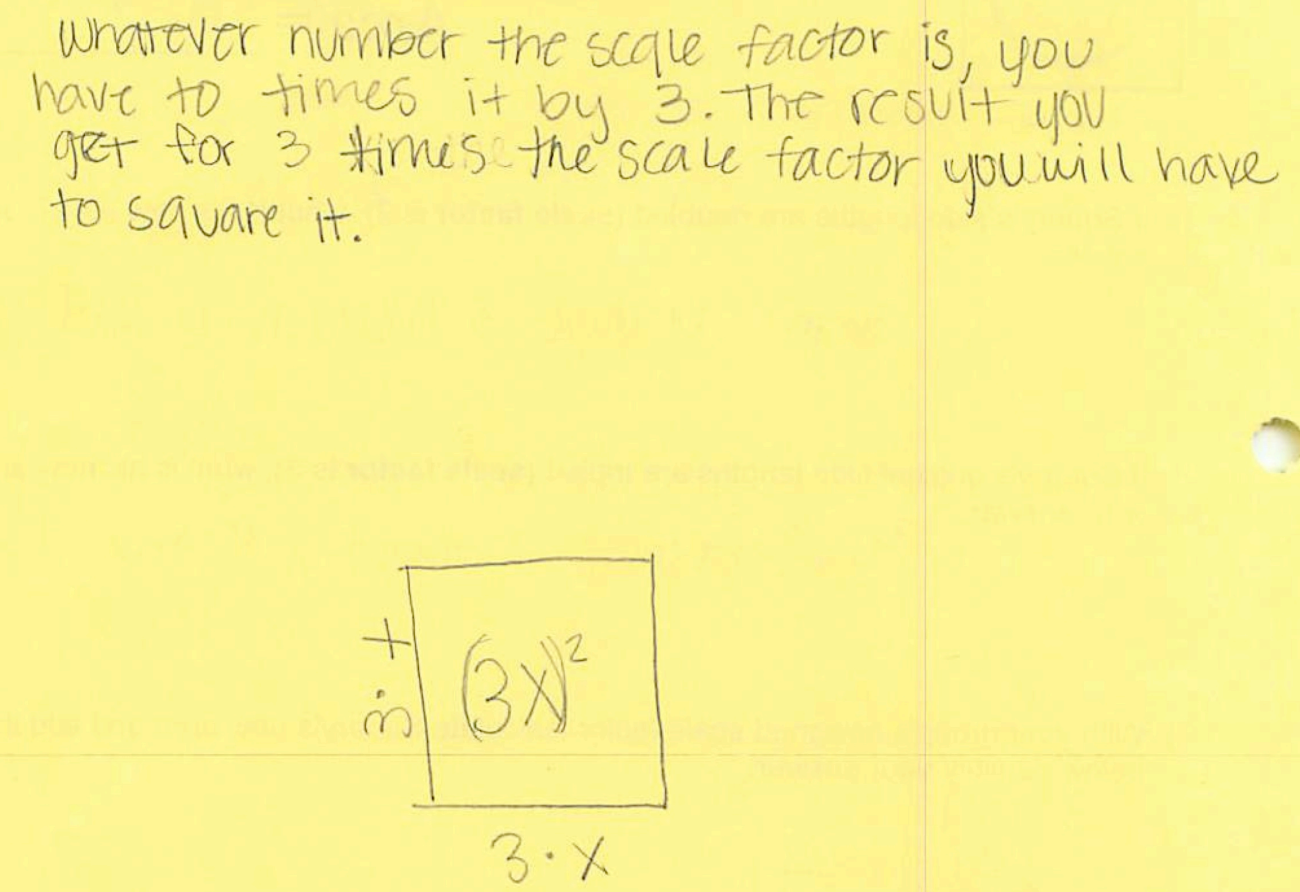

Figure 22: Student appeals to known information as the form of reasoning in this justification

Six students gave justifications similar to Nate and Kay's justifications described previously. These justification could be characterized as "model based" because they relied on Nate's justification as a model. All of which were also generic examples (because the pictorial representation was of a specific figure that was reasoned about generally), and the degree of generality varied in terms of how closely the general argument was connected to the specific shape. The student's work in Figure 23 also indicated transformational reasoning: the arrows in the diagram indicate an imagined enlarging of the rectangle to accommodate the inner four rectangles of original size. 


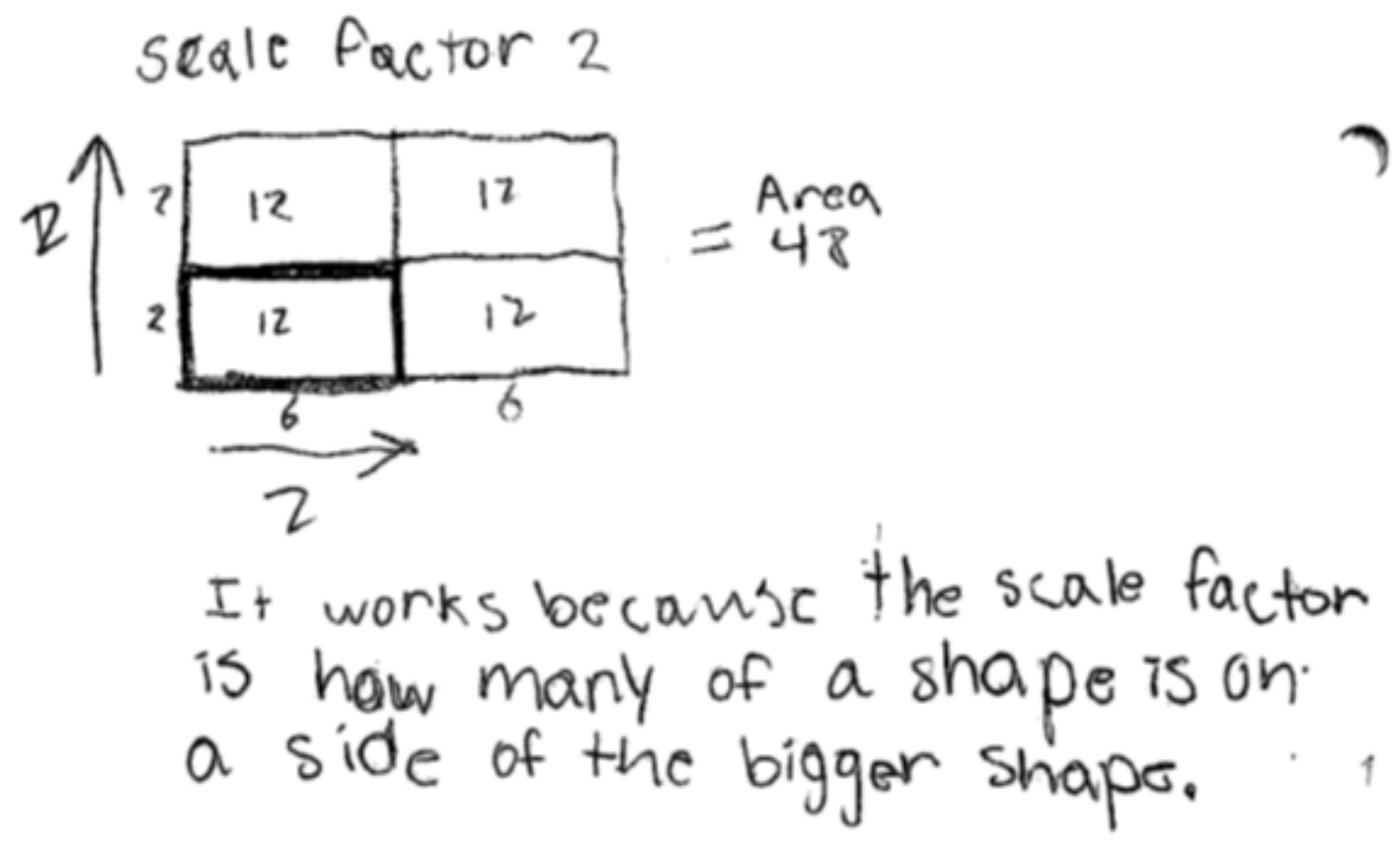

Figure 23: Student diagram indicates the scale factor of 2 results in a rectangle with 4 times the area

Only one student produced a pattern-result argument (shown in Figure 24) in the written work of the second year. This student listed out several values in a table and assumed that the pattern would hold, but did not justify why. 
6) Provide a convincing argument that clearly shows why it always works. Include a picture or a diagram that helps support your argument.

$$
\begin{aligned}
& (3 x)^{2} \text { w.11 always work with } x \text { as the } \\
& \text { scale fector. }
\end{aligned}
$$

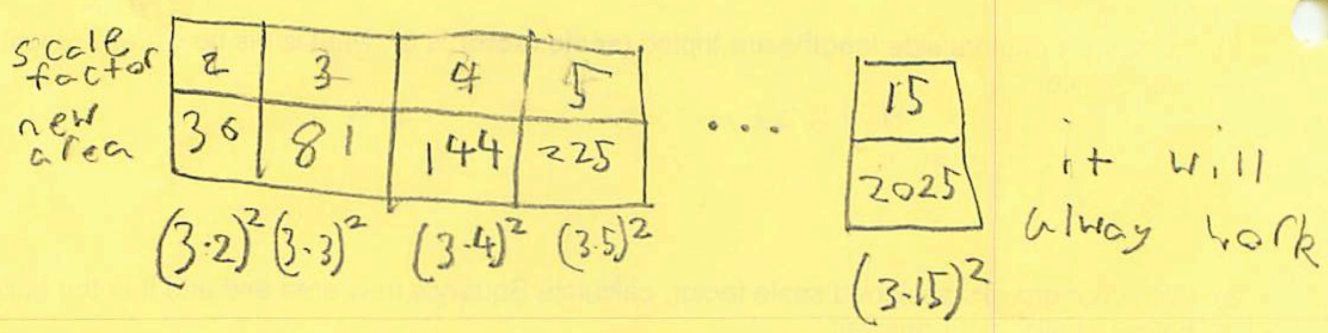

Figure 24: Pattern-result reasoning is indicated by the table of values: the student assumes the pattern will hold by does not justify why

Overall, the justifications offered in the second year were more developed and exhibited more varied forms of reasoning than in the first year. The structure of the task in the second year had a direct impact on student justifications: students focused on a single shape and were asked to make meaning of their operations in the early stages of the task. Structuring the task to include a rationale for a rule (algebraic equation) and a diagram helped students connect their understanding of the geometric scaling process with algebraic operations. Also, a student presentation of a strong justification served as a model for subsequent student justifications.

\section{Discussion and Conclusions}

The research indicates that scaffolding open-ended, mathematical tasks can be both valuable and problematic. Too little structure and students are less likely to arrive at a specific targeted understandings, while over-scaffolding inhibits student exploration 
and can decrease the cognitive demand of the task. This case study describes the scaffolding of a single case over two different implementations, focusing on scaffolds within the written task and scaffolds within the implementation of the task.

In the first year the task was implemented, the mathematical scaffolds present in the task directed students' attention toward patterned sets of examples listed as numerical values in a table. The scaffolding of the task focused student attention to the numeric value of the examples, rather than a deep understanding of why the examples worked. In addition, the disconnect between the numerical value of the examples and how the examples worked was further exacerbated by Mr. Hummel's interjection early in the task that reduced the cognitive demand. As a result, justification attempts typically took the form of result-pattern reasoning, in which a computational pattern was identified and assumed to hold without explaining why. These findings mirror those found by Lannin (2005), that when presented with a table, students typically engage in result-pattern reasoning. In addition, by focusing on the number patterns first and then asking why second, result-pattern reasoning occurred.

In the second year, students were asked to deeply understand a single example and generated a wider variety of valid justifications. The initial extended work with a square helped students gain a deeper understanding of the relationship between area and scale factor, which may have contributed to the initial generic-example based reasoning. Also Nate's pictorially represented, transformational generic-example argument served as a model for other student justifications for different shapes. Thus having a model of a strong justification served as a model for subsequent student justifications. In summary, extended work with a single example produced generic-example based reasoning. 
Additionally, a strong understanding of the computational process for computing areas of a single shape also led to algebraic-based justifications that appealed to known information.

This case study analysis indicates that appropriate scaffolding for a justification task included a focus on building concepts, strong use of examples or models, and a sustained press for justification. Mathematical concepts are developed via models and examples. Embedded within a specific and sustained press for justification, the end goal of student justification can be reached. A critical element in the success of student justifications includes an appropriate justification goal for the task. In this case, the goal shifted from justifying a relationship observed in a numeric pattern to understanding why the pattern existed using algebra and diagrams. This shift in goals corresponded to a shift in the task design, and a change in the subsequent student activity.

The following sections elaborate on the ideas building concepts, community understanding of examples or models, and sustained press for justification and explains their connections to student reasoning. Each of these are considered general task scaffolds, because they represent a contribution of a mathematical tool or resource to guide or focus a student's mathematical activity.

\section{Building Concepts}

Successful construction of justifications requires sufficient knowledge of mathematical content. Weber and Alcock (2004) found that students with instrumental understanding produced syntactic proofs reliant upon "symbol pushing," while experts with relational understanding could create semantic proofs that approached material from an intuitive level. While syntactic arguments can be sufficient for proving the validity of 
a statement, a strong justification in the middle school classroom is one that not only establishes the truth of a claim, but also has the capacity to describe why something is true. Thus it is reasonable that in order to construct a strong justification, a person would require relational, or what I call conceptual, understanding of the material.

In the first year's implementation of the task, Mr. Hummel developed a shared vocabulary and a shared process for computing area. However, when the class miscomputed the area of the scaled up figures, he did not scaffold the development of conceptual understanding of the relationship. Instead, he mandated a prescriptive method, and the task devolved into computing without connections.

In contrast, in the second year the task was scaffolded to guide students toward a conceptual understanding of what it means to scale a figure. Connecting a diagram to an equation was a critical part of this development, and it gave students the mathematical content knowledge necessary to explain why the relationship held. These explanations served as the foundation for valid justifications.

The relationship between conceptual understanding and justification is not unidirectional. Bartlo’s (2013) work indicates that while content knowledge is needed to construct justifications, justifications can also play an important role in the development of content knowledge. Thus scaffolds that support the construction of justifications - such as forming connections between representations - are the same scaffolds necessary for the development of conceptual understanding.

\section{Community Understanding of Examples or Models}

Shared understanding of an example or model was another critical component in the scaffolding of justification. An example is a mathematical object that is specific or 
concrete and is also a member of a larger, general class (Mills, 2014), while a mathematical model is a commonly understood process or representation for a mathematical task or object. Developing a community understanding of these models or examples influenced how students approached the task, and thus impacted the resulting student forms of reasoning.

In the first year's implementation of the task, students did not have a shared model for understanding the scaling process. Although students could algorithmically compute the areas for scaled-up figures, that process was never leveraged toward a more general, algebraic argument. The task had the potential to result in algebraic justifications, but without a sustained press for justification, such justifications did not materialize.

In the second year, the task was designed to explore the scaling of a single example of a square. Using a square to find the area of a scaled up shape resulted in several "computational" justifications that described the computational process for finding a scaled-up area. These justifications appealed to known information as their form of reasoning, because they relied on the known operations for scaling and computing area. This single example of a square also generated generic example justifications, in which students reasoned generally about a specific example, a square of side length 3, as part of their justification.

In the second year Nate's justification also served as a model for other students' future justifications. His pictorially represented justification was a generic example, but also included elements of transformational reasoning. His justification served as a model for subsequent student justifications. Some of those model-based justifications were also 
generic examples that exhibited some transformational reasoning. Other student justification attempts were classified as strictly model-based reasoning: they saw the occurrence of tessellation with figures other than a square (namely parallelograms and rectangles), and due to the similarity applied Nate's model without justifying the applicability of the model. In this case, the model presented in the class scaffolded subsequent student justifications and resulted in student forms of reasoning based on the original justification.

\section{Sustained press for justification}

The sustained press for justification was a final critical element in the scaffolding of justifications. It may seem redundant that a reminder to justify could be considered a scaffold for justification; however the press for justification in the initial steps of the task resulted not only in justifications at those stages, but also a deeper understanding of the relationships that informed justifications at later stages in the task.

In the first year's implementation of the task, students were asked to generate data (by computing areas), create a table, observe a pattern, and only then were they asked to explain (or justify) the pattern. This "do first, justify later" approach inhibited the students' ability to justify, because their initial steps for doing the math were based on a proscribed procedure rather than on an understanding of the content. Had students explored the "why" behind the generation of their data in the table, they would have been much better equipped to justify the pattern they found. By pushing the justification to the end, it encouraged students to disconnect their procedures from the corresponding geometric transformations. 
In the second year, sustained press for justification throughout the early stages of the task forced students to make sense of their operations as they computed them. Those operations informed how they made sense of the rest of the task, and resulted in stronger justifications.

Additionally, in the first year of the task the prompt for student justification was

placed as an afterthought: "Explain how (and why if you can) this relationship works." In contrast, in the second year the press for justification was direct and specific: students were asked to generate a rule (mathematical equation) and a picture to explain why the relationship held. When asking students to engage in a mathematical activity, setting specific expectations can result in stronger student mathematical activity (Silver \& Stein, 1996). An important (but not sufficient) way to get students to justify is to ask them to justify, and the specific inclusion of representations resulted in student justifications with generic example and transformational reasoning.

Finally, the press for justification must be meaningful for students. They must understand what it means to justify when they are asked. In Mr. Hummel's classroom, he was explicit that a justification should be a convincing argument, which students understood as something more than displaying calculations.

\section{Concluding Thoughts}

Mr. Hummel's case was selected for this analysis was because of the strong contrast in the written task over the two years and the strong contrast in the resulting student work. Such a contrast was likely due to the high fidelity Mr. Hummel's implementation had to the written task. His classroom culture allowed for a long period of investigation within which students worked with the task, and very little time was 
spent "off-script" during whole-class discussions. In the first year when he noticed difficulties, he stuck to the task design instead of taking-up the student misconception and engaging in an extended exploration not laid-out in the written task.

When reflecting on the task over the two years, Mr. Hummel stated, "It is good to have some structure and some organization, but if it is too guided it is not going to lead to the variety that we want, and it is not going to lead to a good justification." This paper illustrated how the table-based task in the first year led to result-pattern reasoning, while the guided exploration of a single example in the second year led to a variety of forms of reasoning, including generic example, transformational, and appealing to known information.

This case study is a valuable contribution to the field because it offers a detailed description of the kinds of scaffolds that support student justification activity. Research indicates that effective scaffolding is valuable, but descriptions of effective scaffolding are rarely specified. This study was able to track the development of a single task and provide detailed evidence for the relationship between task scaffolds and subsequent student justifications. Future directions for this work would include an analysis of a greater number of justification task implementations to provide further evidence for these relationships and possibly expand the list of effective scaffolds.

\section{References}

Alfieri, L., Brooks, P. J., Aldrich, N. J., \& Tenenbaum, H. R. (2011). Does discoverybased instruction enhance learning? Journal of Educational Psychology, 103(1), 1-18. doi:10.1037/a0021017 
Anghileri, J. (2006). Scaffolding practices that enhance mathematics learning. Journal of Mathematics Teacher Education, 9(1), 33-52. doi:10.1007/s10857-006-9005-9

Ball, D. (1993). With an Eye on the Mathematical Horizon: Dilemmas of Teaching Elementary School Mathematics. The Elementary School Journal, 93(4), 373397.

Bartlo, J. (2013). Why ask Why: An Exploration of the Role of Proof in the Mathematics Classroom. Dissertation, Portland, OR.

Bieda, K. (2010). Enacting proof-related tasks in middle school mathematics: Challenges and opportunities. Journal for Research in Mathematics Education, 41(4), 351382.

Bliss, J., \& Askew, M. (1996). Effective teaching and learning: Scaffolding revisited. Oxford Review of Education, 22(1), 37.

Braun, V., \& Clarke, V. (2006). Using thematic analysis in psychology. Qualitative Research in Psychology, 3(2), 77-101. doi:10.1191/1478088706qp063oa

Cohen, D. (1990). A revolution in one classroom: The case of Mrs. Oublier. Educational Evaluation and Policy Analysis, 12(3), 311-329.

Council of Chief State School Officers (CCSSO) \& National Governors Association Center for Best Practices (NGA Center) (2010). Common Core State Standards

Franke, M., Webb, N., Chan, A., Ing, M., Freund, D., \& Battey, D. (2009). Teacher questioning to elicit students' mathematical thinking in elementary school classrooms. Journal of Teacher Education, 60(4), 380-392. 
Gravemeijer, K. (2004). Local Instruction Theories as Means of Support for Teachers in Reform Mathematics Education. Mathematical Thinking and Learning, 6(2), 105128. doi:10.1207/s15327833mt10602_3

Henningsen, M., \& Stein, M. K. (1997). Mathematical Tasks and Student Cognition: Classroom-Based Factors That Support and Inhibit High-Level Mathematical Thinking and Reasoning. Journal for Research in Mathematics Education, 28(5), 524-549. doi: $10.2307 / 749690$

Hiebert, J., Carpenter, T. P., Fennema, E., Fuson, K., Human, P., Murray, H., Olivier, A., and Wearne, D. (1996). Problem Solving as a Basis for Reform in Curriculum and Instruction: The Case of Mathematics. Educational Researcher, 25(4), 12-21. doi:10.3102/0013189X025004012

Hsu, E., Kysh, J., Ramage, K., \& Resek, D. (2009). Helping teachers un-structure: A promising approach. Montana Mathematics Enthusiast, 6(3).

Jackson, K., Garrison, A., Wilson, J., Gibbons, L., \& Shahan, E. (2013). Exploring Relationships Between Setting Up Complex Tasks and Opportunities to Learn in Concluding Whole-Class Discussions in Middle-Grades Mathematics Instruction. Journal for Research in Mathematics Education, 44(4), 646-682. doi:10.5951/jresematheduc.44.4.0646

Kirschner, P. A., Sweller, J., \& Clark, R. E. (2006). Why Minimal Guidance During Instruction Does Not Work: An Analysis of the Failure of Constructivist, Discovery, Problem-Based, Experiential, and Inquiry-Based Teaching. Educational Psychologist, 41(2), 75-86. doi:10.1207/s15326985ep4102_1 
Lannin, J. K. (2005). Generalization and Justification: The Challenge of Introducing Algebraic Reasoning Through Patterning Activities. Mathematical Thinking and Learning, 7(3), 231-258. http://doi.org/10.1207/s15327833mt10703_3

Martin, T. S., McCrone, S. M. S., Bower, M. L. W., \& Dindyal, J. (2005). The Interplay of Teacher and Student Actions in the Teaching and Learning of Geometric Proof. Educational Studies in Mathematics, 60(1), 95-124. doi:10.1007/s10649-0056698-0

Martino, A. M., \& Maher, C. A. (1999). Teacher Questioning to Promote Justification and Generalization in Mathematics: What Research Practice Has Taught Us. The Journal of Mathematical Behavior, 18(1), 53-78. doi:10.1016/S07323123(99)00017-6

Mayer, R. E. (2004). Should There Be a Three-Strikes Rule Against Pure Discovery Learning? American Psychologist, 59(1), 14-19. doi:10.1037/0003-066X.59.1.14

McClain, K., \& Cobb, P. (2001). An Analysis of Development of Sociomathematical Norms in One First-Grade Classroom. Journal for Research in Mathematics Education, 32(3), 236-266. doi:10.2307/749827

Merrill, M. D. (2007). A Task-Centered Instructional Strategy. Journal of Research on Technology in Education (International Society for Technology in Education), $40(1), 5-22$.

National Council of Teachers of Mathematics. (2000). Principles and standards for school mathematics. Reston, VA: National Council of Teachers of Mathematics 
Rasmussen, C., \& Marrongelle, K. (2006). Pedagogical Content Tools: Integrating Student reasoning and Mathematics in Instruction. Journal For Research in Mathematics Education, 37(5), 388-420.

Rogoff, B. (1995). Observing sociocultural activity on three planes: Participatory appropriation, guided participation, and apprenticeship. In J. Wertsch, P. del Rio, \& A. Alvarez (Eds.), Sociocultural studies of mind. New York, NY: Cambridge University Press.

Sherman, M. (2012). Supporting students' mathematical thinking during technologyenhanced investigations using DGS. In D. Martinovic, D. McDougall, \& Z. Karadag (Eds.), Technology in Mathematics Education: Contemporary Issues. Santa Rose, CA: Informing Science.

Simon, M. A., \& Tzur, R. (1999). Explicating the Teacher's Perspective from the Researchers' Perspectives: Generating Accounts of Mathematics Teachers' Practice. Journal for Research in Mathematics Education, 30(3), 252. doi:10.2307/749835

Speer, N., \& Wagner, J. (2009). Knowledge needed by a teacher to provide analytic scaffolding during undergraduate mathematics classroom discussions. Journal For Research in Mathematics Education, 40(5), 530-562.

Staples, M. (2007). Supporting whole-class collaborative inquiry in a secondary mathematics classroom. Cognition and Instruction, 25(2-3), 161-217.

Staples, M. (unpublished manuscript). Case Study report: JAGUAR Project.

Stein, M. K., Grover, B. W., \& Henningsen, M. (1996). Building Student Capacity for Mathematical Thinking and Reasoning: An Analysis of Mathematical Tasks Used 
in Reform Classrooms. American Educational Research Journal, 33(2), 455 488. doi:10.3102/00028312033002455

Stein, M. K., Smith, M. S., Henningsen, M., \& Silver, E. (2000). Implementation standards-based mathematics instruction: A casebook for professional development. New York: Teachers College Press.

Sweller, J. (1994). Cognitive load theory, learning difficulty, and instructional design. Learning and Instruction, 4(4), 295-312. http://doi.org/10.1016/09594752(94)90003-5

Tharpe, R. \& Gallimore, R. (1988). Rousing minds to life: Teaching, learning, and schooling in social context. Cambridge: Cambridge University Press.

Weber, K., \& Alcock, L. (2004). Semantic and Syntactic Proof Productions. Educational Studies in Mathematics, 56(2-3), 209-234.

http://doi.org/10.1023/B:EDUC.0000040410.57253.a1

Wood, T. (1994). Patterns of interaction and the culture of mathematics classrooms. In S. Lerman (Ed.), Cultural perspectives on the mathematics classroom. Dordrecht: Kluwer.

Wood, D., Bruner, J. S., \& Ross, G. (1976). The Role of Tutoring in Problem Solving. Journal of Child Psychology and Psychiatry, 17(2), 89-100. doi:10.1111/j.14697610.1976.tb00381.x

Wood, T., Cobb, P., \& Yackel, E. (1991). Change in Teaching Mathematics: A Case Study. American Educational Research Journal, 28(3), 587-616. doi:10.3102/00028312028003587 
Yin, R. (2009). Case Study Research: Design and Methods (4th ed.). Thousand Oaks, CA: SAGE Publications. 


\section{Chapter 8: Conclusions}

This dissertation identifies relationships between teacher conceptions, teacher practice and student outcomes in the context of middle school justification activity. Data for the analysis was drawn from the JAGUAR project, a collaborative research and development project focused on developing knowledge and practice to support justifications in the classroom. In this paper, a justification is a mathematical argument that establishes the validity of a result while also explaining why the result holds.

The primary content of the dissertation consists of three interrelated, yet distinct, case studies. In the first paper, Middle School Teacher Conceptions of Justification, I provide a detailed description of four teachers' conceptions of justification. Using Schoenfeld's (2011) framework as a theoretical lens, I described teachers' orientations to justification (including their beliefs about the definition of justification and preferences regarding justification), their purpose or goal for using justification in their classroom, and their proficiencies with justification. Results indicate that teachers' conceptualized justification as both a mathematical practice that focused on establishing why and a pedagogical practice that focused on student reasoning and understanding.

The second paper, Middle School Teacher Treatment of Examples in the Context of Justification Activity, describes teacher understanding of empirical reasoning and teacher treatment of empirical reasoning in their classrooms. Results from this paper include a framework of ways teachers treat examples in their classrooms; many of which aligned with example usage by mathematicians. The paper also found that teacher treatment of examples in their classroom was influenced by knowledge of empirical 
reasoning, as well as teacher definition of justification and beliefs about teaching and learning.

In the final paper, Scaffolding Mathematical Tasks to Support Student

Justifications, is a case study analysis of a single teacher's implementation and revision of a justification task over the course of two years. Using Stein, Smith, Henningsen, and Silver's (2000) framework for mathematical task design to guide the analysis, I describe the task as written, as set-up in the classroom, and the subsequent student justification activity. The case demonstrates how the scaffolding of the task impacted student forms of reasoning, and concludes that effective scaffolding for justification tasks should provide the building of concepts, community understanding of concepts or models, and a sustained press for justification.

Taken collectively, these three case studies offer a significant contribution toward understanding justification in the middle school classroom. They describe different types of teacher knowledge and conceptions necessary to support this ambitious practice. They also explain how that knowledge is transformed into practice in their classrooms as they support students in justification work. This research builds the base for future work in developing a pedagogy of justification; such research might include a replication study in which the knowledge and pedagogy of justification is analyzed for a larger group of participants. My work also forms a foundation for the creation of future professional development to help other teachers learn to teach for justification. 


\section{Terminal References}

Alcock, L., \& Inglis, M. (2008). Doctoral Students' Use of Examples in Evaluating and Proving Conjectures. Educational Studies in Mathematics, 69(2), 111-129.

Alfieri, L., Brooks, P. J., Aldrich, N. J., \& Tenenbaum, H. R. (2011). Does discoverybased instruction enhance learning? Journal of Educational Psychology, 103(1), 1-18. doi:10.1037/a0021017

Anghileri, J. (2006). Scaffolding practices that enhance mathematics learning. Journal of Mathematics Teacher Education, 9(1), 33-52. doi:10.1007/s10857-006-9005-9

Balacheff, N. (2002). Treatment of Refutations: Aspects of the Complexity of a Constructivist Approach to Mathematics Learning. In E. Glasersfeld (Ed.), Radical Constructivism in Mathematics Education (Vol. 7, pp. 89-110). Springer Netherlands. Retrieved from http://www.springerlink.com/content/v74h0p4u57184738/abstract/

Ball, D. (1993). With an Eye on the Mathematical Horizon: Dilemmas of Teaching Elementary School Mathematics. The Elementary School Journal, 93(4), 373397.

Ball, D. L., Hoyles, C., Jahnke, H. N., \& Movshovitz-Hadar, N. (2003). The teaching of proof. arXiv:math/0305021. Retrieved from http://arxiv.org/abs/math/0305021

Ball, D. L., Thames, M. H., \& Phelps, G. (2008). Content Knowledge for Teaching What Makes It Special? Journal of Teacher Education, 59(5), 389-407. http://doi.org/10.1177/0022487108324554

Barkai, R., Tsamir, P., Tirosh, D., \& Dreyfus, T. (2002). Proving or Refuting Arithmetic Claims: The Case of Elementary School Teachers. In Proceedings of the twentysixth annual meeting of the International Group for the Psychology of Mathematics Education. Psychology for mathematics education Retrieved from http://eric.ed.gov/?id=ED476089

Bartlo, J. (2013). Why ask Why: An Exploration of the Role of Proof in the Mathematics Classroom. Dissertation, Portland, OR.

Bieda, K. (2010). Enacting proof-related tasks in middle school mathematics: Challenges and opportunities. Journal for Research in Mathematics Education, 41(4), 351-382.

Bliss, J., \& Askew, M. (1996). Effective teaching and learning: Scaffolding revisited. Oxford Review of Education, 22(1), 37.

Boaler, J., \& Staples, M. (2008). Creating mathematical futures through an equitable teaching approach: The case of Railside School. The Teachers College Record, $110(3), 608-645$.

Braun, V., \& Clarke, V. (2006). Using thematic analysis in psychology. Qualitative Research in Psychology, 3(2), 77-101. doi:10.1191/1478088706qp063oa 
Bray, W. S. (2011). A Collective Case Study of the Influence of Teachers' Beliefs and Knowledge on Error-Handling Practices During Class Discussion of Mathematics. Journal for Research in Mathematics Education, 42(1), 2-38.

Buchbinder, O., \& Zaslavsky, O. (2011). Is this a coincidence? The role of examples in fostering a need for proof. $Z D M, 43(2), 269-281$. doi:10.1007/s11858-011-0324-7

Carpenter, T. (2004). Using Knowledge of Children's Mathematical Thinking in Classroom Teaching: An Experimental Study. In T. Carpenter, J. Dossy, J. Koehler, E. Fennema, P. Peterson, C.-P. Chiang, \& M. Loef (Eds.), Classics in Mathematics Education Research (pp. 134-151). Reston, VA: The National Council of Teachers of Mathematics.

Chazan, D. (1993). High School Geometry Students' Justification for Their Views of Empirical Evidence and Mathematical Proof. Educational Studies in Mathematics, 24(4), 359-387. doi:10.2307/3482650

Chazan, D., \& Ball, D. (1999). Beyond being told not to tell. For the Learning of Mathematics, 19(2), 2-10.

Cobb, P., \& Bowers, J. (1999). Cognitive and Situated Learning Perspectives in Theory and Practice. Educational Researcher, 28(2), 4-15.

http://doi.org/10.3102/0013189X028002004

Cochran-Smith, M., \& Lytle, S. L. (1999). Relationships of Knowledge and Practice: Teacher Learning in Communities. Review of Research in Education, 24, 249305. http://doi.org/10.2307/1167272

Cohen, D. (1990). A revolution in one classroom: The case of Mrs. Oublier. Educational Evaluation and Policy Analysis, 12(3), 311-329.

Corbin, J., \& Strauss, A. (2008). Basics of Qualitative Research: Techniques and Procedures for Developing Grounded Theory (3rd ed.). Thousand Oaks: SAGE Publications.

Council of Chief State School Officers (CCSSO) \& National Governors Association Center for Best Practices (NGA Center) (2010). Common Core State Standards for Mathematics. http://www.corestandards.org/assets/CCSSI_Math\%20Standards.pdf

Creswell, J. (2007). Qualitative Inquiry and Research Design: Choosing Among Five Approaches (2nd ed.). Thousand Oask, CA: SAGE Publications.

Darling-Hammond, L. (2000). Teacher quality and student achievement: A review of state policy evidence. Educational Policy Analysis Archives, 8(1).

De Villiers, M. (1990). The role and function of proof in mathematics. Pythagoras, 24(1), 17-24.

Dewey, J. (1933). How We Think: A Restatement of the Relation of Reflective Thinking to the Educative Process. Boston: Heath.

Dreyfus, T. (1999). Why Johnny can't prove. Educational Studies in Mathematics, 38(1), 85-109. 
Ellis, A., Lockwood, E., Williams, C., Dogan, M. F., \& Knuth, E. (2012). Middle school students' example use in conjecture exploration and justification. In Proceedings of the 34th Annual Meeting of the North American Chapter of the Psychology of Mathematics Education. Kalamazoo, MI.

English, L. D. (2003). Reconciling theory, research, and practice: A models and modeling perspective. Educational Studies in Mathematics, 54(2-3), 225-248. doi:10.1023/B:EDUC.0000006167.14146.7b

Fennema, E., \& Franke, M. (1992). Teachers' knowledge and its impact. In Handbook of Research on Mathematics Teaching and Learning (1st ed., pp. 147-164). New York: MacMillan.

Floden, R. (2001). Research on Effects of Teaching: A Continuing Model for Research on Teaching. In V. Richardson (Ed.), Handbook of Research on Teaching (4th ed., pp. 3-16). Washington, DC: American Educational Research Association.

Franke, M., Webb, N., Chan, A., Ing, M., Freund, D., \& Battey, D. (2009). Teacher questioning to elicit students' mathematical thinking in elementary school classrooms. Journal for Teacher Education, 60(4), 380-392.

Goettling, M. (1995). The college students' understanding of mathematical proof. Unpublished dissertation. University of Maryland, Maryland.

Gravemeijer, K. (2004). Local Instruction Theories as Means of Support for Teachers in Reform Mathematics Education. Mathematical Thinking and Learning, 6(2), 105128. doi:10.1207/s15327833mt10602_3

Hanna, G. (1990). Some pedagogical aspects of proof. Interchange, 21(1), 6-13. http://doi.org/10.1007/BF01809605

Hanna, G. (2000). Proof, Explanation and Exploration: An Overview. Educational Studies in Mathematics, 44(1-2), 5-23. http://doi.org/10.1023/A:1012737223465

Harel, G. (2001). The development of mathematical induction as a proof scheme: A model for DNR-based instruction. In S. Campbell \& R. Zaskis (Eds.), Learning and Teaching Number Theory: Research in Cognition and instruction (Vol. 2, pp. 185-212). New Jersey: Ablex Publishing Corporation.

Harel, G., \& Sowder, L. (1998). Students' proof schemes: Results from exploratory studies. Research in Collegiate Mathematics Education III, 7, 234-282.

Healy, L., \& Hoyles, C. (2000). A Study of Proof Conceptions in Algebra. Journal for Research in Mathematics Education, 31(4), 396-428. doi:10.2307/749651

Henningsen, M., \& Stein, M. K. (1997). Mathematical Tasks and Student Cognition: Classroom-Based Factors That Support and Inhibit High-Level Mathematical Thinking and Reasoning. Journal for Research in Mathematics Education, 28(5), 524-549. doi:10.2307/749690

Herbst, P., Miyakawa, T., \& Chazan, D. (2012). Revisiting the functions of proof in mathematics classrooms: A view from a theory of instructional exchanges Retrieved from http://hdl.handle.net/2027.42/78168. 
Hersh, R. (1993). Proving is convincing and explaining. Educational Studies in Mathematics, 24(4), 389-399. http://doi.org/10.1007/BF01273372

Hiebert, J., Carpenter, T. P., Fennema, E., Fuson, K., Human, P., Murray, H., Olivier, A., and Wearne, D. (1996). Problem Solving as a Basis for Reform in Curriculum and Instruction: The Case of Mathematics. Educational Researcher, 25(4), 12-21. doi:10.3102/0013189X025004012

Hill, H. C., Blunk, M., Charalambous, C., Lewis, J., Phelps, G., Sleep, L., \& Ball, D. L. (2008). Mathematical knowledge for teaching and the mathematical quality of instruction: An exploratory study. Cognition and Instruction, 26(4), 430-511.

Hill, H. C., Rowan, B., \& Ball, D. L. (2005). Effects of teachers' mathematical knowledge for teaching on student achievement. American educational research journal, 42(2), 371-406.

Hoyles, C. (1997). The Curricular Shaping of Students' Approaches to Proof. For the Learning of Mathematics, 17(1), 7-16.

Hsu, E., Kysh, J., Ramage, K., \& Resek, D. (2009). Helping teachers un-structure: A promising approach. Montana Mathematics Enthusiast, 6(3).

Inglis, M., Mejia-Ramos, J. P., \& Simpson, A. (2007). Modelling mathematical argumentation: the importance of qualification. Educational Studies in Mathematics, 66(1), 3-21.

Jackson, K., Garrison, A., Wilson, J., Gibbons, L., \& Shahan, E. (2013). Exploring Relationships Between Setting Up Complex Tasks and Opportunities to Learn in Concluding Whole-Class Discussions in Middle-Grades Mathematics Instruction. Journal for Research in Mathematics Education, 44(4), 646-682. doi:10.5951/jresematheduc.44.4.0646

Kazemi, E., \& Hubbard, A. (2008). New Directions for the Design and Study of Professional Development Attending to the Coevolution of Teachers' Participation Across Contexts. Journal of Teacher Education, 59(5), 428-441. doi:10.1177/0022487108324330

Kazemi, E., \& Stipek, D. (2001). Promoting Conceptual Thinking in Four UpperElementary Mathematics Classrooms. The Elementary School Journal, 102(1), 59-80.

Kirschner, P. A., Sweller, J., \& Clark, R. E. (2006). Why Minimal Guidance During Instruction Does Not Work: An Analysis of the Failure of Constructivist, Discovery, Problem-Based, Experiential, and Inquiry-Based Teaching. Educational Psychologist, 41(2), 75-86. doi:10.1207/s15326985ep4102_1

Knuth, E. J. (2002a). Secondary school mathematics teachers' conceptions of proof. Journal for Research in Mathematics Education, 33, 379-405.

Knuth, E. J. (2002b). Teachers' conceptions of proof in the context of secondary school mathematics. Journal of Mathematics Teacher Education, 5, 61-88. 
Knuth, E., Choppin, J., Slaughter, M., \& Sutherland, J. (2002). Mapping the conceptual terrain of middle school students' competencies in justifying and proving. In Proceedings of the 24th annual meeting of the North American Chapter of the International Group for the Psychology of Mathematics Education (Vol. 4, pp. 1693-1670). Athens, GA: Clearinghouse for Science, Mathematics, and Environmental Education.

Ladson-Billings, G. (2009). Critical Race Theory in Education. The Routledge International Handbook of Critical Education, 110.

Lampert, M. (1990). When the Problem Is Not the Question and the Solution Is Not the Answer: Mathematical Knowing and Teaching. American Educational Research Journal, 27(1), 29-63. http://doi.org/10.3102/00028312027001029

Lannin, J. K. (2005). Generalization and Justification: The Challenge of Introducing Algebraic Reasoning Through Patterning Activities. Mathematical Thinking and Learning, 7(3), 231-258. http://doi.org/10.1207/s15327833mt10703_3

Larsen, S. \& James, C. (unpublished manuscript). From empirical reasoning to general arguments: Forms of reasoning in middle school mathematics

Lave, J., \& Wenger, E. (1991). Situated Learning: Legitimate Peripheral Participation. Cambridge University Press.

Leatham, K. (2006). Viewing mathematics teachers' beliefs as sensible systems. Journal of Mathematics Teacher Education, 9, 91-102. doi:10.1007/s10857-006-9006-8

Lesseig, K. (2011). Mathematical knowledge for teaching proof. Retrieved from http://ir.library.oregonstate.edu/xmlui/handle/1957/23465

Lewis, J. M., \& Blunk, M. L. (2012). Reading between the lines: Teaching linear algebra. Journal of Curriculum Studies, 44(4), 515-536Martin, T. S., McCrone, S. M. S., Bower, M. L. W., \& Dindyal, J. (2005). The Interplay of Teacher and Student Actions in the Teaching and Learning of Geometric Proof. Educational Studies in Mathematics, 60(1), 95-124. doi:10.1007/s10649-005-6698-0

Lockwood, E., Ellis, A., Dogan, M., Williams, C., \& Knuth, E. (2012). A Framework for Mathematicians' Example-Related Activity When Exploring and Proving Mathematical Conjectures. In Proceedings of the 34th annual meeting of the North American chapter of the international group for the psychology of mathematics education (pp. 151-158).

LMT (Learning Mathematics for Teaching). (2006, Winter). Learning Mathematics for Teaching: Survey of Middle School Teachers of Mathematics. University of Michigan, School of Education.

Maher, C. A., \& Martino, A. M. (1996). The development of the idea of mathematical proof: A 5-year case study. Journal for Research in Mathematics Education, 194 214.

Martin, G., \& Harel, G. (1989). Proof frames of preservice elementary teachers. Journal for Research in Mathematics Education, 20(1), 41-51. 
Martin, T. S., McCrone, S. M. S., Bower, M. L. W., \& Dindyal, J. (2005). The Interplay of Teacher and Student Actions in the Teaching and Learning of Geometric Proof. Educational Studies in Mathematics, 60(1), 95-124. doi:10.1007/s10649-0056698-0

Martino, A. M., \& Maher, C. A. (1999). Teacher Questioning to Promote Justification and Generalization in Mathematics: What Research Practice Has Taught Us. The Journal of Mathematical Behavior, 18(1), 53-78. doi:10.1016/S07323123(99)00017-6

Mason, J., \& Pimm, D. (1984). Generic Examples: Seeing the General in the Particular. Educational Studies in Mathematics, 15(3), 277-289.

Mason, J., \& Watson, A. (2001). Getting Students to Create Boundary Examples. MSOR Connections, 1(1), 9-11. doi:10.11120/msor.2001.01010009

Mayer, R. E. (2004). Should There Be a Three-Strikes Rule Against Pure Discovery Learning? American Psychologist, 59(1), 14-19. doi:10.1037/0003-066X.59.1.14

McClain, K., \& Cobb, P. (2001). An Analysis of Development of Sociomathematical Norms in One First-Grade Classroom. Journal for Research in Mathematics Education, 32(3), 236-266. doi:10.2307/749827

Merrill, M. D. (2007). A Task-Centered Instructional Strategy. Journal of Research on Technology in Education (International Society for Technology in Education), 40(1), 5-22.

Mills, M. (2014). A framework for example usage in proof presentations. The Journal of Mathematical Behavior, 33, 106-118. http://doi.org/10.1016/j.jmathb.2013.11.001

Mingus, T. T. Y., \& Grassl, R. M. (1999). Preservice Teacher Beliefs About Proofs. School Science and Mathematics, 99(8), 438-444. http://doi.org/10.1111/j.19498594.1999.tb17506.x

Moses, R. P., \& Cobb, C. E. (2001). Radical equations: Civil rights from Mississippi to the Algebra Project. Beacon Press.

Mueller, M., Yankelewitz, D., \& Maher, C. (2012). A framework for analyzing the collaborative construction of arguments and its interplay with agency. Educational Studies in Mathematics, 80(3), 369-387. doi:10.1007/s10649-0119354-x

Nathan, M. \& Knuth, E. (2003). A study of whole classroom mathematical discourse and teacher change. Cognition and instruction, 21(2), 175-207.

National Council of Teachers of Mathematics. (2000). Principles and standards for school mathematics. Reston, VA: National Council of Teachers of Mathematics

Nespor, J. (1987). The role of beliefs in the practice of teaching. Journal of Curriculum Studies. 19, 317-328.

Peshkin, A. (1988). In Search of Subjectivity-One's Own. Educational Researcher, 17(7), 17-21. doi:10.3102/0013189X017007017 
Pedemonte, B., \& Buchbinder, O. (2011). Examining the role of examples in proving processes through a cognitive lens: the case of triangular numbers. $Z D M, 43(2)$, 257-267. doi:10.1007/s11858-011-0311-z

Phillips, D. C., \& Soltis, J. F. (1998). Perspectives on learning. New York: Teachers College, Columbia University.

Rasmussen, C., \& Marrongelle, K. (2006). Pedagogical Content Tools: Integrating Student reasoning and Mathematics in Instruction. Journal For Research in Mathematics Education, 37(5), 388-420.

Reid, D. A. (2002). Conjectures and Refutations in Grade 5 Mathematics. Journal for Research in Mathematics Education, 33(1), 5-29. http://doi.org/10.2307/749867

Rogoff, B. (1995). Observing sociocultural activity on three planes: Participatory appropriation, guided participation, and apprenticeship. In J. Wertsch, P. del Rio, \& A. Alvarez (Eds.), Sociocultural studies of mind. New York, NY: Cambridge University Press.

Ross, K. A. (1998). Doing and Proving: The Place of Algorithms and Proofs in School Mathematics. The American Mathematical Monthly, 105(3), 252-255. http://doi.org/10.2307/2589080

Schoenfeld, A. (1994). What do we know about mathematics curricula? Journal of Mathematical Behavior, 13, 55-80.

Schoenfeld, A. H. (2011). Toward professional development for teachers grounded in a theory of decision making. ZDM, 43(4), 457-469. http://doi.org/10.1007/s11858011-0307-8

Selden, A., \& Selden, J. (2008). Overcoming students' difficulties in learning to understand and construct proofs. In M. P. Carlson \& C. Rasmussen (Eds.), Making the Connection: Research and Teaching in Undergraduate Mathematics Education (pp. 95-110). MAA.

Sherman, M. (2012). Supporting students' mathematical thinking during technologyenhanced investigations using DGS. In D. Martinovic, D. McDougall, \& Z. Karadag (Eds.), Technology in Mathematics Education: Contemporary Issues. Santa Rose, CA: Informing Science.

Simon, M. A. (1996). Beyond inductive and deductive reasoning: The search for a sense of knowing. Educational Studies in Mathematics, 30(2), 197-210.

Simon, M. A., \& Blume, G. W. (1996). Justification in the mathematics classroom: A study of prospective elementary teachers. The Journal of Mathematical Behavior, 15(1), 3-31. doi:10.1016/S0732-3123(96)90036-X

Simon, M. A., \& Tzur, R. (1999). Explicating the Teacher's Perspective from the Researchers' Perspectives: Generating Accounts of Mathematics Teachers' Practice. Journal for Research in Mathematics Education, 30(3), 252-264. http://doi.org/10.2307/749835 
Sowder, L., \& Harel, G. (1998). Types of students' justifications. The Mathematics Teacher, 91(8), 670-675.

Speer, N., \& Wagner, J. (2009). Knowledge needed by a teacher to provide analytic scaffolding during undergraduate mathematics classroom discussions. Journal For Research in Mathematics Education, 40(5), 530-562.

Staples, M. (2007). Supporting Whole-class Collaborative Inquiry in a Secondary Mathematics Classroom. Cognition and Instruction, 25(2-3), 161-217. doi:10.1080/07370000701301125

Staples, M. (unpublished manuscript). Case Study report: JAGUAR Project.

Staples, M., \& Bartlo, J. (2010). Justification as a learning practice: Its purposes in middle grades mathematics classrooms. CRME Publications. Retrieved from http://digitalcommons.uconn.edu/merg_docs/3

Staples, M. E., Bartlo, J., \& Thanheiser, E. (2012). Justification as a teaching and learning practice: Its (potential) multifacted role in middle grades mathematics classrooms. The Journal of Mathematical Behavior, 31(4), 447-462. http://doi.org/10.1016/j.jmathb.2012.07.001

Staples, M., \& Newton, J. (in progress) Student Justification.

Staples, M., \& Truxaw, M. (2009). A journey with justification: Issues arising from the implementation and evaluation of the Math ACCESS Project. In Proceedings of the thirty-first annual meeting of the North American Chapter of the International Group for the Psychology of Mathematics Education (Vol. 5, pp. 827-835).

Steffe, L., \& Thompson, P. (2000). Teaching experiment methodology: Underlying principles and essential elements. In R. Lesh \& E. Kelly (Eds.), Research Design in Mathematics and Science Education (pp. 267-307). Mahwah, NJ: Lawrence Erlbaum Associates.

Stein, M. K., Grover, B. W., \& Henningsen, M. (1996). Building Student Capacity for Mathematical Thinking and Reasoning: An Analysis of Mathematical Tasks Used in Reform Classrooms. American Educational Research Journal, 33(2), 455 488. doi:10.3102/00028312033002455

Stein, M. K., Smith, M. S., Henningsen, M., \& Silver, E. (2000). Implementation standards-based mathematics instruction: A casebook for professional development. New York: Teachers College Press.

Stylianides, A. J. (2007). Proof and proving in school mathematics. Journal for Research in Mathematics Education, 38(3), 289-321.

Stylianides, A. J., \& Ball, D. L. (2008). Understanding and describing mathematical knowledge for teaching: knowledge about proof for engaging students in the activity of proving. Journal of Mathematics Teacher Education, 11(4), 307-332. http://doi.org/10.1007/s10857-008-9077-9 
Stylianides, A. J., \& Stylianides, G. J. (2009a). Proof constructions and evaluations. Educational Studies in Mathematics, 72(2), 237-253.

http://doi.org/10.1007/s10649-009-9191-3

Stylianides, G. J., \& Stylianides, A. J. (2009b). Facilitating the transition from empirical arguments to proof. Journal for Research in Mathematics Education, 40(3), 314352.

Stylianides, A. J., Stylianides, G. J., \& Philippou, G. N. (2004). Undergraduate students' understanding of the contraposition equivalence rule in symbolic and verbal contexts. Educational Studies in Mathematics, 55(1-3), 133-162. http://doi.org/10.1023/B:EDUC.0000017671.47700.0b

Sweller, J. (1994). Cognitive load theory, learning difficulty, and instructional design. Learning and Instruction, 4(4), 295-312. http://doi.org/10.1016/09594752(94)90003-5

Tabach, M., Levenson, E., Barkai, R., Tsamir, P., Tirosh, D., \& Dreyfus, T. (2011). Secondary teachers' knowledge of elementary number theory proofs: the case of general-cover proofs. Journal of Mathematics Teacher Education, 14(6), 465481. http://doi.org/10.1007/s10857-011-9185-9

Tabach, M., Levenson, E., Barkai, R., Tsamir, P., Tirosh, D., \& Dreyfus (2009). Teachers' knowledge of students' correct and incorrect proof constructions. In Proceedings of the ICMI Study 19 Conference: Proof and Proving in Mathematics Education (Vol. 2, pp. 214-219). Taipei, Taiwan: National Taiwan Normal University.

TDG (Teachers Development Group). (2010). About the Mathematics Studio Program. Retrieved May 16, 2014, from http://www.teachersdg.org/Assets/About\%20Studio\%20Brochure\%20v.3.0.pdf

Thanheiser, E., Staples, M., Bartlo, J., Heim, K., Sitomer, A. (2010). Justification in middle school classrooms: How do middle school teachers define justification and its role in the classroom. Conference Proceedings of Psychology of Math Education- North American Chapter. Cincinnati, OH.

Tharpe, R. \& Gallimore, R. (1988). Rousing minds to life: Teaching, learning, and schooling in social context. Cambridge: Cambridge University Press.

Thompson, A. G. (1992). Teachers' belief and conceptions: A synthesis of the research. In Handbook of Research on Mathematics Teaching and Learning (1st ed., pp. 127-146). New York: MacMillan.

Tirosh, D. \& Vinner, S. (2004). Prospective teachers' knowledge of existence theorems. In Proceedings of the 28th Conference of the International Group for the Psychology of Mathematics Education. Bergen University College.

Toulmin, S. (1969). The uses of argument. Cambridge: Cambridge University Press.

Tsamir, P., Tirosh, D., Dreyfus, T., Barkai, R., \& Tabach, M. (2009). Should proof be minimal? Ms T's evaluation of secondary school students' proofs. The Journal of 
Mathematical Behavior, 28(1), 58-67.

http://doi.org/10.1016/j.jmathb.2009.04.002

Usiskin, Z. (1980). What should not be in the algebra and geometry curricula of average college-bound students? The Mathematics Teacher, 73(6), 413-424.

Usiskin, Z. (1987). Resolving the continuing dilemmas in school geometry. In M.

Lindquist \& A. Shulte (Eds.), Learning and Teaching Geometry K-12 (pp. 17-

31). Reston, VA: National Council of Teachers of Mathematics.

Weber, K. (2001). Student difficulty in constructing proofs: The need for strategic knowledge. Educational Studies in Mathematics, 48(1), 101-119. doi:10.1023/A:1015535614355

Weber, K., \& Alcock, L. (2004). Semantic and Syntactic Proof Productions. Educational Studies in Mathematics, 56(2-3), 209-234.

http://doi.org/10.1023/B:EDUC.0000040410.57253.a1

Weber, K., Porter, M., \& Housman, D. L. (2008). Worked examples and conceptual example usage in understanding mathematical concepts and proofs. In M. Carlson \& C. Rasmussen (Eds.), Making the Connection: Research and Teaching in Undergraduate Mathematics Education (pp. 245-252). Washington, DC: MAA.

Weiss, M., Herbst, P., \& Chen, C. (2009). Teachers' perspectives on "authentic mathematics" and the two-column proof form. Educational Studies in Mathematics, 70(3), 275-293. http://doi.org/10.1007/s10649-008-9144-2

Wilson, M., \& Cooney, T. J. (2002). Mathematics teacher change and development: The role of beliefs. In G. C. Leder, E. Pehkonen, \& G. Törner (Eds.), Beliefs: A hidden variable in mathematics education? (pp. 127-147). Dordrecht, The Netherlands: Kluwer Academic.

Wood, T. (1994). Patterns of interaction and the culture of mathematics classrooms. In S. Lerman (Ed.), Cultural perspectives on the mathematics classroom. Dordrecht: Kluwer.

Wood, T. (1999). Creating a Context for Argument in Mathematics Class. Journal for Research in Mathematics Education, 30(2), 171-191. http://doi.org/10.2307/749609

Wood, D., Bruner, J. S., \& Ross, G. (1976). The Role of Tutoring in Problem Solving. Journal of Child Psychology and Psychiatry, 17(2), 89-100. doi:10.1111/j.14697610.1976.tb00381.x

Wood, T., Cobb, P., \& Yackel, E. (1991). Change in Teaching Mathematics: A Case Study. American Educational Research Journal, 28(3), 587-616. doi:10.3102/00028312028003587

Wood, T., \& Turner-Vorbeck, T. (2001). Extending the conception of mathematics teaching. In T. Wood, B. Scott Nelson, \& J. Warield (Eds.), Beyond Classical Pedagogy: Teaching Elementary School Mathematics. 
Wu, H. (1996). The role of Euclidean geometry in high school. Journal of Mathematical Behavior, 15, 221-237.

Yackel, E. (2001). Explanation, Justification and Argumentation in Mathematics Classrooms. In Proceedings of the Conference of the International Group for the Psychology of Mathematics Education (25th) (Vol. 1-4). Utrecht, The Netherlands.

Yackel, E., \& Cobb, P. (1996). Sociomathematical norms, argumentation, and autonomy in mathematics. Journal For Research in Mathematics Education, 27(4), 458477.

Yin, R. (2009). Case Study Research: Design and Methods (4th ed.). Thousand Oaks, CA: SAGE Publications. 


\section{Appendix A: Teacher Justification Survey Sample}

Question \#1

Joe and Fred are thinking about the pair of numbers 5 and 9.

They notice that the SUM $(5+9)$ is EVEN.

They notice that the PRODUCT $(5 \times 9)$ is ODD.

Joe says: If the SUM of two whole numbers is EVEN, their PRODUCT is ODD.

Fred says: If the PRODUCT of two whole numbers is ODD, their SUM is EVEN.

Answer the following questions about this discussion:

a) Are Joe's and Fred's statements saying the same thing?

b) The PRODUCT of two whole numbers is 1247 .

Suppose that Fred's statement is true. Which, if any, of these statements must also then be true? Tick ( ) one box.

You can be sure that the SUM of the two numbers is EVEN.

You can be sure that the SUM of the two numbers is ODD.

You can't be sure whether the SUM is ODD or EVEN until you know what

the two numbers are.

Explain why that statement must also be true, if Fred's statement is true.

c) The SUM of two whole numbers is 1246 .

Suppose that Joe's statement is true. Which, if any, of these statements must also then be true? Tick ( ) one box.

You can be sure that the PRODUCT of the two numbers is EVEN.

You can be sure that the PRODUCT of the two numbers is ODD.

You can't be sure whether the PRODUCT is ODD or EVEN until you know what the two numbers are.

Explain why that statement must also be true if Joe's statement is true.

d) Is Fred's statement actually true?

Explain your answer.

e) Is Joe's statement actually true? Explain your answer.

Question \#2

Amy is building a sequence of geometric figures with toothpicks, by following a specific pattern (making triangles up and down alternatively). Below are the pictures of the first three figures she builds. Variable $t$ denotes the position of a figure in the sequence. 


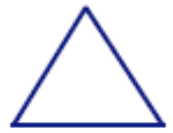

$t=1$

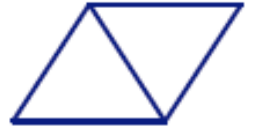

$t=2$

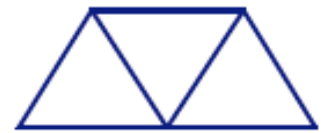

$t=3$

In finding a mathematical description of the pattern, Amy explains her thinking by saying:

"First, I use three sticks for each triangle:

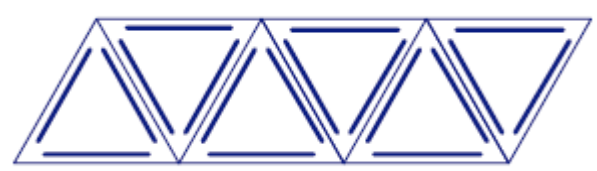

But then I see that I am counting one stick twice for each of the triangles except the last one, so I have to take those away."

Part 1: Of the following expressions, which most closely fits with Amy's explanation? Tick ( ) one box

$2 t+1$

$2(t+1)-1$

$3 t-(t-1)$

प $3 t+1-t$

Explain why you think that one most closely fits Amy's explanation. 


\section{Appendix B: Student Justification Survey Sample}

Question \#1: Some problems that you do in math ask you to give your answer and then "Justify your answer." What are those directions asking you to do? (Pretend a classmate doesn't understand the directions. What would you tell them to do?)

Question \#2

Joe and Fred are thinking about the pair of numbers 5 and 9.

They notice that the SUM $(5+9)$ is EVEN. They notice that the PRODUCT $(5 \times 9)$ is ODD.

Joe says: If the SUM of two whole numbers is EVEN, their PRODUCT is ODD.

Fred says: If the PRODUCT of two whole numbers is ODD, their SUM is EVEN.

Answer the following questions about this discussion:

a. Are Joe's and Fred's statements saying the same thing?

b. Is Joe's statement actually true? ..........Explain your answer.

c. Is Fred's statement actually true? ..........Explain your answer.

d. The PRODUCT of two whole numbers is 1247.

Suppose that Fred's statement is true. Which, if any, of these statements must also then be true? Tick ( ) one box and explain why that statement must also be true, if Fred's statement is true.

You can be sure that the SUM of the two numbers is EVEN.

You can be sure that the SUM of the two numbers is ODD.

You can't be sure whether the SUM is ODD or EVEN until you know what the two numbers are.

Why:

Question \#4

Suppose we already know that an odd number added to another odd number is always an even number. Suppose we also know that an even number added to an odd number is always an odd number.

a. What happens if you add any three odd numbers together? Justify your answer.

b. Josie thinks of 3 odd numbers, she adds them together, and writes down the answer. Will her answer be odd or even (or is it impossible to tell)? Justify your answer. 


\section{Appendix C: Interview Protocol Sample}

1) This project, JAGUAR, focuses on justification and proof. I want to make sure I know what these words currently mean to you.

a) When you talk about justification, what do you mean by that term?

- So justification is ...

- If you had 3 minutes in a faculty lounge with a colleague, how would you explain justification?

- Could you give an example of a justification? When you ask students to justify what do you expect to see?

b) Do you distinguish between justification and proof? Why or why not? What is the distinction for you?

- Sometimes textbooks ask students to "prove" and other times they ask them to "justify". Is there a difference between these two prompts? (If so, what is the difference?)

- Is it important to distinguish between justification and proof?

c) Another term often used in math classes is "explanation." In your mind, is there a difference between justification and explanation?

Is a proof a kind of justification then? (Is a justification a kind of proof? Is proof then a larger category and a justification within that?)

2) How has your thinking about what a justification is changed over the course of the project? In what ways has it changed?

b) What influence, if any, has this had on what you do in the classroom?

c) Next, focus specifically on what you do. Are there any changes you've noticed to your teaching practice since you started the JAGUAR project that you would attribute to participating in the JAGUAR project?

Make sure interviewee is comfortable saying - no-

If say yes, probe to see if the "source" of the change can be identified.

d) Imagine that you were presenting to a group of middle school math teachers about teaching with justification. What are 2 or 3 things that you've learned about teaching with justification (implementing justification tasks) that you'd want to be sure to include in your presentation?

Follow-ups:

- Why would that be important to include?

- How do you see this playing out in your teaching?

- Is this a new aspect of your pedagogy? (Or is it an old one that has been given new life/importance?)

3) What value do you see you see in incorporating justification into the classroom? 
a) how would you summarize why you incorporate justification into your middle school classroom? (or the value you see)

- What is the role of justification in your classroom?

- What is the role of justification in learning mathematics?

Listen carefully for Whether justification plays a role in actually verifying and establishing truths in their mathematics classroom..

\section{$\bullet$}

b) Could some of the things (what you aim to do with justification) get done without incorporating justification? Or do you see justification as a critical means and without it, you couldn't accomplish those particular goals? Need to tweak wording here based on what interviewee says.

\section{NOTE:}

- $\quad$ Listen carefully for Is justification is a valued outcome (disciplinary practice) in and of itself?

- Follow up as needed to gain clarity on this

- Do you focus on justification as a content topic in an of itself? (Justification for the sake of justification.) Why or why not?

5) Some students were asked to explain how they solved $1 / 2+1 / 4$. Here are two responses offered by middle school students.

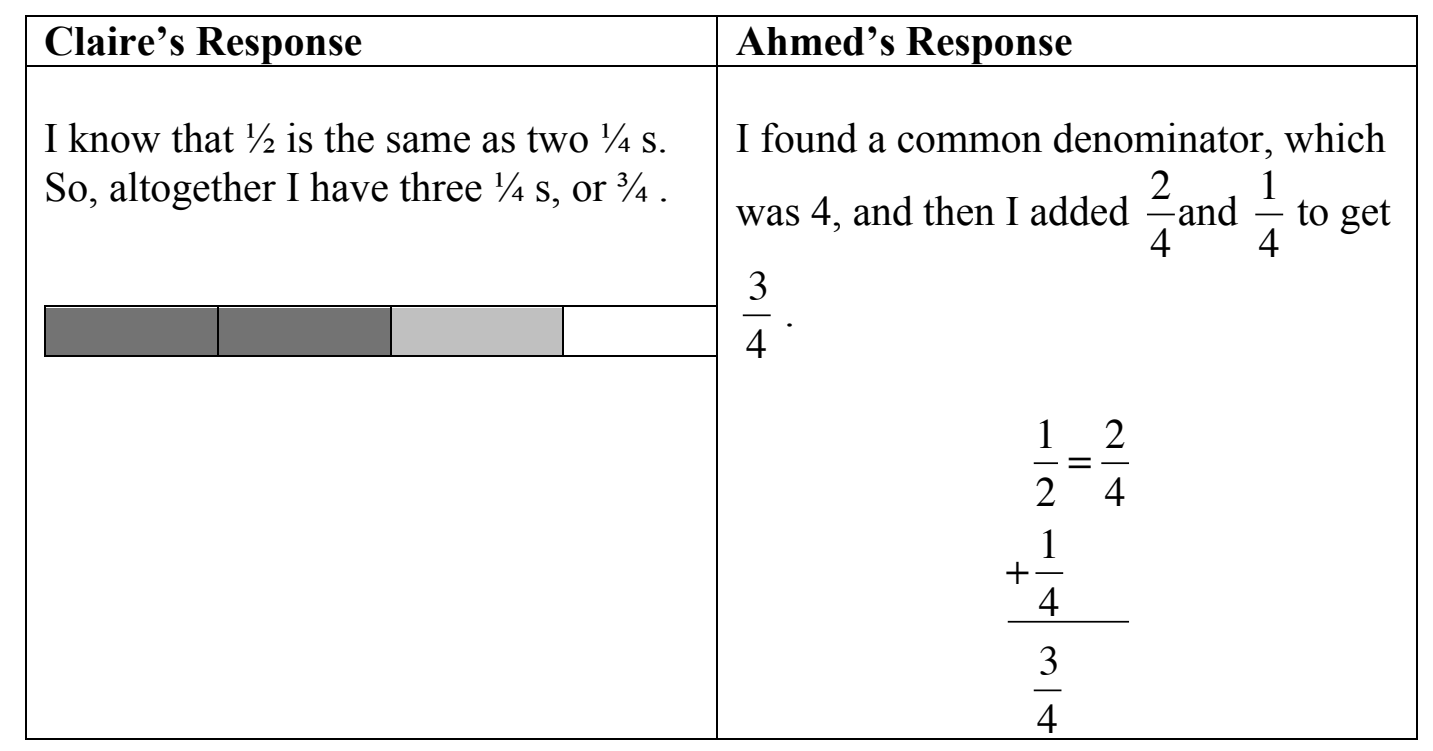

Is either of these responses an example of what you consider to be justification? If so, in what ways? If not, why not? 
A. Do you think Claire's [Ahmed's] is a justification? Why or why not? [Repeat the questions for Ahmed]

\section{If yes:}

a. What makes this a justification?

b. How do you decide?

\section{If no:}

a. What would you characterize this one as [other than justification]?

b. Why is this not a justification?

c. What is missing?

d. What would make it a justification?

B. If they think they are both a justification,

b) Are there any differences between these two justifications that are important to note? (that are important to you as a teacher?)

c) What are those differences?

C. If they think they neither is a justification,

d) Are there any differences between these two solutions that are important to note? (that are important to you as a teacher?)

e) What are those differences? 


\section{Appendix D: Reflective Journal Questions}

\section{Justification Tasks Reflective Journal Entries \\ JAGUAR - Lesson Cycle 4}

Instructions: Please respond to each of the questions below. Please complete Question 1 before the lesson. Please complete the other questions no later than the Sunday after the lesson. It is important that your reflection is informed by your active memory of the lesson in addition to the video.

Thank you! We're looking forward to reading your thoughts about your lesson.

\section{BEFORE THE LESSON}

1) A. What is the primary goal of this lesson?

B. What role will justification play in this lesson?

C. What kinds of justifications do you expect students might produce as they work on the task for this lesson? Please address the kinds of statements, reasons, and representations students might use.

\section{AFTER TEACHING THE LESSON, watch the lesson:}

2) Find the moments when students were engaged in justification (on some level) during the lesson and write them down. (Please also include the time on the video.)

3) Did these justifications align with what you thought would happen?

4) Pick one instance involving student justification that you thought was productive and/or went well. Identify the time on the tape and explain what you valued about this instance.

5) Pick one instance involving student justification that didn't go as well as it could have, and transcribe that exchange between the student(s) and yourself. Please include the date of the lesson and time on the tape.

a) Please explain why this is an instance that didn't go as well as it could have.

b) What would you do next time with this exact situation to make it go better?

c) Explain why you revised it as you did.

6) a) What, if anything, do you think students understood about the math content that was a result of, or strengthened by, justification?

b) What, if anything, do you think students learned about justification as a result of this lesson?

7) What, if anything, did you learn about teaching to promote student justification as a result of this lesson? Please be sure to explain how this lesson led to that learning.

8) Given where your students are with justification right now,

a) What goals do you have for your students with respect to justification? 
b) What will you do next time to move towards these goals? (When you answer this question, think specifically about your interactions with students.)

9) Anything else on your mind with respect to justification or your students' work with justification.

10) a) Can we use the clips you selected in Question 4 and/or Question 5 in future sessions?

b) Are there other clips you'd be interested in having the group look at? If so, please specify the time of the clip and let us know a bit about why you'd like to have the group look at it. 


\section{Appendix E: Classroom Data Collection Forms}

\section{LESSON LOG - TEMPLATE - JAGUAR - revised 02.12.10}

\section{Lesson Table}

\begin{tabular}{|c|c|}
\hline Teacher initials: & $\begin{array}{l}\text { Grade/course/class: Period only needs to be included } \\
\text { if there are multiple sections of given class that the } \\
\text { teacher teaches. E.g. - Grade 7, pre-algebra, Period } 3 \\
\text { or Grade 8, Math 8, period } 2\end{array}$ \\
\hline $\begin{array}{l}\text { File name: this should be } \\
\text { "Lesson table" cycle initials } \\
\text { date, e.g., Lesson Table } \\
\text { y1c1 AC } 2010.02 .12\end{array}$ & $\begin{array}{l}\text { Initials of Preparer: } \\
\text { Log (last modified): }\end{array}$ \\
\hline Teacher's Goal: & This may be inferred \\
\hline \multicolumn{2}{|l|}{ Topic: } \\
\hline \multicolumn{2}{|l|}{$\begin{array}{l}\text { Handouts, curric } \\
\text { materials: (see cover } \\
\text { sheet) }\end{array}$} \\
\hline Classroom Description: & \\
\hline
\end{tabular}

\begin{tabular}{|c|c|c|c|c|}
\hline Time & $\begin{array}{c}\text { Description of } \\
\text { Activity }\end{array}$ & $\begin{array}{l}\text { Organization of } \\
\text { Interaction }\end{array}$ & $\begin{array}{l}\text { Description of } \\
\text { Content }\end{array}$ & Other \\
\hline $\begin{array}{l}\text { Record } \\
\text { time on } \\
\text { video in } \\
\text { form } \\
\text { Xx:xx- } \\
x x: x x \\
\text { Use hrs } \\
\text { as } \\
\text { needed } \\
\text { Within } \\
30 \text { secs } \\
\text { is fine. }\end{array}$ & $\begin{array}{l}\text { This column } \\
\text { has a high } \\
\text { level } \\
\text { description of } \\
\text { the activity. } \\
\text { Please use the } \\
\text { terms: } \\
\text { Whole Class } \\
\text { Small Group } \\
\text { Individual } \\
\text { Transition }\end{array}$ & $\begin{array}{l}\text { Teacher is xxx } \\
\text { Students are xxx } \\
\text { This column describes } \\
\text { more about the nature of } \\
\text { interaction during the } \\
\text { given activity. } \\
\text { There may be more than } \\
\text { one kind of interaction } \\
\text { during a given activity. } \\
\text { Please list all major kinds } \\
\text { of interaction in new cells. } \\
\text { For Activity, you can write } \\
\text { "continue". }\end{array}$ & $\begin{array}{l}\text { This column } \\
\text { focuses on the } \\
\text { mathematics. If } \\
\text { possible, record } \\
\text { the problem } \\
\text { that is being } \\
\text { discussed. } \\
\text { There are likely } \\
\text { several } \\
\text { mathematical } \\
\text { ideas that are } \\
\text { related to any } \\
\text { one Activity. }\end{array}$ & $\begin{array}{l}\text { Additiona } \\
1 \text { notes as } \\
\text { needed, } \\
\text { including } \\
\text { those } \\
\text { related to } \\
\text { technical } \\
\text { stuff (e.g., } \\
\text { teacher } \\
\text { mic } \\
\text { fuzzy) }\end{array}$ \\
\hline
\end{tabular}


Teacher:

Date:

No. of Students:

Length of lesson:

Lesson Cycle: $\quad 1 \quad 2$

Number in Cycle: —_ of $\quad$ (3 or 4$)$

Focal Lesson: $\quad$ YES NO
Grade/period:

Class:

(e.g., math 7 vs pre-algebra):

Was this a lesson developed during the summer course? YES NO

Please list handouts and materials (paperclip copies of all handouts; note all sections of text):

$*$
$*$
$*$
$*$

Anything unusual/any comments: 


\section{Appendix F: Teacher Working Session Task}

Triangle Number Task: Forms of Reasoning Evaluation

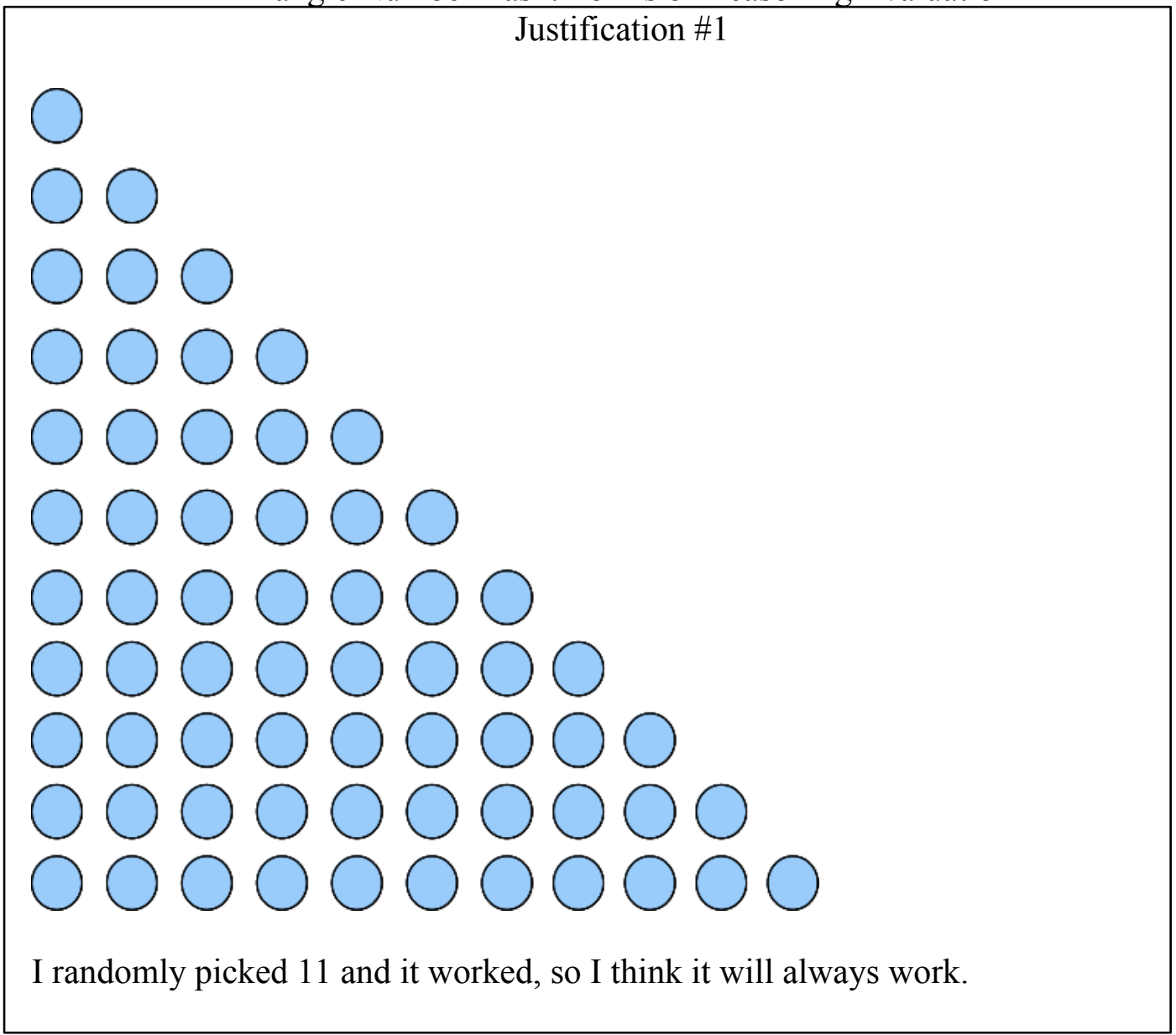




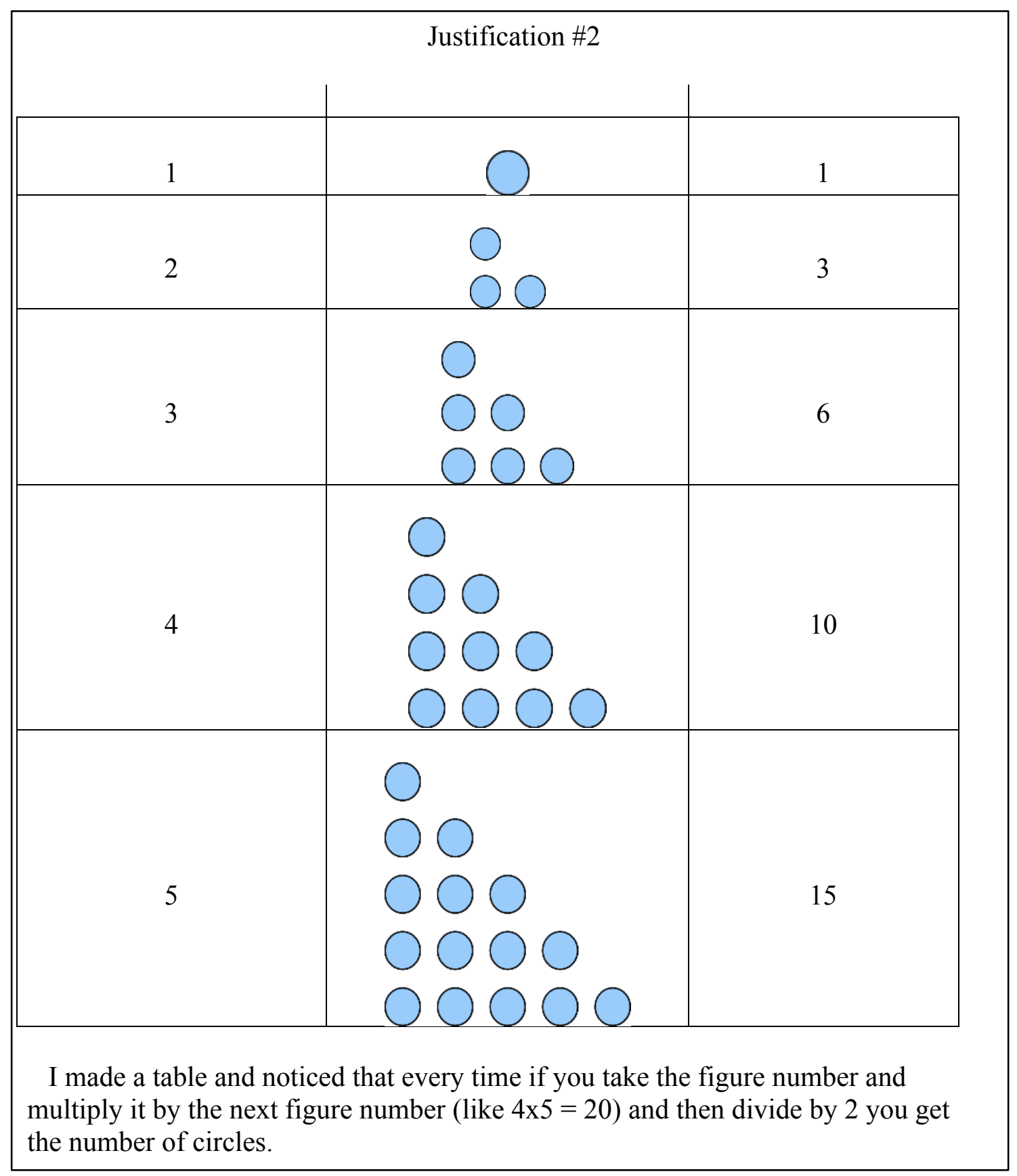




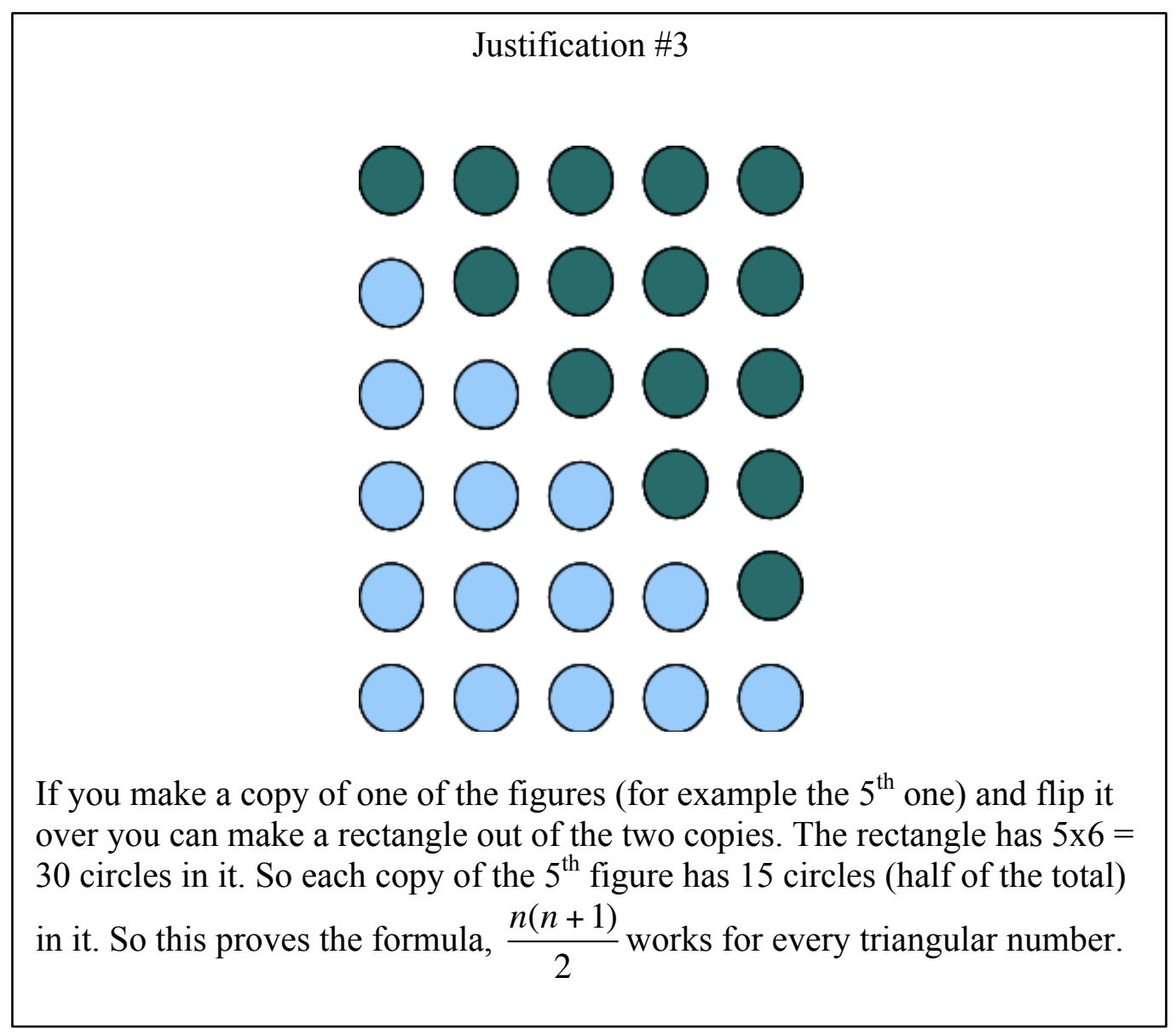




\section{Justification \#5}

\begin{tabular}{|c|c|}
\multicolumn{1}{|c|}{ Base number $n$} & $n$th Triangular Number \\
\hline 1 & 1 \\
\hline 2 & 3 \\
\hline 3 & 6 \\
\hline 4 & 10 \\
\hline 5 & 15 \\
\hline 6 & 21 \\
\hline
\end{tabular}

Notice the pattern in the second column of the table. When you add the next base number to any triangular number you get the next triangular number.

From the table we can see that the formula works for the $5^{\text {th }}$ triangular number since $\frac{5 \times 6}{2}=15$.

For the $6^{\text {th }}$ one:

$\frac{5 \times 6}{2}+6=\frac{5 \times 6+2 \times 6}{2}=\frac{6 \times 7}{2}$. Yes!

For the $7^{\text {th }}$ one:

$\frac{6 \times 7}{2}+7=\frac{6 \times 7+2 \times 7}{2}=\frac{7 \times 8}{2}$. Yes!!

It goes on like this forever! Each time we add the next base number we get a new version of the formula with each number in the top getting bigger by one. So the formula $\frac{n(n+1)}{2}$ will always work! Woo Hoo! 


\section{Justification \#6}

For example, we get the $7^{\text {th }}$ triangular number by adding the first 7 numbers together.

$1+2+3+4+5+6+7$. We can reverse this list and add the two lists together like so:

$$
\begin{array}{rlr}
1+ & 2+3+4+5+6+7 \\
& + & \frac{7+6+5+4+3+2+1}{8+8+8+8+8+8+8}
\end{array}
$$

This gives $7 \times 8$. This is double what we wanted so the $7^{\text {th }}$ triangular number is $\frac{7 \times 8}{2}$. This works for any triangular number. So the formula $\frac{n(n+1)}{2}$ will always work!

\section{Justification \#7}

The $n$th triangular number is given by $\mathrm{T}_{n}=1+2+\ldots+(n-1)+n$. Adding this sum to itself (written in reverse order), we obtain:

$$
\begin{aligned}
& 2 \mathrm{~T}_{n}=\quad 1+2+\ldots+(n-1)+n \\
& +n+(n-1)+\ldots+2+1 \\
& =(n+1)+(n+1)+\ldots+(n+1)+(n+1)=n(n+1)
\end{aligned}
$$

This means that $\mathrm{T}_{n}=\frac{n(n+1)}{2}$ for any $n$. 